\title{
Design Challenges in Polymeric Scaffolds for Tissue Engineering
}

\author{
Maria I. Echeverria Molina ${ }^{\dagger}$, Katerina G. Malollari ${ }^{\dagger}$ and Kyriakos Komvopoulos* \\ Department of Mechanical Engineering, University of California, Berkeley, Berkeley, CA, United States
}

Numerous surgical procedures are daily performed worldwide to replace and repair damaged tissue. Tissue engineering is the field devoted to the regeneration of damaged tissue through the incorporation of cells in biocompatible and biodegradable porous constructs, known as scaffolds. The scaffolds act as host biomaterials of the incubating cells, guiding their attachment, growth, differentiation, proliferation, phenotype, and migration for the development of new tissue. Furthermore, cellular behavior and fate are bound to the biodegradation of the scaffold during tissue generation. This article

OPEN ACCESS

Edited by:

Hasan Uludag,

University of Alberta, Canada

Reviewed by:

Henrique de Amorim Almeida,

Polytechnic Institute of Leiria, Portugal

Houman Savoji,

Université de Montréal, Canada

*Correspondence:

Kyriakos Komvopoulos

kyriakos@me.berkeley.edu

tThese authors have contributed equally to this work

Specialty section:

This article was submitted to Biomaterials,

a section of the journal

Frontiers in Bioengineering and Biotechnology

Received: 14 October 2020 Accepted: 08 March 2021

Published: 14 June 2021

Citation:

Echeverria Molina MI, Malollari KG and

Komvopoulos K (2021) Design

Challenges in Polymeric Scaffolds for

Tissue Engineering.

Front. Bioeng. Biotechnol. 9:617141.

doi: 10.3389/fbioe.2021.617141 provides a critical appraisal of how key biomaterial scaffold parameters, such as structure architecture, biochemistry, mechanical behavior, and biodegradability, impart the needed morphological, structural, and biochemical cues for eliciting cell behavior in various tissue engineering applications. Particular emphasis is given on specific scaffold attributes pertaining to skin and brain tissue generation, where further progress is needed (skin) or the research is at a relatively primitive stage (brain), and the enumeration of some of the most important challenges regarding scaffold constructs for tissue engineering.

Keywords: scaffolds, tissue engineering, cells, biopolymers, structure, biochemistry, biodegradability, mechanical behavior

\section{INTRODUCTION}

The human body is by far the most sophisticated autonomous system consisting of billions of molecular nanomachines built from the DNA code of a person's zygote, which not only can renew certain type of cells in a complex programmable manner but also repair damaged tissue. However, this self-healing capacity is limited to the type of cells comprising the tissue and the multiple factors controlling tissue self-repair, including degenerative diseases, traumatic events, and age. In fact, some tissues do not exhibit a self-healing capability. To this end, tissue engineering (TE) plays a vital role in the development of functional constructs that can promote the generation of tissue and organ equivalents, or enhance tissue regeneration to restore and/or improve the functionality of damaged tissues and organs, ultimately replacing autografts, allografts, or even whole organs. Examples of engineered tissue applications include skin, cartilage, veins, arteries, brain, gastrointestinal tissues, and cornea. Although some of the former engineered tissues have been approved for human use, successful transplantation and, especially, implant longevity are limited due to complications leading to biomaterial rejection by various complex mechanisms (Sheikh et al., 2015; Anderson and Jiang, 2017). 
The increasing demand for human tissues and organs highlighted in a recent report (Israni et al., 2020) and the acceleration of deaths due to acute illnesses, such as ischemic coronary diseases (World Health Organization, 2018), have increased the market demand for TE (Grand View Research, 2020), highlighting the importance of tissue regeneration and repair. TE is a multidisciplinary field concerned with the creation of tissue by different techniques that depend on cell seeding of non-woven, porous scaffold biomaterials and the incorporation of various growth factors that promote tissue growth. Scaffolds are $3 \mathrm{D}$ constructs that mimic the extracellular matrix (ECM) of native tissue, typically made of biodegradable and biocompatible polymers. A polymeric scaffold material must be characterized by multiple attributes, such as no chronic inflammatory response and/or rejection by the surrounding tissue, degradation rate that matches the healing or growth rate of the tissue, non-toxic byproducts that can be expelled by the body in a timely fashion, acceptable shelf life, good mechanical properties compatible with those of the native ECM, which do not impede cell interaction, and no changes in architecture and properties due to sterilization (Pruitt and Chakravartula, 2011). However, cell culture, tissue growth, and implantation may affect the scaffold properties and performance due to material degradation and ever-changing interfaces. The scaffold performance is quantified in multiple ways, especially by the cell behavior that it can stimulate and how closely it mimics the native ECM of the generated tissue.

Important developments in TE have been encountered in the past two decades, largely due to significant advances in biomaterials, fabrication, and techniques designed to instigate specific cellular behaviors that stimulate the formation of tissue analogs. Biomaterials showing a versatile performance depending on the biological environment have been developed by modifying their chemistry. Examples include the assimilation of specific surface cues by plasma treatment, layer-by-layer deposition or surface functionalization with polydopamine (PDA), and the socalled "click" chemistry, which can impart specificity for multiple cues (e.g., drug delivery, crosslinking, and cell attachment) to the bulk and the surface of polymeric scaffolds. Hydrogels are a special class of materials that have attracted considerable attention as scaffolds because they can be delivered to the desired site by minimally invasive methods (e.g., by injection) and doped with drugs, cells, and growth factors, therefore showing high potential for many TE applications, such as brain and skin tissues. Notable breakthroughs in TE have also been accounted as a result of significant progress in the development of versatile fabrication methods for scaffold engineering (Dutta et al., 2017; Walker and Santoro, 2017; Zhao et al., 2018). For example, $3 \mathrm{D}$ printing techniques have provided capabilities to create specific and controlled geometries and shapes of constructs and to simultaneously use biomaterials, growth factors, and cells to create composites that exhibit unique degradation rates, enhanced cell differentiation, specific biological cues, and excellent biomechanical properties throughout the scaffold's lifetime (Do et al., 2015; Di Luca et al., 2016c; Bittner et al., 2018; $\mathrm{Ng}$ et al., 2018; Han et al., 2021). Other less common and/or new fabrication techniques, such as multiphoton, laser-assisted, and computed axial lithography, have also been used to create scaffolds for TE (Liang et al., 2021). In addition, conventional methods modified to incorporate cells and growth factors in polymeric constructs, such as electrospinning and gas foaming, have gained attention recently (Costantini and Barbetta, 2018; Hong et al., 2019; Karpov et al., 2020).

The understanding of the function of different cells that form a tissue or an organ, the improved techniques for harvesting cells, and the insight into how the healing multifactorial process works as well as the interplay of the physicochemical properties and morphology of biomaterials have led to the development of scaffolds that can stimulate the desired cellular behavior, while providing the chemical and mechanical cues for achieving tissue growth and regeneration. However, the difficulty to reproduce the complex biological environment during in vitro testing inhibits direct comparisons with the material's behavior in vivo. Developments in bioreactors have enabled the incorporation of in vivo-like signals, such as static and dynamic electromechanical cues and control of the $\mathrm{pH}$, temperature, gene expression, and growth factors, which are closely associated with the initial stages of cell differentiation. More importantly, because most of the engineered tissues are small versions of human counterparts, they can only be tested in animal models, with most of the attempts to create full size organs being largely ineffective with only a few exceptions, such as $3 \mathrm{D}$ printed human ears (Zhou et al., 2018). Nevertheless, some of the engineered tissues (e.g., skin, cornea, and vascular grafts) have reached pre-clinical trials or commercial application, despite the fact that they cannot be implanted to all patients and/or fully restore normal tissue function, thus illuminating the complexity to recreate totally functional tissues. However, despite significant progress in the development of organ-on-chip platforms that can more closely reproduce physiological settings in vitro (Zhang et al., 2018; Wu et al., 2020), animal models are still a fundamental part of the research needed to better understand diseases and to develop more effective drug delivery methods.

Because scaffold design can greatly affect cellular behavior from its inception, there are many critical factors to consider in TE. The objective of this article is to provide an appraisal of the current state-of-the-art in TE, specifically focusing on the correlation of scaffold parameters and cell fate, the types of polymeric materials currently used in scaffold engineering, and the effects of biochemical characteristics, structure architecture, biodegradability, and mechanical behavior of scaffold materials on the resulting biomimicry cues and their ability to stimulate specific cell behaviors. In addition, two important soft tissue application areas, namely skin and brain scaffold engineering, are discussed in the context of associated anatomy and biological functions, and the design challenges of scaffolds intended for these TE applications are interpreted in the light of recent advances in scaffold engineering.

\section{SCAFFOLD MAIN CHARACTERISTICS}

Scaffolds play a fundamental role in TE because they provide mechanical support, allow perfusion of nutrients and oxygen, transfer biochemical signals that modulate cell behavior (e.g., 
attachment, motility, proliferation, and differentiation), and can be used to release drugs and growth factors. A scaffold must mimic the ECM by exhibiting the biological, chemical, and mechanical cues that influence cell phenotype and tissue formation. Biomaterials for tissue generation must exhibit tailorable properties to enhance cell attachment, migration, growth, and differentiation, prevent undesirable host responses that lead to chronic inflammation at the biomaterial interface, display chemical and mechanical stability for providing structural support while demonstrating controllable microstructure and adequate porosity, and show good biodegradability without producing toxic residues and byproducts. Biomaterial scaffolds for TE must be developed according to the aforementioned design criteria by integrating engineering and biological principles and molecular cues that imitate critical structural aspects of the native tissue and can effectively direct cellular behavior and functionality. Based on the preceding requirements, biomaterial scaffolds can be classified into three main material categories, namely architectured materials with fibrous and porous structures, hybrid or composite materials, and hydrogels.

Architectured materials are mainly synthetic biodegradable polymers characterized by 3D fibrous networks. Natural ECM decellularized tissue materials (typically powdered) also belong in this category. These materials can be formed by various fabrication techniques, such as electrospinning, freeze-drying, gas foaming, solvent casting, particulate or porogen leaching, phase separation, self-assembly, and 3D printing. Polymers that belong in this category are synthetic biodegradable polymers, such as poly(lactic acid) (PLA), poly(glycolic acid) (PGA), poly( $\varepsilon$ caprolactone) (PCL), polyvinyl alcohol (PVA), polyethylene glycol (PEG), polyethylene oxide (PEO), polyurethane (PU), and polyvinylpyrrolidone.

Hybrid materials encompass blends of synthetic polymers, natural polymers, and decellularized tissue with one or few solvents. Alternatively, composite materials include the same polymer-based constituents as hybrid materials, but possess either layered or multi-material structures made by various processes. Hybrid and composite materials are typically produced by fabrication methods designed to synthesize architectured biomaterials, with a few exceptions, such as hydrogel-based hybrid materials.

Hydrogels are swollen natural or synthetic polymer networks crosslinked by physical and/or covalent bonds, which show a high potential for tissue repair because they form ECM-like architectures and can serve as platforms for minimally invasive delivery of macromolecules to the injury site (Hsieh et al., 2017; Chen et al., 2019; Peppas and Hoffman, 2020). Polymerbased hydrogels show numerous advantages over architectured and hybrid/composite materials, such as different chemical, mechanical, and spatial cues for encapsulating cells, and can provide bioactive signals to the host tissue. The capability of hydrogels to modulate nutrient diffusion and cell motility and their mechanical stability depend on the crosslink density and mesh size, which can be tuned during the fabrication.

Basic understanding of how a scaffold can be modified to elicit the cellular response needed for a specific TE application is of paramount importance in scaffold engineering and requires

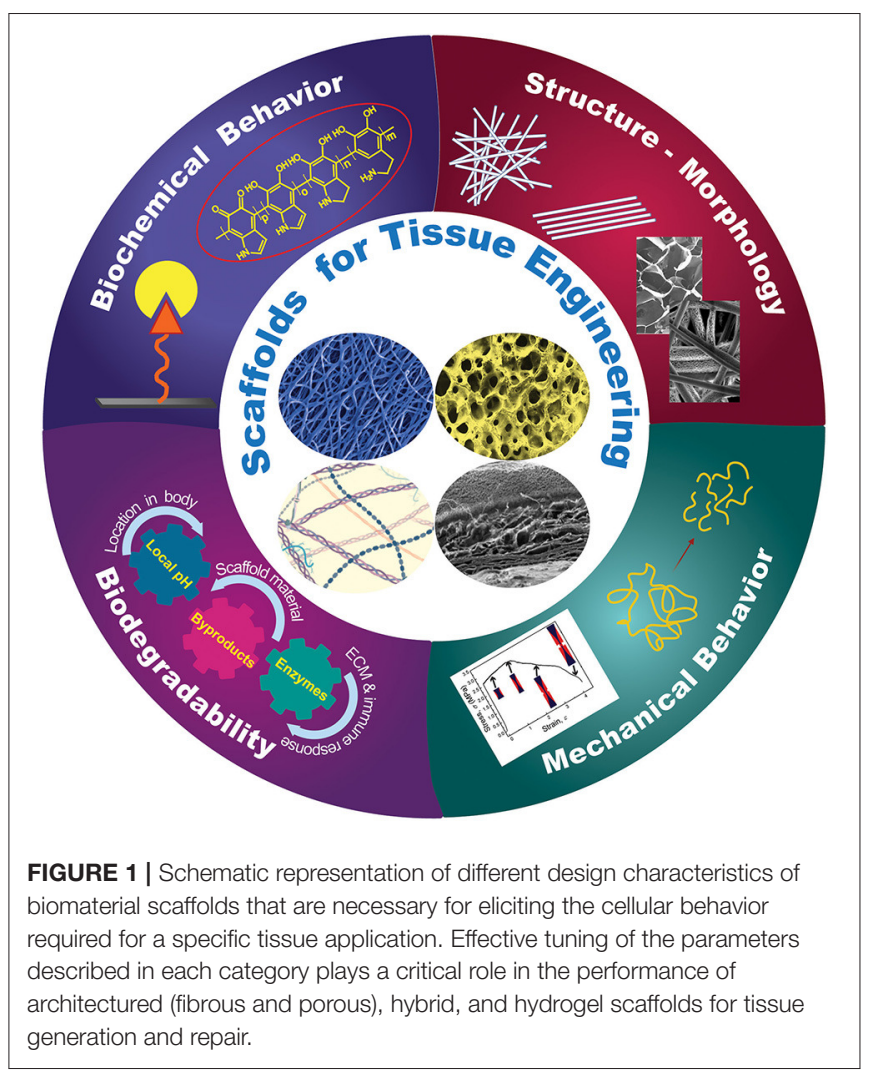

insight into the effects of the biochemical characteristics, structure and morphology, biodegradability, and mechanical behavior on the scaffold performance. The main design characteristics of scaffolds intended for the TE applications discussed in this section are depicted in Figure 1.

\section{Biochemical Behavior}

The affinity of the cells for a scaffold greatly depends on the chemical and topological surface and bulk cues of the scaffold material. Specifically, the hydrophilicity, charge density, and chemical specificity of the scaffold surface affect cell attachment, whereas the bulk chemical characteristics influence cell signaling and infiltration. Both surface and bulk chemistry synergistically regulate cell growth, migration, differentiation, ECM synthesis, and tissue morphogenesis and are critical to achieving scaffold biocompatibility. Scaffold chemical modification has emerged as an effective means of producing biochemical specificity and recognition, with chemical moieties incorporated in the bulk and/or surface of the scaffolds to mediate cell behavior and functionality, direct inflammatory and immunological response, and ameliorate foreign body reaction at the scaffold-tissue interface (Allen et al., 2006; Anderson et al., 2008; Owen and Shoichet, 2010; Nimmo et al., 2011; Lanza et al., 2020).

Click chemistry (Kolb et al., 2001; Zou et al., 2018) has emerged as a potent chemical modification strategy for scaffold biochemical functionalization, primarily because it demonstrates modularity, high reactivity, superb selectivity, high yield, and mild reaction conditions (Jiang et al., 2014). This 
approach offers many attractive possibilities for bioconjugation, accordingly enabling tailored and well-defined properties of polymeric scaffolds to be acquired via a wide range of surface and bulk functionalizations. Various click chemistry tactics, including copper(I)-catalyzed azide-alkyne cycloaddition (CuAAC) (Meldal and Tornøe, 2008), strain-promoted alkyneazide cycloaddition (SPAAC) (Prescher et al., 2004; Laughlin et al., 2008), thiol-X reaction (Hoyle and Bowman, 2010; Daniele et al., 2014), Diels-Alder (DA) reaction (Nimmo et al., 2011; Tasdelen, 2011), and oxime ligation (Kalia and Raines, 2008), have been used to modify the chemistry of biomaterials (Xi et al., 2014; Zou et al., 2018) (Figure 2A). In the CuAAC chemistry reaction, a terminal alkyne reacts with an azide group to form a stable triazole ring. CuAAC chemistry has been used to attach functional ligands to the surface of PCL fibers (Lancuški et al., 2013); specifically, the PCL was end-functionalized with an azide moiety before electrospinning and, subsequently, bioactive groups containing alkyne moieties were conjugated at the fiber surface. The enhanced surface hydrophilicity imparted by the conjugated bioactive groups promoted cell attachment without reducing the molecular weight (Lancuški et al., 2012). Because of the toxicity of $\mathrm{Cu}(\mathrm{I})$ in biological systems, the SPAAC reaction has gained increased interest as a metal-free alternative approach, extending the usage of click chemistry in physiological settings. SPAAC has been used to functionalize the surfaces of fibers and develop in situ hydrogels with controlled crosslink densities (Zheng et al., 2012). Additionally, the functionalization and synthesis of polymeric materials by thiol-X reactions under mild conditions are characterized by simplicity and efficiency (Lowe, 2010). Among different thiol-based reactions, radicalmediated thiol-ene and thiol-yne are the most exploited in TE applications. However, because the former treatment uses UV light that may damage the cells and the tissue, the applicability of this chemical method is limited. In view of this obstacle, nucleophile-mediated thiol-X reactions, such as thiol-Michael addition, have been considered as plausible substitutes (Hoyle et al., 2010). In addition, oxime ligation is a reaction that can be safely implemented both in vitro and in vivo, because it can be performed at room temperature without the need of a metal catalyst and the application of UV light.

Click chemistry can be applied during the scaffold fabrication to modulate crosslink polymerization of functional monomers, or as a post-click functionalization strategy to impart the surfaces of polymeric scaffolds with specific functional groups to elicit cell attachment (Figure 2B). The high-efficiency reactions and excellent bond stability that characterize this method enable the crosslinking reactions to be precisely controlled to achieve tunable crosslink densities. Accurate tuning of the crosslink density is critical in the fabrication of hydrogel scaffolds. For instance, azide or alkyne terminal functionalities can be introduced in macromolecules, such as PEG and hyaluronic acid (HA), or in the presence of $\mathrm{Cu}(\mathrm{I})$ through the CuAAC crosslinking reaction, producing "clickable" hydrogels with tunable morphological and mechanical properties (Crescenzi et al., 2007; Gopinathan and Noh, 2018). Click chemistry also provides a facile way to introduce reactive and clickable sites directly on functional polymers. An example is the incorporation of free thiol groups in poly(3-mercaptopropyl) methylsiloxane-based fibers partially photo-crosslinked by UV illumination during electrospinning, followed by maleimide terminated poly( $\mathrm{N}$-isopropyl acrylamide) brushes added to the fiber surface via a thiol-Michael addition reaction (Yang et al., 2012). The resulting fibers exhibit a thermosensitive behavior that may be desirable in several TE applications (Yang et al., 2012). In addition, because most synthetic polymers utilized in TE are lacking cell-binding moieties and often exhibit hydrophobic behavior, click chemistry can be used to decorate scaffolds with short amino-acid sequences that bind to the receptors on the cell surfaces and mediate cell attachment via specific surfaceligand biological signals. The most commonly immobilized peptide for surface and bulk modification is arginylglycylaspartic acid (RGD), for which the signaling domain is derived from fibronectin and laminin. In addition, several other peptide sequences, such as the Tyr-Ile-Gly-Ser-Arg (YIGSR) and the Ile-Lys-Val-Ala-Val (IKVAV), have also been immobilized on the surface of various biomaterials (Shin et al., 2003).

Although in vivo studies are critical for evaluating the performance of a scaffold, decoupling and elucidating all possible mechanisms that dictate cell fate is cumbersome because of the complex and sophisticated nature of most native biological environments. To disentangle the complexity of in vivo phenomena and elucidate how cells receive and transmit information, it is imperative to employ systems that can assay cell functions in well-defined settings that imitate native environments. To face this challenge, click chemistry has been used to functionalize specific scaffold sites and create 3D patterns for in vitro replicating and evaluating biological processes and environments (Wylie et al., 2011; Azagarsamy and Anseth, 2013; Truong et al., 2015). For instance, 3D-patterned hydrogels have been produced from biocompatible click reactions in conjunction with orthogonal photo-chemistries to sequentially introduce and remove biochemical and biophysical signals with precise spatiotemporal control (DeForest et al., 2009; DeForest and Anseth, 2011, 2012; Ruskowitz and DeForest, 2018). Enzymatically degradable hydrogel platforms with photopatterned biomacromolecules introduced by sequential click reactions have enabled the detection and promotion of specific cellular functions and the direct observation of cellular processes, such as migration, proliferation, and morphology evolution (DeForest and Anseth, 2012). The SPAAC reaction has been used in hydrogel synthesis and the thiol-ene reaction to conjugate biomolecules (DeForest and Anseth, 2012). Thiolene reactions have also been used to introduce bioactive peptides in photo-degradable hydrogels, which were then photo-cleaved from the hydrogel network by UV radiation, enabling spatiotemporal control over peptide concentration (DeForest et al., 2009; DeForest and Tirrell, 2015). The foregoing studies have demonstrated that cell attachment, proliferation, and motility can be controlled, and cell behavior can be confined to patterned regions to provide platforms for studying how cells respond to chemical and mechanical cues (Figure 2C).

In addition to the click chemistry, which has been rapidly implemented in various biomaterial functionalizations, PDA 
A

$\mathrm{Cu}(\mathrm{I})$-catalyzed [3+2] azide-alkyne cycloaddition (CuAAC)

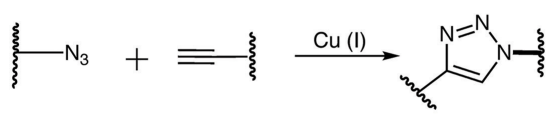

Strain-promoted azide-alkyne cycloaddition (SPAAC)

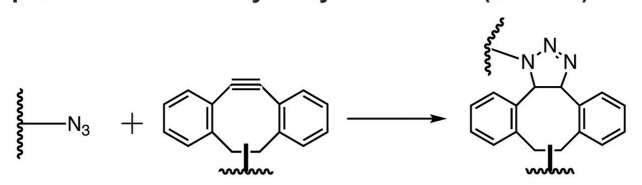

Thiol-ene reaction

$$
\xi \mathrm{SH}+\widehat{八}_{5^{5}} \longrightarrow \xi_{\xi^{5}}
$$

Thiol-Michael addition reaction

$$
\xi \mathrm{SH}+\mathrm{M}^{\mathrm{O}} \mathrm{\xi}^{\mathrm{s}} \longrightarrow \mathrm{\xi}_{\mathrm{O}}^{\mathrm{s}} \mathrm{y}^{\mathrm{s}}
$$

Oxime ligation

$$
\xi \mathrm{CHO}+\mathrm{H}_{2} \mathrm{NO}-\xi_{\xi} \longrightarrow s^{5}=\mathrm{N}^{5} \mathrm{O}^{\xi} \mathrm{mm}_{\mathrm{m}}
$$

Diels-Alder (DA) reaction

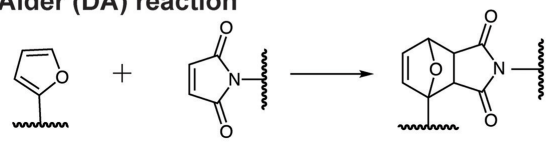

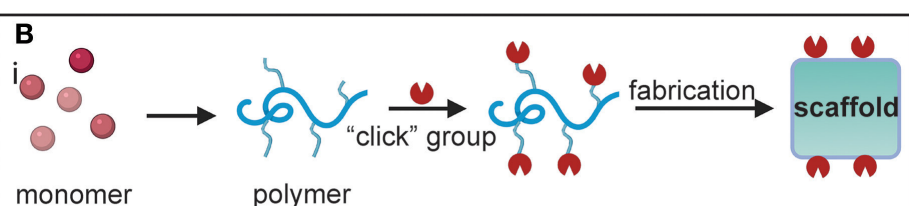

monomer polymer
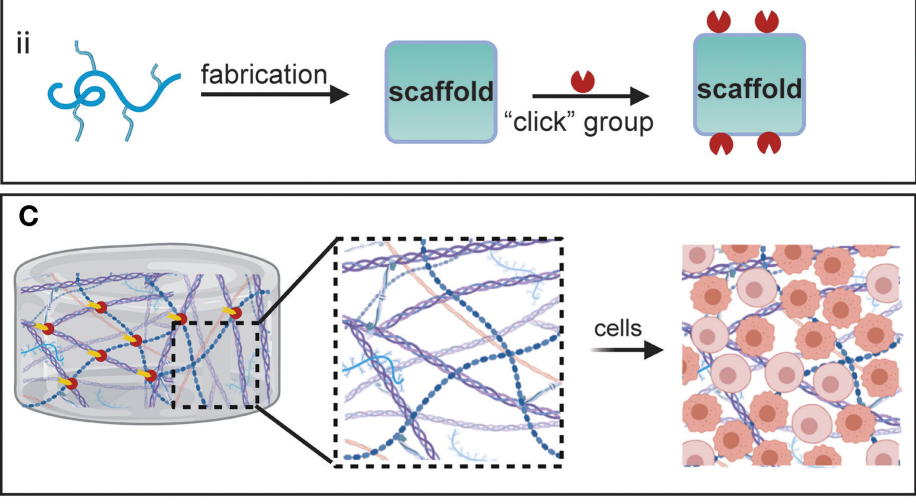

D
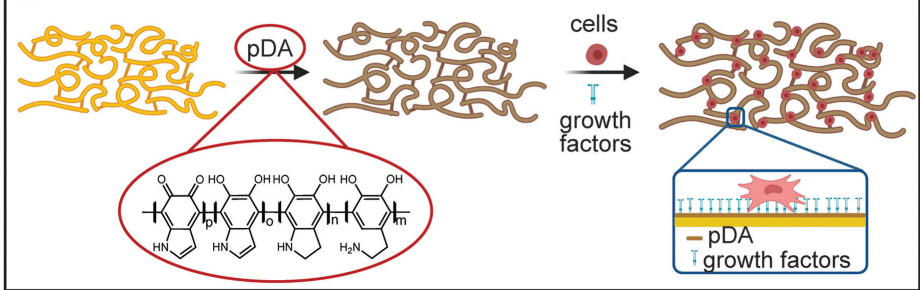

FIGURE 2 | (A) Representation of various click chemistry reactions used in the fabrication of polymeric scaffolds. (B) Fabrication strategies based on click chemistry: (i) pre-click and (ii) post-click. (C) Schematic illustrating a hydrogel crosslinked by click chemistry and functionalized with ECM-based molecules to promote cell attachment and differentiation. (D) Schematic showing a PDA-coated electrospun scaffold decorated with growth factors to promote cell differentiation. [(B-D) were created with BioRender.com].

treatment has also emerged as a facile and versatile chemical functionalization method (Madhurakkat Perikamana et al., 2015; Cheng et al., 2019; Malollari et al., 2019). The principal chemical modification strategies before the introduction of PDA were deposition of self-assembled monolayers (SAMs), plasma-assisted surface chemistry modification (PASCM), and layer-by-layer (LBL) deposition. However, SAMs require compatible chemistry between the surface and the absorbate, surface chemistry functionalization by PASCM is susceptible to alteration with time, and LBL deposition requires multiple coating cycles (Ryu et al., 2018). Since its introduction (Lee et al., 2007), PDA has been extensively used to functionalize a broad range of surfaces, including metals and ceramics, as well as materials exhibiting low surface energy. Depositing a conformal PDA coating to the surfaces of the latter materials not only improves the solubility and stability of the scaffold, but also provides multi-functionality. This is because the reactivity of the chemical residues in the PDA structure toward nucleophilic amines and thiols yields a superior capacity for immobilizing and conjugating a variety of molecules through Michael addition and Schiff base formations (Yang et al., 2014). DNA, drugs, cells, minerals, peptides, and proteins have been functionalized on
PDA-modified substrates for diverse TE applications (Ryu et al., 2010; Tsai et al., 2014; Cheng et al., 2019; Li et al., 2020; Rühs et al., 2020). It has been reported that PDA can promote cell adhesion to various substrates (Ku and Park, 2010). In fact, the former study showed that glass, polydimethylsiloxane, silicone rubber, polytetrafluoroethylene, and polyethylene, which are highly resistant to cell attachment (adhesion), when coated with PDA demonstrate cell adhesion characteristics comparable to those of gelatin-coated substrates seeded with human umbilical cord vascular endothelial cells.

It is also known that PDA enhances cellular interaction with biomaterials by immobilizing cell adhesive ECM biomolecules. Specifically, PDA can serve as a primer for the subsequent conjugation of different cell adhesive moieties via covalent interactions between catechols and the amines or thiols of biomolecules (Figure 2D). Several PDA-coated polymer substrates can be functionalized with adhesive peptide sequences derived from ECM-based biomolecules, such as fibronectin, laminin, and growth factors (Cai et al., 2013). For example, it has been observed that PDA-coated poly(lactic acid-co$\varepsilon$-caprolactone) immobilized dual bioactive factors, i.e., cell adhesive RGD-containing peptide and basic fibroblast growth 
factor (bFGF) for vascular grafting (Lee et al., 2012). The immobilization of RGD and bFGF influenced cell migration and proliferation, respectively, whereas the co-immobilization exhibited a synergistic effect, confirming that PDA can serve as a functionalization platform for vascular grafts. While PDA has been mostly used for post-functionalization, it is also of particular interest in hydrogel fabrication. For instance, PDAcrosslinked hydrogels, such as HA-catechol hydrogels, confer high stability, tunable mechanical properties, and minimal toxicity (Ryu et al., 2011; Hong et al., 2013). Although PDA has been proven to be a multifaceted chemical toolbox and PDAcoated scaffolds demonstrate enhanced adhesion, proliferation, and differentiation of various cells, the long-term in vivo toxicity and integrity of PDA during scaffold degradation require further in-depth investigation.

The above synopsis of surface and bulk chemical modification methods of the scaffold surfaces discloses a strong correlation between the scaffold chemistry and the host tissue response. The immunological response of the host tissue following scaffold implantation or injection can affect tissue regeneration. Consequently, a fundamental understanding of the effect of scaffold surface chemistry on cellular behavior is of utmost importance in the design of biomaterials that can modulate host immune reactions.

\section{Structure and Morphology}

The materials and fabrication methods used in scaffold engineering must be versatile to allow tailoring of various key structure parameters (e.g., fiber diameter, porosity, and fiber alignment) and, thus, produce a scaffold that closely mimics the ECM of the tissue of interest. Variations of these parameters lead to different cellular responses (Jenkins and Little, 2019). One of the tunable parameters in fibrous scaffolds is the fiber diameter that has been proven to modulate cell differentiation (Christopherson et al., 2009; Wang et al., 2012; Bean and Tuan, 2015; Ghanian et al., 2015; Nguyen et al., 2016; Narayanan et al., 2020) and can be controlled by adjusting the fabrication process conditions (Elkasaby et al., 2018) and the degree of crosslinking (Shields et al., 2004; Gonçalves de Pinho et al., 2019). As an example, the alignment of $3-\mu \mathrm{m}$-diameter fibers was found to enhance the arrangement, growth, and differentiation of myoblasts, contrariwise to 300-nm-diameter aligned fibers (Narayanan et al., 2020). Changes in fiber diameter have also been observed to impact gene expression and phenotypic markers (Bashur et al., 2009; Noriega et al., 2012; Erisken et al., 2013; Lee et al., 2017). Similarly, fiber diameter has been shown to affect cell adhesion and proliferation (Erisken et al., 2013; Entekhabi et al., 2016). For instance, tendon fibroblast seeding on electrospun scaffolds consisting of poly(lactic-coglycolic acid) (PLGA) nanofibers demonstrated an enhancement of cell proliferation, total collagen, and proteoglycan, whereas their microfibrous version demonstrated increased expression of phenotypic markers, such as collagen I, II, and V and tenomodulin (Erisken et al., 2013). These findings indicate that nanofibers resemble an injured ECM and stimulate regeneration, whereas microfibers aid to maintain the fibroblastic phenotype. The fiber diameter also exhibits a significant effect on cell infiltration, which is critical to 3D scaffold engineering. Indeed, it has been discovered that the larger the fiber diameter the better the infiltration of human venous myofibroblasts and more homogeneous the cell delivery in the scaffold (Balguid et al., 2009). Other studies have revealed a considerable effect of fiber diameter on the cell morphology and size (Bashur et al., 2009; Hsia et al., 2011; Daud et al., 2012; Kuppan et al., 2015; Lee et al., 2017) as well as on the cell migration velocity and distance range (Wang et al., 2010; Binder et al., 2013; Kievit et al., 2013; Meehan and Nain, 2014; Ottosson et al., 2017; Estabridis et al., 2018). However, fixing the fiber diameter for a particular cell behavior is not possible because it depends on the type, size, and shape of cells, the scaffold material, and the fabrication process, which affects the scaffold structure and fiber diameter (Noriega et al., 2012; Zouani et al., 2012).

Similar to the fiber diameter, microgroove patterns can influence the cell morphology and, in turn, the proliferation rate and spreading of the cells (Thakar et al., 2009) as well as cell differentiation (Watari et al., 2012; Abagnale et al., 2015). For instance, seeding of human mesenchymal stem cells (hMSCs) isolated from lipoaspirates and cultured in a differentiation medium on topographically patterned structures with grooves $5 \mu \mathrm{m}$ in width and ridges of different widths promoted osteogenesis for $2-\mu \mathrm{m}$-wide ridges and adipogenesis (fat cell formation) for $15-\mu \mathrm{m}$-wide ridges, whereas $650-\mathrm{nm}$ wide ridges stimulated differentiation toward osteogenic and adipogenic lineages (Abagnale et al., 2015), in contrast with the findings of a previous study (Watari et al., 2012).

Another scaffold parameter that can be adjusted is the fiber alignment or the structure morphology, which have also been correlated with various cellular responses (Sundararaghavan et al., 2013). In particular, aligned fibers have been observed to enhance stem cell differentiation conversely to randomly oriented fibers (Christopherson et al., 2009; Tijore et al., 2015; Abarzúa-Illanes et al., 2017; Sperling et al., 2017). However, other findings suggest that random fibers represent a more suitable environment for stem cell differentiation (Lins et al., 2017). Enhanced cell proliferation has also been linked to fiber alignment, although there have been reports of increased cell affinity to attach on either aligned or randomly dispersed fibers (Lim et al., 2010; Ren et al., 2013; Lins et al., 2017). For instance, while increased keratocyte proliferation occurred on the aligned nanofibers of a gelatin/poly(L-lactic acid) (PLLA) scaffold, corneal epithelial cells exhibited a higher proliferation on randomly oriented fibers of the same material (Yan et al., 2012), revealing a unique cell response to scaffold fiber alignment. Moreover, correlations between cell shape and fiber orientation have been observed in several investigations. Typically, cells tend to elongate in the direction of fiber alignment and assume a spherical or polygonal shape when seeded on scaffolds with randomly oriented fibers (Bashur et al., 2009; Vimal et al., 2016). Surprisingly, while keratocytes spread randomly on fibers oriented in various directions and elongate along the direction of aligned fibers, corneal epithelial cells remain large, round, and flat on both randomly oriented and aligned fibrous gelatin/PLLA scaffolds (Yan et al., 2012). Additionally, the fact that cell migration occurs faster in the direction of fiber alignment 
(Ottosson et al., 2017) reveals a dependence of cell migration on both fiber diameter and alignment and highlights the importance of optimizing the scaffold morphology during the fabrication.

Pore scaffold architecture, including pore size, shape, and density, is of principal importance in cellular behavior. Generally, high porosity and large pores are associated with increased proliferation, differentiation, and gene expression (Lowery et al., 2010; Zhang et al., 2010; Zhang Q. et al., 2014; Nunes-Pereira et al., 2015; Di Luca et al., 2016c,d), although an opposite trend has been reported in some studies (Mandal and Kundu, 2009; $\mathrm{Ng}$ et al., 2018). For instance, in the case of silk fibroin porous membranes of fixed porosity fabricated by freeze-drying, large pores enhanced the proliferation of human dermal fibroblast (HDF) cells compared to membranes with small pores; however, membranes with high porosity and interconnectivity showed increased cell proliferation and cellular migration even for a much smaller pore size (Mandal and Kundu, 2009). These results suggest that high porosity and interconnectivity assist cell migration within the construct, facilitating cell growth in a compatible environment. Moreover, the pore size may exhibit a more profound effect on the proliferation of HDF cells compared to the fiber diameter and may also affect the cell morphology. For example, while $20 \mu \mathrm{m}$ pores promoted cell elongation along the fibers of electrospun PCL scaffolds, $6.5 \mu \mathrm{m}$ pores resulted in cell spreading across the fibers (Lowery et al., 2010). In general, pores larger than the cell stimulate cell alignment along a single fiber, whereas pores smaller than the cell favor cell bridging across fibers, resulting in slower movement and longer migration distances. This behavior may be attributed to the fact that large pores promote single-fiber cell attachment, which is conducive to faster cell migration. Nonetheless, the pore size effect on the cell behavior is strongly depended on the cell type and scaffold material (Nunes-Pereira et al., 2015).

Pore size and shape gradients are also important scaffold characteristics affecting cellular behavior. For example, in vitro experiments with hMSCs seeded on 3D printed PCL scaffolds with $\sim 73 \%$ porosity and square or rhomboidal pores exhibited differentiation to chondrogenic and osteogenic cells, respectively (Di Luca et al., 2016b). Pore size gradients have also been linked to specific cellular differentiation and gene expression (Oh et al., 2007; Di Luca et al., 2016c,d), whereas radially varying porosity has been reported to yield cell behaviors characterized by gradient gene expression and cell differentiation and proliferation (Di Luca et al., 2016a). Through-thickness variation of the porosity and the fiber density accomplished by combining aligned and randomly oriented fibers in the scaffold structure and the incorporation of surface microwells have been correlated with increased cell migration and proliferation compared to controls of lower porosity consisting of randomly oriented fibers fabricated under the same conditions (Cheng et al., 2013; Pu and Komvopoulos, 2014; Pu et al., 2015).

Surface roughness is another scaffold parameter that strongly affects gene expression (Chen et al., 2017) and the adhesion (Milleret et al., 2012), morphology (Chen et al., 2017), differentiation (Faia-Torres et al., 2015), and proliferation (Ribeiro et al., 2015) of the cells. It has been found that rough and smooth surfaces prompt different cell responses. For instance,

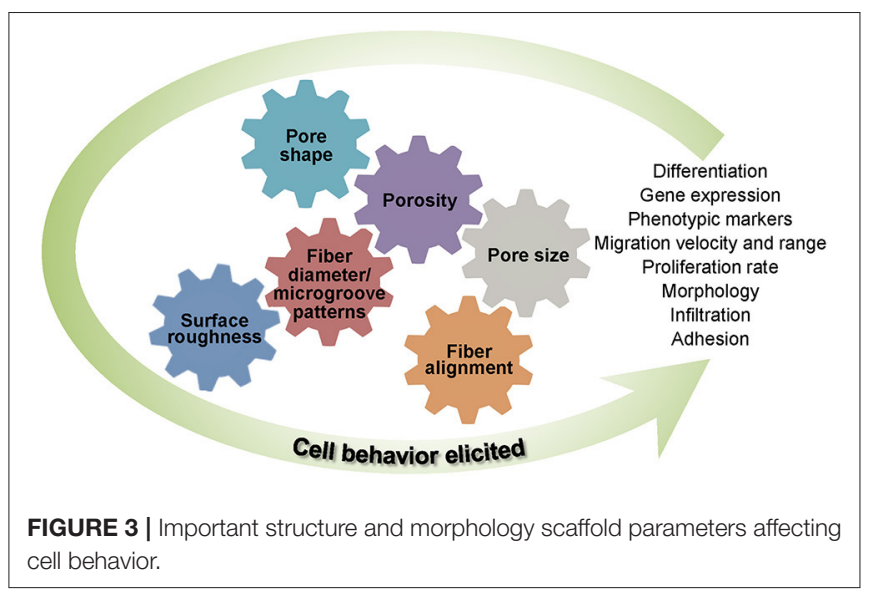

an investigation of the effect of surface roughness of electrospun poly(ethylene oxide terephthalate)/poly(butylene terephthalate) scaffolds on gene expression, differentiation, and morphology of hMSCs showed that relatively high surface roughness [i.e., root-mean-square $(\mathrm{rms})$ roughness $=71 \pm 11 \mathrm{~nm}$ ] was beneficial to some osteogenic genes, whereas low roughness (i.e., rms roughness $=14.3 \pm 2.5 \mathrm{~nm}$ ) led to the expression of other osteogenic genes and a chondrogenic gene of the hMSCs, with the cells exhibiting a small spindle shape on the rough surfaces as opposed to an elongated and multipolar shape on the smother surfaces (Chen et al., 2017). In other studies, increasing the roughness of electrospun PLLA scaffolds decreased osteoblast proliferation but increased fibroblast proliferation (Ribeiro et al., 2015). The discrepancies about the effect of surface roughness on the cellular response, such as higher osteoblast proliferation and lower fibroblast proliferation on rough and smooth microporous poly(hydroxybutyric acid) membrane surfaces, respectively (Huaga et al., 2009), can be attributed to complex cell effects depending on the cell line and different chemical, topographical, and mechanical surface cues.

All of the foregoing studies substantiate that the architecture, fiber diameter and alignment, pore size and shape, and surface roughness cannot be uniquely specified for all types of cells. Consequently, designing scaffolds to direct and promote specific cell behavior and morphology depends on the intrinsic specificities of the targeted application. Figure 3 provides a synopsis of the important structure and morphology parameters affecting cellular behavior in TE that were discussed in this section.

\section{Biodegradability}

Biodegradability is of particular importance in scaffold engineering because it must be coordinated with tissue generation for the construct to maintain sufficient strength and effectively sustain the mechanical stresses in the tissue environment. Importantly, the byproducts of polymer biodegradation must be non-toxic to avoid an immune response and also extractable through normal body function. The degradation rate of biopolymer scaffolds is therefore of utmost significance because it is intertwined with the tissue 


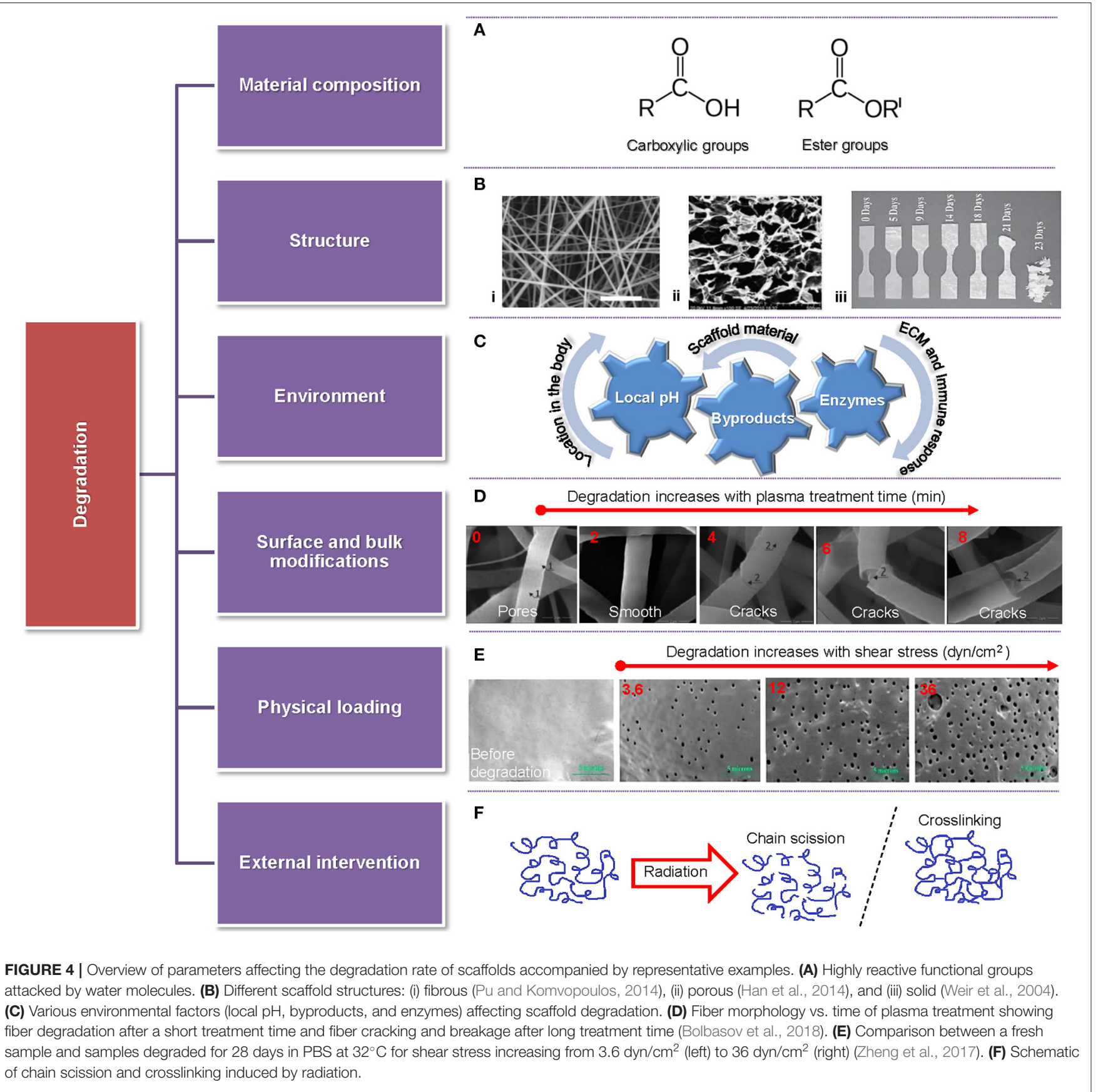

viability. Specifically, if scaffold degradation is faster than wound healing and native tissue regeneration, the cells will be deprived of the ECM-like structure, the formed tissue can be defective or unfeasible, and the produced byproducts may not be promptly expelled from the body (Cajori et al., 1924; Pucino et al., 2019). Alternatively, too slow scaffold degradation may lead to scaffold encapsulation, triggering an immune response and poor integration or rejection from the host tissue (Balguid et al., 2009; Sanz-Herrera et al., 2009; Park et al., 2010; Holloway et al., 2014). The degradation rate is controlled by the material composition (functional groups), the scaffold environment $(\mathrm{pH}$ and enzymes) and structure (porous, hydrogels, and bulk), the surface and bulk chemical modification of the scaffold, the mechanical environment (physical loading), and the type of external intervention (e.g., ultrasound, heat, radiation, etc.), as illustrated in Figure 4. The degradation rate is typically quantified as a mass loss, despite the fact that not only affects the mass but also the crystallinity, geometry (shape), and topology of the scaffold (Suuronen et al., 1998; Annor et al., 2012; Zhang H. et al., 2014; Milošev et al., 2017). Other factors affecting the rate of scaffold degradation include the implant location and the patient's age, gender, and comorbidities (Roman et al., 2017). 
The degradation rate of polymeric scaffolds strongly correlates with the material composition, the polymer molecular architecture (e.g., side groups, aromatic groups, double or triple bonds, and crosslinking), and the fabrication method (e.g., blending and copolymerization), which controls the degree of chain scission (Liu et al., 2012; Ferrari et al., 2017; Ferreira et al., 2019; Keirouz et al., 2020; Sadeghi-avalshahr et al., 2020) and modulates the biodegradability, hydrophilicity, and biocompatibility as well as cell adhesion, proliferation, growth, and antibacterial activity in TE applications (Gao et al., 2019). Polymer crosslinking reduces the degradation rate (Bi et al., 2011; Kishan et al., 2015; Chen et al., 2020), whereas the incorporation of a high fraction of nanoparticles (NPs) to play the role of bioactive sites in the scaffold may increase the degradation rate (Mehrasa et al., 2016; RadwanPragłowska et al., 2020), although some studies have shown an opposite effect (Mehrasa et al., 2016; Park et al., 2018). The degradation rate can also be tuned by chemical modification methods or by adding NPs that can neutralize acidic products (Zhang H. et al., 2014; Shuai et al., 2019).

Biopolymer degradation is a manifestation of several distinct but non-mutually exclusive mechanisms, namely hydrolytic degradation (chain scission by water molecules), enzymatic degradation (enzyme catalysis), oxidative degradation (radicals produced from peroxides), and physical degradation associated with various factors, such as loading, wear, and swelling (Brannigan and Dove, 2017). The most common synthetic polymers used in TE, i.e., polyhydroxy esters, such as PLLA, PCL, PGA, PEO, and PVA, degrade abundantly by hydrolytic chain scission, where the loss of monomers and oligomers activates bulk or surface erosion mechanisms, depending on the dynamics of diffusion-reaction phenomena (Drury and Mooney, 2003; You et al., 2005; Annor et al., 2012), and generates acidic byproducts (Idaszek et al., 2013; Kianpour et al., 2020). Alternatively, because the macromolecules of natural polymers, such as collagen, HA, alginate, and chitosan, are similar to the native ECM, they are prone to enzymatic degradation (Lam et al., 2009; Annor et al., 2012). Particularly, collagen is naturally degraded by collagenase and proteases, allowing for locally controlled degradation by the cells in the tissue (Drury and Mooney, 2003; Annor et al., 2012). Accordingly, to tailor the degradation rate, natural polymers have been used in conjunction with synthetic polymers (Wan et al., 2008; Fu et al., 2014).

Degradation also changes intrinsic topography features of the scaffold, such as fiber roughness and diameter, porosity, and wettability, depending on the surface area-to-volume ratio of the scaffold, consequently affecting the cellular behavior (Lam et al., 2009). A larger surface area-to-volume ratio typically leads to faster degradation. Indeed, a comparison between electrospun biodegradable L-tyrosine-based PU membranes and thin films of the same material revealed a higher degradation rate for the electrospun membranes than the films, with the hydrolytic degradation rate of the membranes showing a dependence on blending ratio (Spagnuolo and Liu, 2012). The surface area-to-volume ratio is linked to the wetting angle (hydrophilicity/hydrophobicity) and water intake (swelling) of the scaffold. For instance, electrospun $\operatorname{poly}(\mathrm{D}, \mathrm{L}$-lactic acid)
(PDLLA) and PEO/PLA (PELA) block copolymer scaffolds have been reported to demonstrate faster degradation compared to casted film counterparts, especially in the early stage of the hydrolysis process, with the difference in degradation rate between the two materials decreasing after 10 weeks of incubation in phosphate buffered saline (PBS) at $37^{\circ} \mathrm{C}$. It was also reported that the fibrous PDLLA exhibited a larger wetting contact angle than the fibrous PELA and even larger than the cast PDLLA (Cui et al., 2008), in agreement with the findings of an earlier investigation (Cui et al., 2006).

Loading effects on scaffold degradation have received relatively less research attention. Degradation studies of $3 \mathrm{D}$ printed PLGA in a PBS solution have shown faster scaffold degradation in a shaking incubator than in a microchannel with recirculating solution or static incubators, with the degradation rate of the samples in the static incubator being between those of the other two cases, illuminating the importance of the effects of fluid flow and loading on the degradation of PLGA scaffolds (Ma et al., 2018). Similarly, cyclic loading has been observed to accelerate PLGA degradation compared to static loading (Yang Y. et al., 2010), whereas high fluid shear rates in drug-releasing PLGA films used in vascular drug-eluting stent applications have been correlated to a faster release of sirolimus particles from the films, matching the degradation rate of the PLGA matrix (Zheng et al., 2017).

Various external factors (e.g., ultrasound, heat, and radiation) encountered during scaffold sterilization, patient therapy, and scaffold surface modification can also influence the rate of scaffold degradation by indirectly affecting the aging, crosslinking, morphology, hydrophilicity, and physical, chemical, and mechanical properties of the polymer material in combination with the cellular behavior (Yixiang et al., 2008; Rediguieri et al., 2016). For instance, under typical cancer therapy radiation levels, PCL undergoes backbone changes that have been associated with crosslinking and faster degradation (Cooke and Whittington, 2016). In vivo studies of electrospun PLLA scaffolds coated with titanium by reactive magnetron sputtering in nitrogen plasma atmosphere have shown that plasma treatment can mitigate inflammatory response, increase wettability, and stimulate cell attachment to the scaffolds, while, at the same time, expediting the commencement of scaffold degradation (Bolbasov et al., 2018).

The degradation byproducts may modify the local $\mathrm{pH}$ of the media surrounding the cells, consequently affecting cell energy metabolism, matrix synthesis, and cell behavior (Jones et al., 2015). An acidic $\mathrm{pH}$ environment may promote fibroblast proliferation and the migration and regulation of bacterial colonization, with keratinocytes showing optimal migration at more alkaline $\mathrm{pH}$ levels, e.g., $\mathrm{pH} \approx 8.5$ (Sharpe et al., 2009). Furthermore, enzyme activity is $\mathrm{pH}$ sensitive. For instance, protease exhibits a peak activity in the $\mathrm{pH}$ range of $7-8$ and a decreased activity in acidic media, suggesting the need for a balanced $\mathrm{pH}$ for this enzyme because an excess of proteases hinders the wound healing process (Greener et al., 2005). Investigations of the $\mathrm{pH}$ effect on the metabolism of chondrocytes embedded in agarose gel have shown that even for a narrow $\mathrm{pH}$ range of 6.6-7.3 acidic $\mathrm{pH}$ suppresses the production of lactate 
and increases glycosaminoglycan synthesis without affecting the synthesis of collagen, suggesting that metabolic activities and the biosynthetic ability of chondrocytes are strongly influenced by the media $\mathrm{pH}$ (Wu et al., 2007). As mentioned earlier, many synthetic polymers generate acidic byproducts upon degradation, consequently stimulating local inflammation and interfering with the healing process. Therefore, other biopolymers, such as biodegradable PU foams and polycarbonate, which exhibit good biocompatibility, reduced inflammatory response, and controlled degradation to non-cytotoxic byproducts, have been used to promote cell attachment, collagen deposition, and keratinocyte growth and retention, especially for skin TE applications (Hafeman et al., 2011; Greenwood and Wagstaff, 2016; Xu and Guan, 2016; Brannigan and Dove, 2017).

Several studies have been focused on the effect of the scaffold degradation rate on cellular behavior, including adhesion, proliferation, differentiation, and metabolism. For example, the slow degradation of electrospun PCL scaffolds maintained the rigidity needed for myofibroblast differentiation and the secretion of higher levels of matrix components, whereas the decreased rigidity of the faster degrading poly(glycolic acid)-poly(4-hydroxybutyrate) scaffolds led to the accumulation of acidic byproducts, reduced matrix production, poor cell proliferation and differentiation, and undesirable collagen crosslinking (Balguid et al., 2009). Porous silk fibroin scaffolds prepared with the salt leaching process and two different solvents (i.e., hexafluoroisopropanol and aqueous solution) demonstrated remarkable differences in degradation rate exclusively due to the process condition (solvent), conversely to chemical modification followed by in vitro seeding with human bone marrow stem cells in an osteogenic medium for 56 days, where the faster degrading aqueous-derived scaffold exhibited a higher metabolic rate (i.e., higher glucose consumption and lactate production) during osteogenesis due to the enhancement of proliferation and osteoblastic differentiation (Park et al., 2010). In another study, 3D printed porous PLGA scaffolds showed similar degradation rates with that of new bone generation and maturation after 24 weeks of implantation in a rabbit model (Ge et al., 2009). The degradation of injectable porous hydrogels is another emerging application area. This is because TE relies on the scaffold's capacity to effectively release drugs, proteins, and nanoparticles to aid the wound healing process. An in vitro study of two porous injectable hydrogels, namely serum bovine albumin (BSA) and vascular $\mathrm{K}_{2}(\mathrm{SL})_{6} \mathrm{~K}_{2}$ polypeptide/BSA (KK-BSA) crosslinked via sulfydryl groups by $\mathrm{Ag}^{+}$ions, showed that KK-BSA hydrogel degraded faster than the BSA and completely within 7 days of soaking in PBS, suggesting that antibacterial units $\left(\mathrm{Ag}^{+}\right)$and vascular polypeptide can be released in the early stage of wound healing, matching the physiological drive for wound healing (Cheng et al., 2020).

\section{Mechanical Behavior}

The cells sense the physicochemical characteristics of their microenvironment via surface mechanoreceptors and accordingly respond by actively remodeling it. Although various factors of a cellular microenvironment (e.g., cell interactions, growth factors, and ECM biochemistry and structure) contribute to vital signaling for the cells, the signals generated by the ECM play a particularly crucial role in the biochemical response of the cells (Dvir et al., 2011). The ECM influences the basic biological functions and the fate of the cells through both biochemical interactions (e.g., growth factors and adhesive motifs) and mechanical cues (e.g., stiffness and deformability). Mechanical signals have profound effects on cell differentiation, proliferation, and death, greatly affecting tissue growth in vivo (Vogel and Sheetz, 2006; Wang et al., 2009). In the design of scaffolds for TE it is often required to recapitulate the modulus and ductility of a range of native environments. However, the complexity of the cellular environment requires an awareness of its physical, biochemical, and mechanical properties for the successful fabrication of functional tissue analogs.

One of the main aspects affecting cell micromechanics is the scaffold structure characteristics, such as porosity, pore size, fiber diameter, and fiber alignment (Kennedy et al., 2017). For fibrous constructs, such as electrospun scaffolds, altering the fiber diameter influences both the cell behavior and the cell morphology, such as the cytoskeletal arrangement and adhesion sites, ultimately changing the intracellular tension forces that direct cell phenotypes (Badami et al., 2006; Noriega et al., 2012). Changes in the fiber diameter can greatly affect the fiber stiffness. Indeed, because large-diameter PCL and PVA fibers are more amorphous due to the fact that they possess a less aligned molecular structure, they exhibit a lower elastic modulus compared to small-diameter PCL and PVA fibers that show increased crystallinity and, accordingly, higher elastic modulus (Wong et al., 2008; Stachewicz et al., 2012). It is well-accepted that cell-matrix interactions depend on the degree of fiber alignment (Baji et al., 2010; Wen et al., 2014). Fiber alignment in scaffolds that mimic the ECM of the tissue, such as blood vessels (Ma et al., 2005) and nerve tissue (He et al., 2010), have been found to direct cell phenotypes. Even though the fiber alignment does not directly impact the elastic modulus of the fibers, it influences the stiffness experienced by the cells. Because the fibers display a higher effective stiffness in the longitudinal direction than the transverse direction, cell attachment and migration mostly occur along the axial direction of the fibers. Moreover, the packing density of the fibers may also influence the effective stiffness. For instance, bundling of collagen fibers increases the effective stiffness (from $\sim 1 \mathrm{kPa}$ for a single fiber to $\sim 5 \mathrm{kPa}$ for fiber bundles), enhancing the cell adhesion and migration rate (Doyle et al., 2015).

While changing key structure parameters of scaffolds, such as the pore size, fiber diameter, and fiber alignment, is an effective method for tuning the mechanical properties of scaffolds, the material chemistry can also be used to independently modify the mechanical behavior of the scaffolds. Thus, the mechanical properties of polymeric scaffolds can be altered by changing the photopolymerization time or the number of photoreactive groups (Kennedy et al., 2017). These approaches can be employed during the formation of hydrogels or electrospun scaffolds to control the mechanics while maintaining the structure architecture. For example, a PEG dimethacrylate nanofiber hydrogel matrix with tunable elasticity fabricated by integrating electrospinning with photopolymerization was used to study the 
effects of scaffold elasticity on the differentiation rate of hMSCs to vascular cells in vitro (Wingate et al., 2012). An increase in polymerization time enhanced the degree of crosslinking, producing scaffolds with elastic modulus in the range of 2-15 $\mathrm{kPa}$, consistent with in vivo stiffness. It was also found that the matrix elasticity instigated the cells to express different vascular phenotypes that demonstrated high differentiation efficiency, with softer scaffolds resulting in upregulation of the endothelial cell markers (Flk-1) and stiffer scaffolds eliciting smooth muscle cell (SMC) markers. The former study (Wingate et al., 2012) also illuminated the importance and capacity of local elasticity to control MSC differentiation to endothelial or SMC-like cells, leading to a vascular tissue regeneration in which the endothelial cell layer was softer than the SMC layer. In another investigation, electrospun photoactivatable methacrylated HA scaffolds induced chondrogenic differentiation of hMSCs by altering the fiber mechanics through the crosslink density and the cell adhesiveness mainly through the concentration of conjugated tripeptide RGD motifs (Khetan et al., 2013). It was also shown that fiber mechanics govern gene expression, with softer fibers promoting the expression of chondrogenic markers and the adhesive motifs at the fiber surface directing cell adhesion, proliferation, and migration. Studies dealing with the effects of the matrix stiffness and spatial distribution of cell-adhesive motifs on the attachment and differentiation of stem cells have demonstrated that both the matrix stiffness and the presence of adhesive cues can override other physical effects affecting the stem cell fate (Ye et al., 2015; Yevick et al., 2015). The scaffold mechanics can also be adjusted by varying the weight ratio of polymer blends (Vatankhah et al., 2014), although this may alter the surface roughness and hydrophilicity of the scaffold and, consequently, change the cell behavior.

Likewise, both the strength and the stiffness of bulk hydrogel scaffolds depend on the rigidity of the polymer chains and the crosslink density. Sequential photopolymerization allows for spatiotemporal control of the hydrogel stiffness (Leijten et al., 2017). The degree of photopolymerization, which depends on the irradiation dose and the crosslink density, can be tuned to produce unreacted functional groups in the matrix, which can enhance the hydrogel's mechanical properties through a second crosslinking reaction at a certain time (Guvendiren and Burdick, 2012; Guvendiren et al., 2014). In a specific case, matrix metalloproteinase (MMP)-degradable PEG hydrogels of different stiffness were used to examine the effect of the matrix modulus on the behavior of valve interstitial cell myofibroblasts seeded in 3D scaffolds as compared to flat hydrogel counterparts (Mabry et al., 2015). It was found that in situ stiffening of cell-laden PEG hydrogels by thiol-ene chemistry is an effective means of independently varying the scaffold mechanics at different length scales. The former study also provided insight into how cells sense mechanical signals originating from multiple length scales. While chemistry can be a powerful approach when modulating the micromechanical characteristics of scaffolds, modifying the mechanics by either blending or photopolymerization introduces a new surface chemistry, which may affect the cell behavior, the cell affinity to attach onto the scaffold surface, and the interaction of the cells with their microenvironment.
Although scaffolds undergo dynamic mechanical changes due to degradation and loading effects, the cells can also change the mechanical properties of scaffolds through the deposition of ECM, the application of cellular tractions, or even the reconstruction of the surrounding tissue. A scaffold implanted in the body experiences physiological loads (e.g., shearing by body fluids) that depend on the host tissue and/or cellular traction forces, which can induce deformations in the surrounding environment. Cellular traction forces manifest themselves during cell attachment. Cell seeding can result in scaffold contraction when there is a scaffold-tissue stiffness mismatch and the scaffold elasticity is inadequate to absorb the forces exerted by the moving cells. However, a small degree of local contraction is needed to assist cell migration and differentiation (Ulrich et al., 2010). In a study with a new dextran methacrylate hydrogel system that resembled the fibrous architecture of native ECM where the fiber stiffness, diameter, and alignment were controlled, lower fiber stiffness caused the cells to recruit neighboring fibers, effectively increasing the adhesive ligand density and enhancing cell adhesion and spreading (Baker et al., 2015). It was also shown that increasing the stiffness of the 3D fibrous constructs suppressed cell spreading and proliferation, whereas increasing the stiffness of flat hydrogel counterparts was conducive to MSC spreading and proliferation. The mechanical properties of scaffolds can also be affected by hydrolytic and/or enzymatic scaffold degradation, with the degradation rate exhibiting material dependence. For instance, PCL is a slowly degrading polymer that preserves its bulk mechanical properties for an extended period ( $\sim 65$ days), as opposed to PCL-PLGA blends that display significant deterioration of the mechanical properties and considerable mass loss (Baker et al., 2009).

It is well-known that cells are dynamic systems responding to changes of their microenvironment by altering their morphology and applying tractions or by modifying their microenvironment through cell-mediated enzymatic degradation. However, more studies are needed to better understand the interplay between local degradation and cellular tractions and how the latter can influence differentiation and other cellular behaviors.

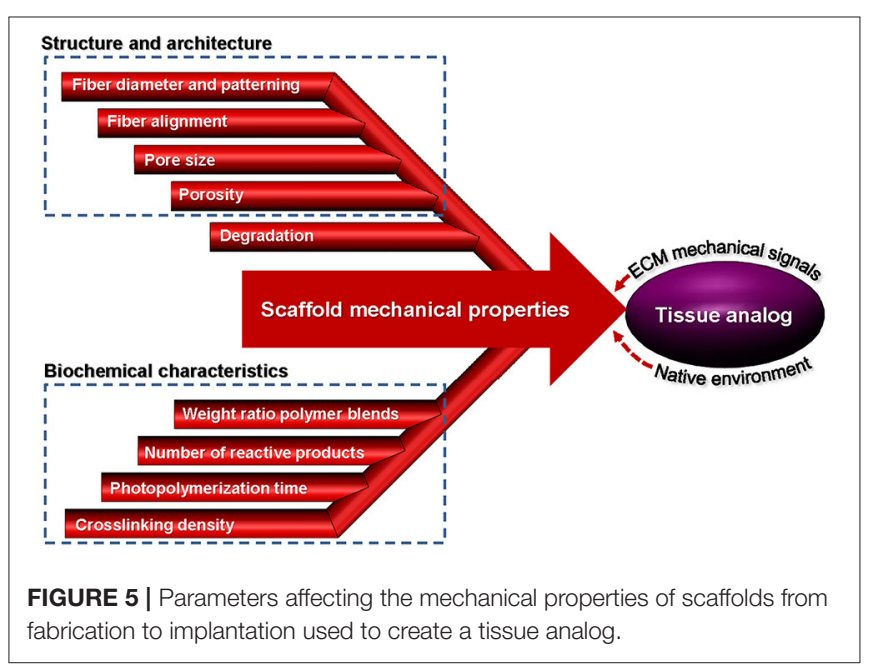


Nevertheless, most studies conducted so far have established that the mechanical properties of synthetic scaffolds can dictate the cell fate and regulate the cell response. Figure 5 summarizes the parameters that play an important role in the mechanical behavior of scaffolds discussed in this section, including the cell-scaffold interface.

\section{IMMUNOMODULATION}

Biomaterials for TE aim to replace damaged or diseased tissues with functional site-specific tissues. Although biomaterials properties, such as strength, porosity, degradability, and chemistry, are considered to be the main design principles for tuning the response of seeded cells and mimicking the nature of the native tissue, another critical factor for achieving successful clinical outcomes is the host tissue response to the implanted biomaterial. The immune system plays a vital role in host defense against pathogens, foreign bodies, and the tissue healing response following injury (Dellacherie et al., 2019). Since biomaterials are essentially foreign bodies, the immune-mediated tissue reaction to the presence of the foreign body is of utmost importance for the success of the TE strategy. Historically, in $\mathrm{TE}$ and regenerative medicine fields, immune responses were considered as challenges that had to be overcome because immunological reactions usually lead to restricted integration and regeneration of transplanted cells, tissues, and organs. However, in recent years, the design of biomaterials has shifted from suppressing the immune response to actively modulating it to promote synergy with the host environment (Sadtler et al., 2019; Stabler et al., 2019). Therefore, immunomodulatory biomaterials which promote or facilitate desired activation state or phenotype within the host immune cells have acquired widespread attention in the development of more effective biomaterials (Andorko and Jewell, 2017; Dziki and Badylak, 2018). To address the importance of immunomodulation in biomaterials design for TE applications, a brief overview of the role of the immune system in tissue repair and the role of physicochemical properties of scaffolds in directing immune responses is provided next.

The immune system continually surveils the body to detect the invasion of harmful pathogens or tissue damage, and upon recognition of a threat, it activates an orchestrated inflammatory cascade of events (Medzhitov, 2008). The recognition of pathogens occurs through the release of molecules by dying cells that are uncommon and not typically found in the body. These molecules are referred to as danger-associated molecular patterns (DAMPS) and pathogen-associated molecular patterns (PAMPS) when occurring from various species of bacteria, viruses, and parasites (Iwasaki and Medzhitov, 2010), as shown schematically in Figure 6. During the innate immune response (i.e., the segment that provides rapid but less specific reaction) these patterns are recognized by tissue-resident immune cells that trigger the secretion of inflammatory signals, which are picked up by antigen-presenting cells, such as dendritic cells (DCs) and macrophages. Initially, neutrophils infiltrate the injury site and act non-specifically to clear pathogens associated with the injury, while secreting cytokines that recruit other immune cells, such as macrophages that clear up the cellular debris (Nathan, 2006; Selders et al., 2017). When the macrophages arrive at the injury site, they exhibit inflammatory M1 phenotype and clear up the cellular debris and the phagocytose pathogens. Once the threat is eliminated, phagocytes transition to anti-inflammatory phenotype M2, promoting tissue repair and generation of new blood vessels. While neutrophils and phagocytes comprise the first line of defense, they act with non-specificity because they cannot identify the pathogen they encounter. As described previously, during infection or acute injury during biomaterial implantation, pathogens or dying cells release antigens and threat signals. In the innate immune response phase, DCs, which are antigen-presenting cells, pick up the pathogen-derived antigens and threat signals and present them as surface activation signals on their membrane, including signals that induce their maturation and migration to the lymph nodes as well as major histocompatibility complexes responsible for presenting antigens to immature B and T cells (Dellacherie et al., 2019), as shown in Figure 6. Antigens and threat signals can also drain to the lymph nodes, where they bind and activate $B$ cells to produce antibodies and/or activate resident antigenpresenting cells to prime $\mathrm{T}$ cells. Priming of immature $\mathrm{T}$ and $\mathrm{B}$ cells leads to the development of effector $\mathrm{T}$ cells and plasma cells and the development of memory $\mathrm{T}$ and $\mathrm{B}$ cells that can be activated when the same antigen is encountered (Kurosaki et al., 2015). The effector T cells and antibodies home to the affected tissue and participate in the adaptive immune effector phase.

Scaffolds for TE applications incorporate signals or cells which, upon implantation or injection, induce proliferation of the encapsulated cells, alter the phenotype of the infiltrating cells, and promote changes in tissue growth and function. Similarly, altering the physical properties of biomaterials can affect the immune response. Alteration in size and shape, composition, charge, and topography of biomaterial constructs can impact the intrinsic immunogenicity. For instance, physically confining the macrophage shape by micropatterning (i.e., elongated or pancake-like shapes) can affect the phenotype without the need to add exogenous cytokines (McWhorter et al., 2013). Also, the pore size of scaffolds can impact fibrotic capsule formation and shift macrophage phenotype. Studies have revealed a correlation between increased pore size of electrospun scaffolds and a shift toward M2 macrophage phenotype (Garg et al., 2013; Sussman et al., 2014). However, while porosity can be tuned to promote a regenerative environment by modulating macrophage phenotype, it may negatively impact the mechanical strength of the construct, which may be detrimental for recapitulating the strength of the native tissue. Changes in stiffness can also modulate host immune interactions, impacting both the biomaterial mechanics and its degradation rate. Modifying the extent of crosslinking and, in turn, the biomaterial stiffness can affect the M2to-M1 macrophage ratio while, at the same time, altering the type of crosslinking; consequently, degradability can also influence immune cell recruitment and inflammatory response. For instance, changing the crosslinking of collagen scaffolds 


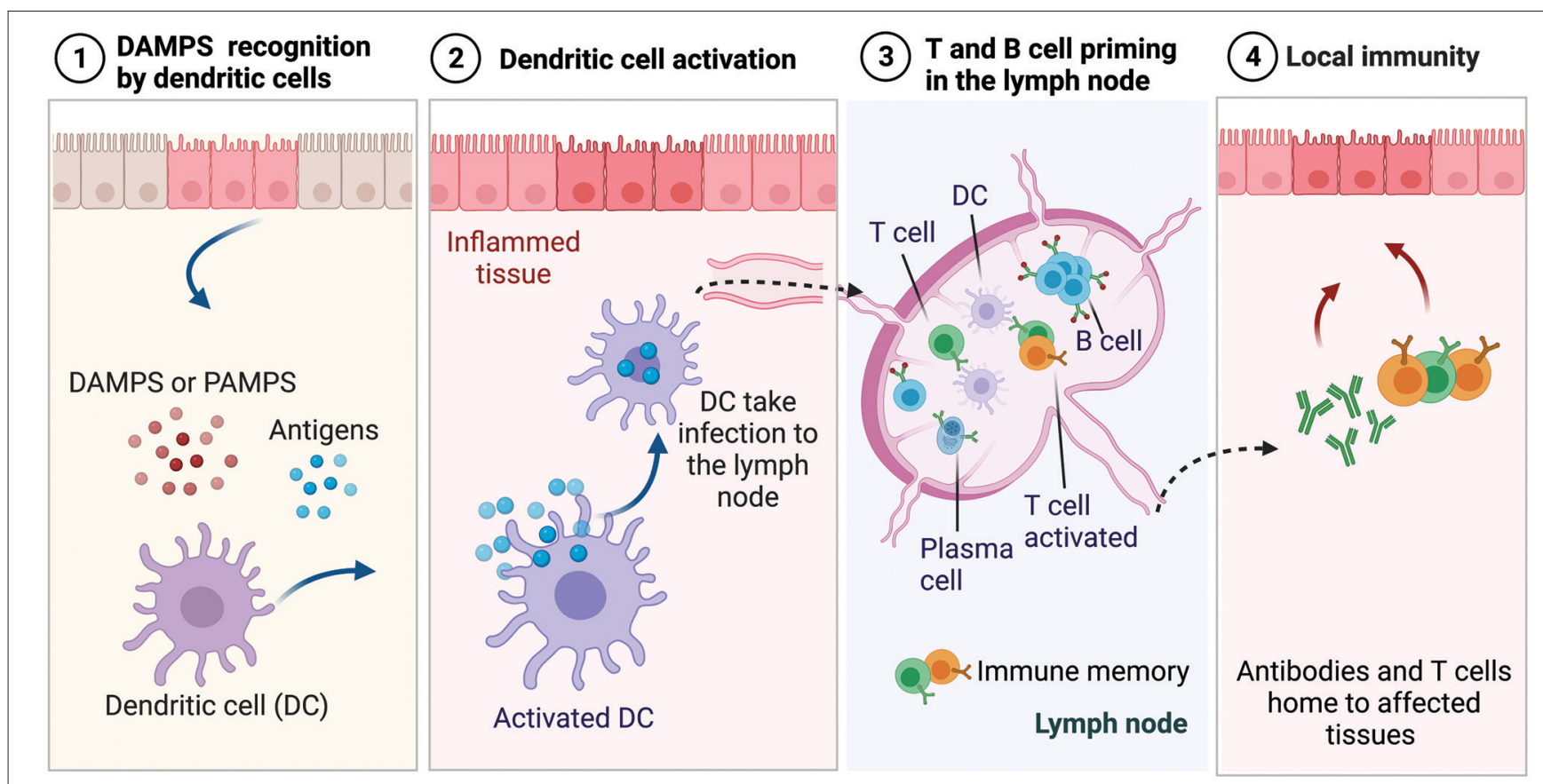

FIGURE 6 | Overview of innate immune response upon injury or infection.

from glutaraldehyde to hexamethylene diisocyanate resulted in a 10-fold enhancement of neutrophil recruitment even after 28 days of subcutaneous implantation (Ye et al., 2010). Additionally, tuning the chemical properties of scaffolds can have a dramatic effect on the host response. Crosslinking agents, including carbodiimide or glutaraldehyde, which aim to strengthen ECM-based scaffolds, have been shown to promote an early pro-inflammatory immune cell phenotype and inhibit the degradation of ECM by macrophages (Valentin et al., 2009; Brown et al., 2012; Sadtler et al., 2016). Furthermore, the size and geometry of scaffolds affect responding immune cell phenotypes by altering foreign body reaction and fibrosis. Tuning the geometry of implanted materials can influence their host recognition and propagation of foreign body reactions. For instance, it has been shown that increasing the implant size is insufficient in battling foreign body responses and that spherically-shaped implants are essential for resisting host fibrosis (Veiseh et al., 2015). Also, the degradation products of ECM-based hydrogels have been reported to have a diverse effect on macrophage phenotype compared to particulate powder ones (Dziki et al., 2017; Sadtler et al., 2017).

The design of biomaterials which can actively modulate the immune response rather than circumvent or suppress it is of paramount importance to achieving tissue repair and regeneration. Leveraging the immunomodulatory capabilities of biomaterials requires control over their physicochemical features, careful design and selection of their morphology and architecture, and thorough in vitro and in vivo studies to reveal the interplay between the biomaterial and the resulting immune response.

\section{RECENT PROGRESS IN SCAFFOLDS FOR SKIN AND BRAIN TISSUE ENGINEERING}

The previous sections were devoted to the main characteristics of scaffolds and an analysis of how the scaffold properties can be tuned to meet specific tissue characteristics, such as cellular behavior, mechanical integrity, biodegradability, and chemical cues recognition. This section provides an appraisal of the latest progress in two soft tissue applications and the results obtained through the implementation of the previously discussed design criteria integrated with biomaterials selection and delivery of small molecules and macromolecules (i.e., drugs, growth factors, etc.) to create functional scaffolds that elicit specific cellular responses. While there are many soft tissue applications, this section is focused on skin and brain tissues for several reasons. First, these two tissue types can be juxtaposed by considering their accessibility since the skin is significantly easier to access than the brain. Second, these tissues possess different levels of research maturity. Skin replacements have been engineered for decades with relatively good success, whereas brain tissue repair has not been studied as broadly as the skin, although there are still major challenges to be overcome before fully functional skin tissue can be created, mainly because of its highly heterogeneous and multilayered structure. Third, recent technological advancements, including but not limited to tissue/material interfaces and wearable electronics, demand more robust solutions (i.e., size scale and full thickness function) for both the brain and the skin. To recognize the fundamental properties that the skin and brain scaffolds must possess, it is informative to briefly describe the basic anatomy, biological 
function, and etiology of the respective native tissues before delving into the recent advancements in these TE applications. Specifically, the research progress reported here is categorized by the biomaterial of choice, while highlighting how the addition of drugs, growth factors, and particles can elicit the desired cellular behavior.

\section{Skin Scaffolds}

The skin is the largest organ of the human body accounting for about $15-20 \%$ of the total body mass and the first line of the body's defense against the outside environment, microorganisms, UV radiation, and harmful chemical, biological, and physical effects. In addition, it plays a critical role in thermoregulation, endocrine regulation, exocrine secretion, and sensation (Hansen, 2009). The skin consists of three main layers, namely the epidermis, dermis, and hypodermis. The epidermis is the external layer and mostly consists of keratinocytes as well as melanocytes, Langerhans cells, and Merkel cells. It does not contain any blood vessels or lymphatics but has a few nerve terminals and its thickness depends on the body location, varying from $\sim 0.05 \mathrm{~mm}$ in the eyelids to $\sim 1.55 \mathrm{~mm}$ in the hand palms and the feet soles. Alternatively, the dermis is a very dense matrix mostly consisting of fibroblast cells that produce collagen and ECM constituents such as elastin, and its 3D random fibrous structure provides the skin with the needed strength and toughness. The dermis also contains hair follicles (HF), nerves, blood vessels, and sweat and sebaceous glands. The hypodermis is located below the dermis and contains adipocytes cells that store fat for energy-related processes (thermal regulation) (Moore et al., 2013; Stojic et al., 2019).

The wound healing process comprises several stages of hemostasis, including inflammation, cell proliferation and migration, angiogenesis, re-epithelization, appropriate synthesis, crosslinking and alignment of collagen, and ECM remodeling, which occur in cascade fashion, overlapping each other in an auto-regulated manner. During the hemostasis, blood vessels constrict and fibrin clots form, releasing pro-inflammatory cytokines and growth factors. The inflammatory phase is instigated when inflammatory cells migrate to the wound's ECM, and neutrophils, macrophages, and lymphocytes infiltrate the wound tissue to clean it. Macrophages lead to a transition from inflammation to proliferation that results in epithelial cell proliferation and migration, while fibroblasts and endothelial cells work synergistically to provide capillary growth, collagen, and granulation tissue. Finally, the remodeling phase occurs during which the density of vascular capillaries increases, the ECM approaches initial normal tissue, and physical contraction of the wound is instigated until full closure. All of the cells that participated in the healing process and no longer are needed undergo programmed apoptosis. Local factors that disrupt this process causing a delay or impairment of the wound healing process include oxygenation, infection, foreign body, and venous sufficiency. These local factors can be affected by systemic factors, such as age and gender, hormones, stress, ischemia, and other comorbidities. Local and systemic factors are non-mutually exclusive, both contributing to the healing process (Guo and
DiPietro, 2010; Sorg et al., 2017) and the wide range of physical properties (Edwards and Marks, 1995).

Most of the needs in skin TE are for full-thickness skin wounds for which the body is incapable to fully regenerate the tissue through the normal healing process. These wounds may be due to burns, injuries, or disease (e.g., ulcerations due to cancer, diabetes, etc.). Third-degree burn injuries are the most difficult to treat due to permanent damage of the epidermis, dermis, and even the subcutaneous tissue, deep fascia, and muscle. For these injuries, the main goal is to restore the functionality and thickness of the skin, while preventing an immune response and implant rejection. One of the common approaches is grafting. Autologous grafting is advantageous because the tissue is harvested from the patient's body; thus, there is no risk for immune rejection. However, if the injured area is very large, it may be impossible to harvest all of the needed grafts from the patient's body. Consequently, either allografts garnered from either deceased or living human donors or xenografts from different species may be used in the case of unavailable or insufficient allografts. However, because allografts and xenografts usually provide a temporary solution, a second implantation of an autologous graft is necessary to reduce the risk for infection and immune rejection (Janeway et al., 2001). Applying skin grafts over full-thickness wounds usually results in poor skin graft matching, wound contraction, and defected skin tissue remodeling (Sundaramurthi et al., 2014). While some commercially available skin grafts developed for small and chronic wounds have been found to enhance wound healing, they are frail (Dai et al., 2020).

Skin scaffolds must supply vital cues for cell viability (i.e., survival, adhesion, and proliferation) and differentiation and support to the growing tissue while loaded with cells, growth factors, and/or medication to prevent inflammation, kill microorganisms, and ultimately reduce wound contraction, skin color mismatch, and other defects in the tissue. Hybrids and composite materials have been used to enhance the scaffold capacity to facilitate the growth of skin tissue. For instance, considering PCL as a synthetic material, hybrid PCL-based fibrous scaffolds electrospun with gelatin using a single solvent have been reported to yield core-shell (coaxial) fibers (Kannaiyan et al., 2019) or uniform fibers (PradoProne et al., 2020) and improved cell attachment, proliferation, and matrix formation. Similarly, freeze-dried PCL scaffolds grafted with collagen/chitosan blends by aminolysis (Sadeghiavalshahr et al., 2020) or blended with collagen/PEG/chitosan (СРCP) (Aghmiuni et al., 2020) demonstrated increased porosity, hydrophilicity, cell infiltration, and antibacterial activity. The CPCP displayed mechanical and chemical properties comparable to those of the decellularized dermal matrix used as control, and when seeded with human adipose-derived stem cells, it resulted in differentiation into both epidermis and dermis keratinocytes, mimicking the human keratinocyte differentiation pattern. Besides seeding scaffolds with stem cells, growth factors have also been directly incorporated into the scaffolds to promote granulation, regeneration of skin-like tissue after implantation in full-thickness defects (Figure 7A), and stimulation of dermal vascularization. The efficacy of the foregoing method has been demonstrated by 3D printed gelatin scaffolds coated with 

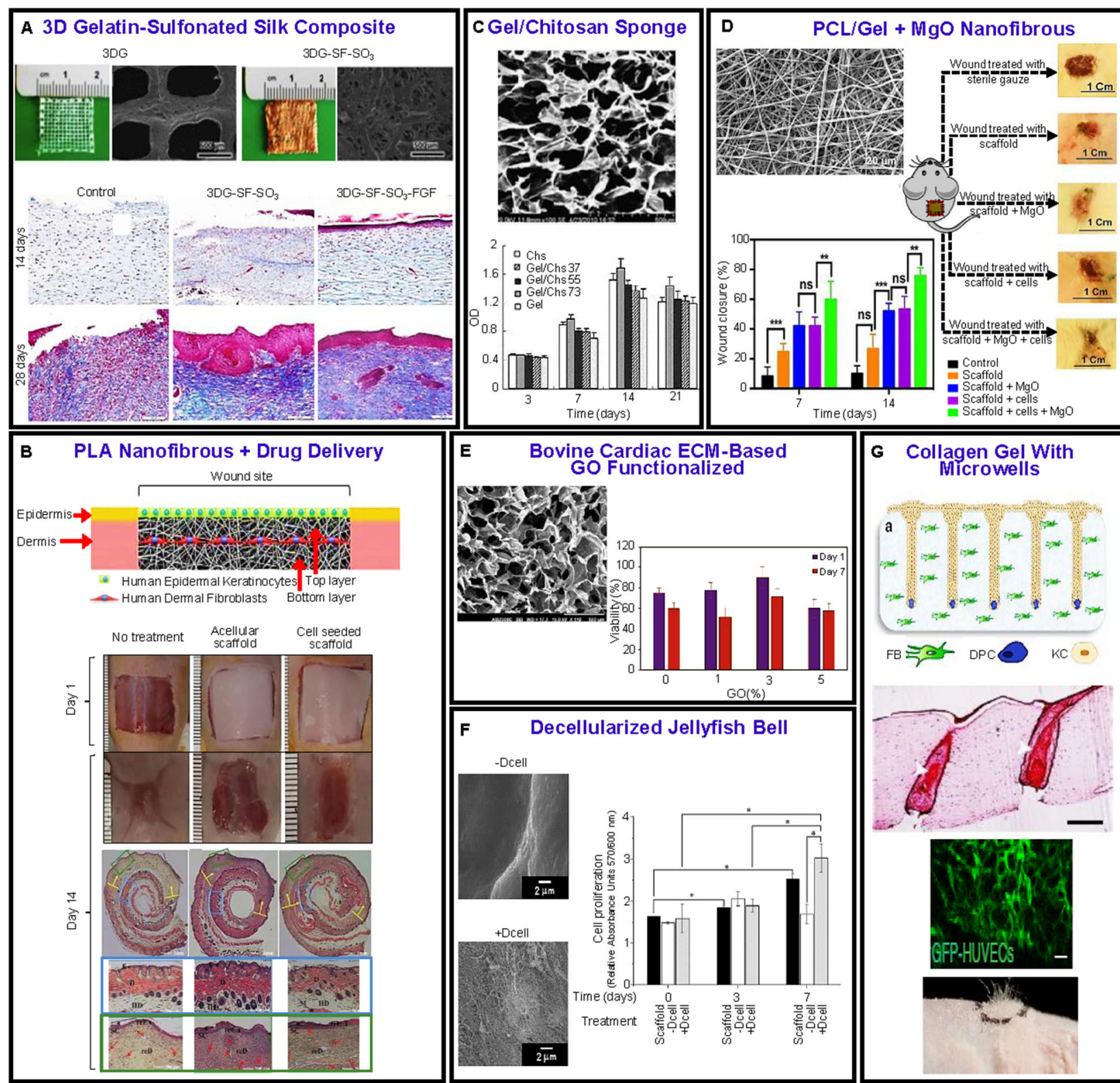

FIGURE 7 | Examples of recent advances in biomaterial scaffolds for skin wound healing. (A) Gelatin sulfonated silk scaffolds with FGF-2 growth factor. Masson trichrome staining shows the histology of a repaired wound. The treated samples reveal an increase in collagen content with time relative to the control sample (Xiong et al., 2017). (B) Ibuprofen-loaded PLA layered scaffold seeded with fibroblasts and keratinocytes. Wound closure at 1 and 14 days and histological staining of skin samples at 14 days from control wound sites without scaffolds, with acellular scaffold, and cell-seeded scaffold (Mohiti-Asli et al., 2017). (C) Gelatin/chitosan freeze-dried scaffold showing enhanced cell viability (Han et al., 2014). (D) Hybrid PCL/gel fibrous scaffold loaded with MgO particles showing significantly more wound healing compared to controls (Ababzadeh et al., 2020). (E) Porous structure of bovine cardiac ECM-GO functionalized scaffold. Cell viability vs. GO content (Jafarkhani et al., 2020). (F) Decellularized (+Dcell) and non-decellularized (-Dcell) jellyfish bell scaffolds. Fibroblast cell proliferation after 0, 3 , and 7 days shows a significant difference between +Dcell and -Dcell at 7 days of culture (Fernández-Cervantes et al., 2020). (G) Schematic of scaffold and cells seeded, histological staining showing differentiated keratinocyte morphology and graft vascularization, and high follicle density engraftment (Abaci et al., 2018).

sulfonated silk fibroin and basic fibroblast growth factor 2 (FGF2) bound by a sulfonic acid $\left(\mathrm{SO}_{3}\right)$ group (Xiong et al., 2017). In another 3D cell printing study of vascularized human skin, the results obtained with a three-layer structure fabricated by consecutive printing hypodermis, vascular channels, dermis, and epidermis using specific materials, cells, and growth factors for each layer (Kim et al., 2019) showed a good prospect for the development of fully functional skin substitutes through the incorporation of skin-related cells.

Skin scaffolds can also be loaded with various medications for local wound release and activation to combat sources of inflammation. PLA electrospun scaffolds loaded with ibuprofen 
for reducing inflammation and seeded with human epidermal keratinocytes (HEK) and HDF cells in two different layers were found to improve wound contraction and neovascularization (Figure 7B) (Mohiti-Asli et al., 2017). Hybrid materials like PU/PLA scaffolds synthesized by salt leaching and loaded with ciprofloxacin have been proven to inhibit bacterial infections and maintain their physicochemical and mechanical properties for 36 months, consistent with skin tissue regeneration requirements (Iga et al., 2020). Scaffolds based on chitosan/gelatin (freezedried) loaded with ciprofloxacin hydrochloride have been reported to exhibit decreased inflammatory response and effective cell support and attachment (Figure 7C) (Han et al., 2014). Other antimicrobial agents incorporated in skin scaffolds, such as tetracycline hydrochloride, curcumin, and althea officinalis, have also revealed promising results (Ezhilarasu et al., 2019; Ghaseminezhad et al., 2020).

An effective method to combat inflammation is to add small molecules and/or ligands, such as micro/nanoparticles, selfantigen, and antibodies, which can directly modulate the immune response but not the source of inflammation (Rosique et al., 2015; Gammon and Jewell, 2019; Cleetus et al., 2020). Loading scaffolds with specific types of microparticles and nanoparticles not only can improve the antimicrobial and immune response but may also enhance the scaffold's mechanical performance. To improve scaffold durability and antibacterial activity, skin scaffolds can be loaded with conductive particles or NPs to stimulate cell behavior by applying direct current. However, selecting the size and concentration of NPs is challenging because they may exhibit passivation and cytotoxicity (AshaRani et al., 2009; Jatoi et al., 2019) and the stabilizer may negatively affect the biocompatibility. Importantly, the size of NPs is critical because extremely small particles can penetrate the cell membrane, leading to the formation of vacuoles and, ultimately, premature apoptosis, or aggravate a chronic inflammatory response. Examples of the promising usage of particles in scaffold engineering include fibrous electrospun constructs synthesized from PCL and gelatin blends doped with $\mathrm{MgO}$ particles that resulted in $79 \%$ wound size reduction when seeded with human endometrial stem cells in vitro compared to $11 \%$ size reduction accomplished with sterile gauze control (Figure 7D) in addition to improved mechanical properties (Ababzadeh et al., 2020); 3D printed structures of PCL/poly(propylene succinate) copolymer doped with $\mathrm{AgNO}_{3}$ demonstrating improved degradation behavior, cell viability, and antimicrobial properties compared to PCL scaffolds (Afghah et al., 2020); electrospun scaffolds of chitosan/gelatin with $\mathrm{Fe}_{3} \mathrm{O}_{4}$ NPs demonstrating enhanced mechanical properties and antibacterial activity (Cai et al., 2016); and scaffolds functionalized with conductive NPs, such as $\mathrm{ZnO}$, $\mathrm{Fe}_{3} \mathrm{O}_{4}, \mathrm{Au}, \mathrm{Ag}$, and $\mathrm{TiO}_{2}$, which enhanced cell proliferation, adhesion, and migration by means of electrical stimulation, or surface roughening by the particles at the scaffold surface (Babitha and Korrapati, 2017; Zulkifli et al., 2017; Kianpour et al., 2020; Radwan-Pragłowska et al., 2020).

Another strategy for skin TE is to augment the cell viability by using decellularized tissue with retained primary ECM constituents. ECM-based materials can be sourced from different organs, such as small bovine intestine (Parmaksiz et al., 2019) and bovine cardiac tissue (Jafarkhani et al., 2020). Functionalized freeze-dried scaffolds consisting of bovine cardiac ECM-based graphene oxide (GO) have demonstrated better mechanical properties and cell viability than decellularized tissue scaffolds (Figure 7E) (Jafarkhani et al., 2020). A marine organism (decellularized jellyfish bell) has also been considered as plausible ECM for engineered skin tissue and found to display intact collagen I that promoted good adhesion and proliferation of HDF cells (Figure 7F), structural stability, good thermal characteristics, and mechanical properties similar to those of collagenous tissues and slightly better than those of human skin (Fernández-Cervantes et al., 2020).

In addition to the materials already mentioned, hydrogelbased skin scaffolds have shown great potential for drug delivery of injectable materials for wound repair because of their intrinsic cellular interaction and biocompatibility (Chaudhari et al., 2016). Several innovations have been reported for injectable hydrogels (Lokhande et al., 2018; Chen et al., 2019; Cheng et al., 2020; Zheng et al., 2020). A notable achievement is an injectable polypeptide-protein hydrogel crosslinked with $\mathrm{Ag}^{+}$demonstrating vascularization, antibacterial activity, wound healing, HF growth, and angiogenesis (Cheng et al., 2020). $3 \mathrm{D}$ scaffolds of collagen gel with surface microwells have been developed to control the spatial arrangement of HF (Abaci et al., 2018). Seeding these scaffolds with HDF and human dermal papilla cells (highly specialized mesenchymal cells) and the wells with human dermal keratinocytes led to HF differentiation. In addition, vascularized hair-bearing scaffolds implanted in immunodeficient mice resulted in efficient hair growth. The regeneration of an entire HF from cultured human cells may affect the treatment of different types of alopecia and chronic wounds (Figure 7G) (Abaci et al., 2018). Another approach for generating skin is scaffold-free $3 \mathrm{D}$ bioprinting that can deposit layers of different biological materials, called bioinks, including classical biomaterials used to fabricate structural scaffolds (synthetic, natural, or ECM based), different types of cells, growth factors, drugs, DNA, and other bioactive substances. The bioprinting approach has been investigated both in vivo and in vitro (Pourchet et al., 2017; Kim et al., 2019; Stojic et al., 2019; Jorgensen et al., 2020).

\section{Brain Scaffolds}

Understanding how the human brain works has been the focus of numerous studies. The brain, one of the central nervous system's main parts, is a complex organ that controls vital functions, such as breathing, sleep, sensory processing for vision and hearing, and cognition like reasoning and memory. It is considered to be the crown jewel of the human body and contains more than 100 billion neurons interconnected via branch-like projections of fibrous extensions called axons, which receive and transmit electrochemical signals and contribute in the formation of neuronal-axonal networks. These exquisite networks are complemented by glial cells, recognized as support cells, which are essential for the structural, metabolic, and functional activities of both neurons and axonal tracts. Moreover, the blood brain barrier (BBB), a selective barrier formed by the creation of tight junctions of endothelial cells lining the vasculature in the brain, 
acts as a physical barrier that regulates the passage of ions, molecules, and cells between the blood and the brain (Abbott et al., 2006). This semi-permeable gate keeps the neural tissue safe and stable by preventing toxins, pathogens, and other harmful substances from entering the brain, while at the same time allowing small gaseous molecules, such as $\mathrm{O}_{2}$ and $\mathrm{CO}_{2}$, to diffuse freely (Abbott et al., 2010).

When the brain is healthy, it works like a finely calibrated, highly sophisticated machine; however, many serious problems arise when it malfunctions or is injured. During an incidence of traumatic brain injury or a stroke, the sudden energy deficit and hypoxic conditions can cause neurons and glial cells to undergo apoptosis and necrosis, while, concurrently, the BBB triggers the infiltration of immune cells and releases free radicals (Martin et al., 1994). Cell apoptosis and break down of the BBB activate microglia (local inflammatory cells), which express enzymes that reduce the ECM (Graeber and Streit, 2010), leading to the progressive degradation of the mechanical and chemical integrity of the brain tissue, ultimately leading to the formation of a cavity. As a defense mechanism against infarct expansion and further matrix degradation, activated astrocytes undergo astrogliosis, forming a glial scar that acts as a physical and chemical barrier that compartmentalizes the infarct region (Sofroniew and Vinters, 2010). The glial scar isolates the lesion site and prevents the degeneration from proliferating into the healthy tissue. However, the glial scar also inhibits the outgrowth and regeneration of damaged axons, which can cause functional abnormalities or even the death of neurons (Nih et al., 2016).

Most of the efforts focused on brain tissue repair and regeneration have revolved around the delivery of drugs and cells. However, these approaches have not been widely adopted due to daunting challenges. Primary problems related to drug delivery include the constraint of drug diffusion imposed by the BBB and the rapid degradation of the drug once it enters the circulatory system, while challenges associated with cell delivery involve poor survival after delivery and reduced integration into the host tissue. Biomaterial scaffolds play a central role in contemporary strategies for developing viable solutions that can mitigate some of the above limiting issues and, consecutively, facilitate brain tissue regeneration, reconstruction, and reconnectivity of neuronal-glial networks following degeneration due to brain injury or disease (Zhong and Bellamkonda, 2008; Khaing and Schmidt, 2012; Khaing et al., 2014) (Figure 8A). The fragile nature of the brain tissue, which is soft (its elastic modulus ranges from 1 to $14 \mathrm{kPa}$ ) and anisotropic (its ECM consists of collagen type IV, HA, fibronectin, laminin, and proteoglycans), in conjunction with its confined space are specific design criteria for biomaterials intended for brain tissue repair (Tuladhar et al., 2018). The ultimate goal of such biomaterial scaffolds is to facilitate functional recovery of the brain tissue by promoting regeneration, elicit plasticity, and drive neurogenesis. Scaffolds for brain tissue repair have been used to perform localized drug and cell therapies to the injury site, provide mechanical support to the surrounding tissue, and guide the growth of neural axonal networks.

Hydrogels have attracted considerable interest as scaffolds for brain repair because they can form ECM-mimetic architectures and may serve as a platform for minimally invasive drug and cell delivery directly at the injury site (Lee and Mooney, 2001). When designing injectable hydrogels for the post-injury environment of the brain, the physical properties that must be taken into account are the porosity, chemical composition, and mechanical characteristics. Because the brain tissue is more sensitive to stress effects than other tissues (Liao et al., 2008; Pettikiriarachchi et al., 2010), the stiffness of biomaterials implanted in the brain must be similar to that of the host tissue, because stiffer materials usually lead to gliosis and inflammation, whereas softer materials result in implant instabilities and failure. Hydrogel scaffolds can provide structural support to the surrounding tissue, can be loaded with drugs and growth factors, and can also serve as cell transplantation vehicles to deliver neural progenitor cells (NPCs), hence providing an important mechanism for rebuilding a functional neuronal network after brain injury (Orive et al., 2009; Erning and Segura, 2020). Natural hydrogels, such as HA (Tian et al., 2005; Wang et al., 2011; Mittapalli et al., 2013), collagen (Guan et al., 2013), chitosan (Yang Z. et al., 2010), agarose (Jain et al., 2011), and methylcellulose (Cooke et al., 2011; Austin et al., 2012), have been used in brain injuries and their capability to reduce inflammation, guide axonal growth, and promote angiogenesis has been assessed (Kornev et al., 2018).

Localized drug delivery by injectable hydrogels outperforms traditional drug delivery approaches because hydrogel biomaterials provide a delivery platform that demonstrates superior spatiotemporal control (Zhu et al., 2015). The encapsulation of drugs and growth factors into particulates incorporated in the bulk of implantable hydrogels reduces inflammation, improves neurogenesis, and results in minimal tissue damage. For instance, hyaluronan-methylcellulose encumbered with PLGA NPs loaded with drug and/or growth factors are classified as composites with highly tunable and sustainable delivery profiles. The injection of this system above a stroke-induced lesion of a mice caused the local and sustained delivery of brain-derived neurotrophic factor to increase neuroplasticity and decrease the lesion cavity and neuron loss (Obermeyer et al., 2019). Moreover, hydrogel biomaterials used in brain injuries can be loaded with antiinflammatory drugs to control inflammatory reaction. For example, biodegradable gelatin microspheres loaded with antiinflammatory drug were used to protect the encapsulated drug from inflammation-derived degradation after administering it to the injury site (Jin et al., 2014). The direct transport of angiogenic agents, such as vascular endothelial growth factor (VEGF), can cause further brain damage by augmenting BBB breakdown and inducing immature and disorganized vessel formation (Aday et al., 2017). To overcome this barrier, hydrogel biomaterials have been used to guide the delivery of VEGF, overcoming difficulties with repetitive local injections and the short half-life of VEGF. An HA-based hydrogel crosslinked in situ with MMP degradable peptide and decorated with RGD adhesive motifs co-injected with VEGF clustered on heparin NPs into an injury cavity suppressed inflammation and enhanced angiogenesis, neurogenesis, and axonal growth (Figure 8B) (Nih et al., 2018). 

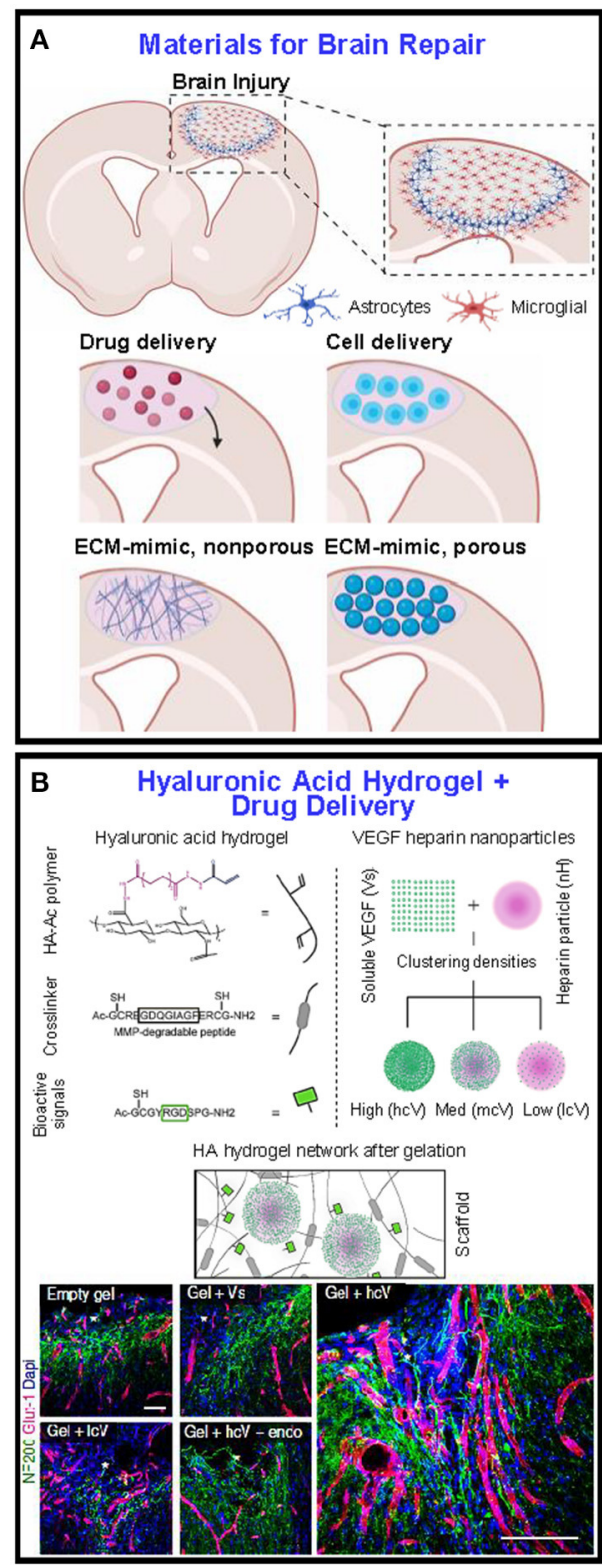
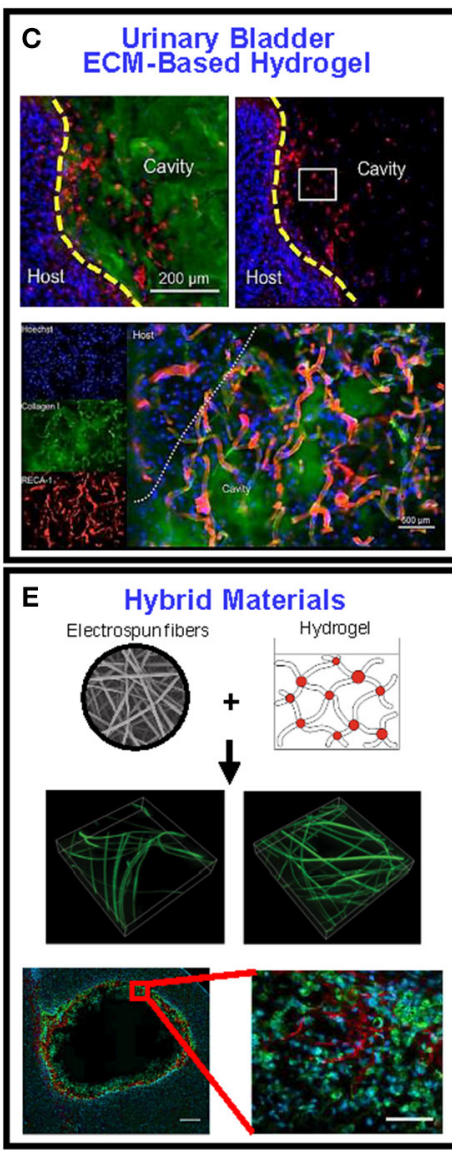

\section{F Bio-Printed Hydrogels}

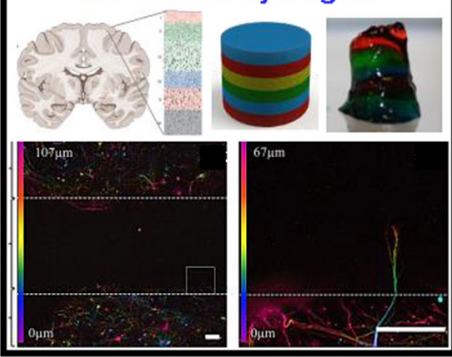

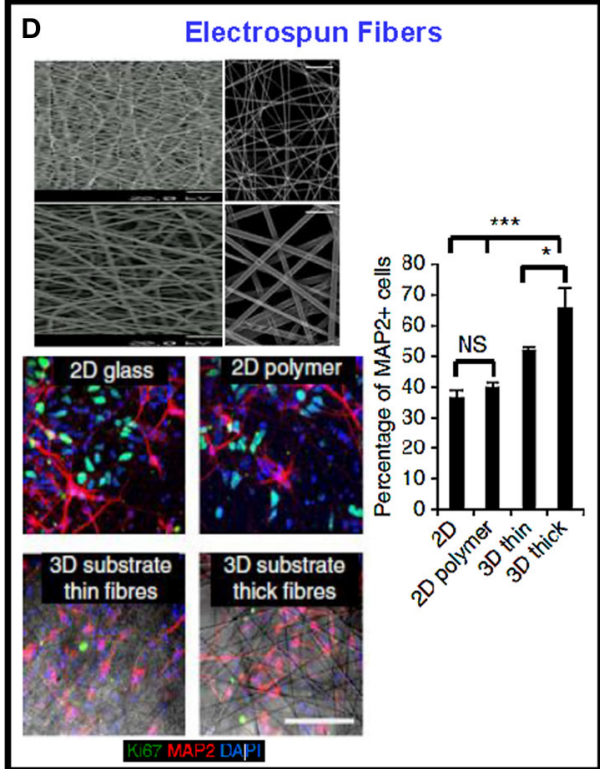
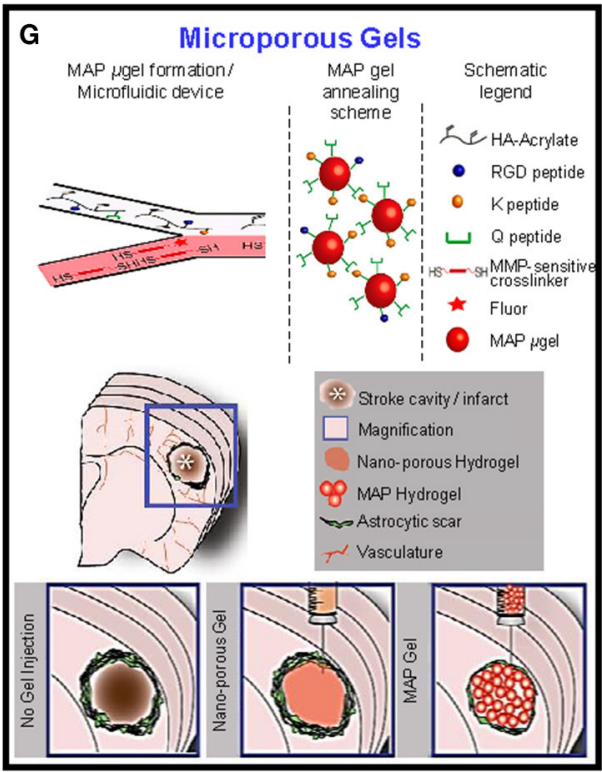

FIGURE 8 | Examples of recent advances in biomaterial scaffolds developed for brain tissue repair after injury. (A) Schematic illustration of the pathophysiology after brain injury illuminating the development of astrogliosis and the increase of the microglial density. (B) Design of HA with clustered VEGF on heparin NPs. The immunostained images of neurons and vessels show that the gel with high clustered VEGF delivery enhanced angiogenesis and neurogenesis (Nih et al., 2018). (C) Urinary bladder-based hydrogel. The immunostained images illustrating ECM hydrogel and cell nucleus show that the hydrogel modulated neuroinflammation and enhanced neurogenesis and angiogenesis (Ghuman et al., 2018). (D) Electrospun fibers with different architectures and porosities infiltrated with human-induced neuronal cell populations. Significantly higher numbers of human iN cells expressed microtubule-associated protein 2 in the thick fibrous scaffolds relative to the $2 \mathrm{D}$ controls and thin fibrous scaffolds (Carlson et al., 2016). (E) Fibers incorporated in hydrogels. When implanted into the striatum, the scaffold displayed higher cellular infiltration and a more loosely defined glial boundary. The images show the tissue-scaffold interface-astrocytes (red), macrophages/microglia (green), and cell nuclei (labeled with DAPI, blue) (Rivet et al., 2015). (F) Bio-printed brain-like layer structures (each color represents a different layer). Confocal microscope images of neurons in different layers, colored for the distribution of cells through the $z$-axis, showing an axon penetrating the adjacent layer (Lozano et al., 2015). (G) Schematic illustration of the production of hydrogel microparticles in a flow-focusing microfluidic device (Nih et al., 2017). These gels can be injected at the location of interest while preserving their structure.

Hydrogel scaffolds can also direct the movement and differentiation of neural stem and progenitor cells into specific cell types, thus contributing to the recovery process. Because cell survival during transplantation is critical, optimizing the hydrogel properties (e.g., stiffness, gelation time, porosity, etc.) is very important (Adil et al., 2017). In a study that used an in situ formed HA/peptide hydrogel to transplant NPCs derived from stem cells into the infarct cavity of a stroked mice, the key factors 
that regulated cell survival during transplantation were found to be the injection speed and the needle gauge during the injection and gelation process (Lam et al., 2014). It was also observed that cells encapsulated in the hydrogel demonstrated enhanced NPC differentiation to a neuronal phenotype (neuroblasts) compared to cells transplanted without using the hydrogel as a vehicle. Additionally, hydrogels exhibiting mechanical properties close to those of native tissue, which were decorated with natural ECM molecules and loaded with tissue-relevant factors and topography cues, were found to direct the differentiation of the transplanted cells (Khaing et al., 2014). Another strategy for brain repair is to prepare scaffolds from decellularized tissue. ECM hydrogels have been used in endogenous brain repair after injury (Ghuman et al., 2016; Wu et al., 2017). ECM-based hydrogels can be sourced from different organs, such as the urinary bladder matrix (Freytes et al., 2008), peripheral nervous system (Prest et al., 2018), and brain (Crapo et al., 2012). For example, a porcine-derived urinary bladder ECM matrix was used to form injectable ECM hydrogels for delivery in an ischemic stroke mouse model (Figure 8C) and the results showed that low concentration and optimal biodegradation rate of the hydrogel improved immunomodulation, angiogenesis, and neurogenesis (Ghuman et al., 2018).

Hydrogels are often mentioned in TE approaches for brain repair due to their biocompatibility and inherent bioactive properties. However, synthetic polymeric scaffolds have also been utilized because their bulk properties and degradation rates can be more easily controlled (Kweon et al., 2003; Chew et al., 2007; Mahumane et al., 2018). Most of the studies considered synthetic polymeric scaffolds as potential carriers of drugs, cells, and growth factors to the injury site. The architecture, fiber alignment, porosity, and topography are critical when designing synthetic polymeric scaffolds for brain repair. The composition of a polymer scaffold governs the early interfacial phenomena that control cell attachment, whereas the polymer architecture (fibrous or porous) directs the longterm cellular behavior. For example, studies with electrospun tyrosine-derived polycarbonate substrates with thin and thick fibers and different porosities (Figure 8D) demonstrated that larger voids in the substrates with thick fibers enhanced the volumetric permeability for cellular infiltration, promoted stem cell neuronal reprogramming and neural network establishment, and supported neuronal engraftment in the brain; however, the substrates with thin fibers did not show the same results (Carlson et al., 2016). Although the nature of the brain tissue promulgated the development of injectable hydrogels for implementation at the site of injury, implantable polymeric scaffolds have also been used mostly together with hydrogels to form hybrid materials that can synergistically provide the physical and chemical cues for instigating cell migration into the hybrid matrix (Bosworth et al., 2013; Rivet et al., 2015). In vitro studies with the foregoing hybrid materials (Figure 8E) have provided insight into fundamental problems regarding the use of biomaterials for brain tissue repair (Hopkins et al., 2015). In this context, recent advancements in $3 \mathrm{D}$ printing and the concomitant use of bio-inks and cells can be instrumental to the development of brain-like constructs consisting of discrete cell layers that can be used in vitro to further explore cellular behavior and elucidate critical biomaterial issues pertaining to brain tissue injury and repair (Figure 8F) (Hopkins et al., 2015; Koffler et al., 2019).

Biomaterial scaffolds for brain tissue repair have been used to improve the delivery of drugs, growth factors, and cell transplantation. Recently, biomaterials that can promote tissue repair and regeneration without the need to transport cells or other therapeutics have provided a powerful approach to brain tissue scaffolding. Injectable porous hydrogels, referred to as hydrogel microparticles (HMPs), have arisen as promising biomaterials for brain repair and biomedical engineering (Figure 8G) (Griffin et al., 2015; Nih et al., 2017; Daly et al., 2019). These porous hydrogels exhibit shear-thinning behavior, are inherently modular, and because of the interstitial space between the packed HMPs they possess significant porosity that is important for tissue repair and reduced inflammation not only in the brain but also in other organs (Madden et al., 2010; Tokatlian et al., 2014). In a specific example, an HA microparticle hydrogel injected in a stroke cavity reduced astrogliosis and modulated neuroinflammation, illuminating the critical role of biomaterial design in tissue repair (Christman, 2019; Sideris et al., 2019).

\section{OUTLOOK AND FUTURE PERSPECTIVES}

The foregoing synopsis elucidates some of the most important accomplishments, the current demands, and the existing challenges regarding biomaterial scaffolds used in various TE applications. The development of such functional constructs for augmenting or replacing native tissues lies at the crossover of biology, medicine, materials science, and engineering. Numerous new strategies have been advanced to fabricate highly tunable and functional scaffolds. However, despite the outstanding progress achieved to date, there are still numerous challenges that must be overcome before scaffold-based TE technologies can attain broad clinical usage and commercialization. Several design considerations that are undistinguishably linked to the formation, function, and implant location of native tissue must be addressed to further advance scaffold engineering. The chemical, morphological, and mechanical properties of scaffolds must be tuned to optimize interactions with the cells and the surrounding tissue, whereas the biodegradation rate must be controlled to preserve the scaffold's integrity until the maturity of the growing tissue. Scaffolds should be designed with an appreciation of the bio-chemo-mechanical properties of the native tissue and the complex mechanisms that control cell interactions. Furthermore, the composition and micro/nanostructure of the ECM of different tissues vary significantly. Therefore, recapitulating the biological roles of the native tissue through a synthetic construct should recognize the structure architecture of the tissue of interest and its biological role. Clearly, there are no universal design criteria that fit all of the tissue characteristics. Because native tissues are characterized by a wide range of functions and compositions, the same scaffold materials cannot be used for all tissues. When selecting and developing new materials for TE, it is imperative to simultaneously consider the complex biochemistry, morphology, 


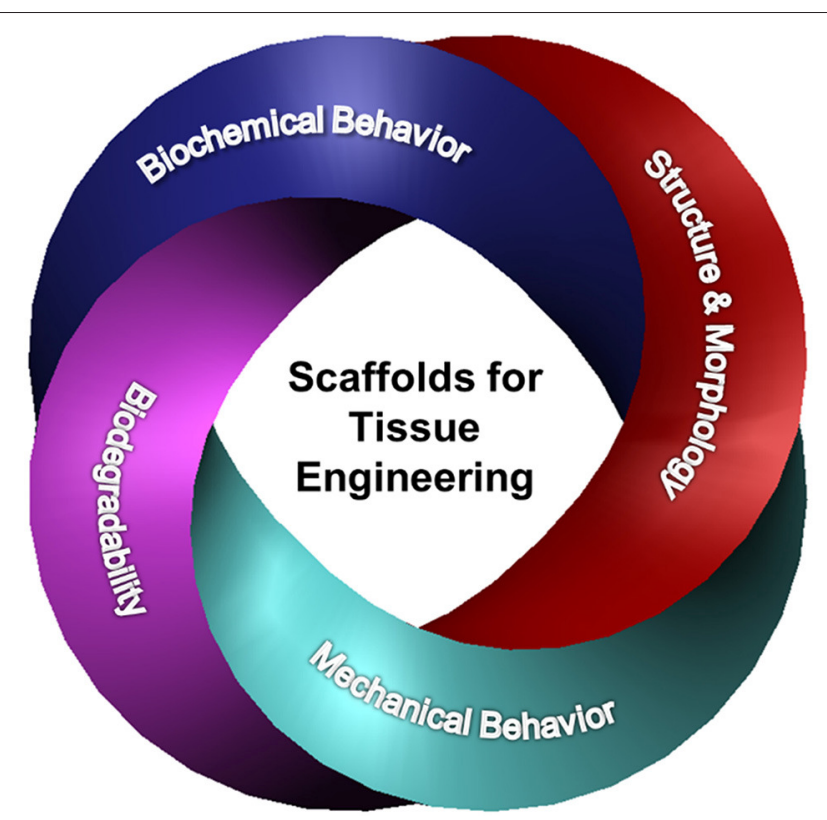

FIGURE 9 | Synergy between biochemical behavior, structure and morphology, biodegradability, and mechanical behavior of scaffolds activates cellular behavior, controls cell fate, and drives TE advancement.

mechanical behavior, and biodegradation characteristics of the scaffold (Figure 9).

The interactions between the native cells and the scaffold promote distinct cell phenotype changes and affect the regeneration of the tissue. While these effects were initially attributed to interactions at the cell-scaffold interface, cumulative evidence suggests that the $3 \mathrm{D}$ structure architecture of the scaffold plays a crucial role. The biochemical behavior of the scaffold dictates whether the cells will proliferate, change the types of ligands and receptors present at their surfaces, or change function. If the scaffold does not possess the right cues, the cells may detach from the matrix and undergo apoptosis. In view of the scaffold-dependent cell behavior, it is imperative to characterize scaffold materials for both short- and long-term cell phenotype effects. Strategies to control and recap cell-material interactions should account for the effect of scaffold structure across multiple length scales.

The necessity for scaffolds that can deliver oxygen and nutrients while removing cell products and waste has been a central theme in multiple TE efforts. Increasing the cellular density in a scaffold to mimic the density of the native tissue may produce a hypoxic core that usually leads to cell dysfunction and death. It is vitally important that a blood supply is within the vicinity of the cells so that they can sense the physiological cues and access the oxygen and nutrients that are necessary for their long-term viability (Lokmic and Mitchell, 2008). In native tissues, the cells are in proximity of a few hundred of micrometers from a flowing blood supply, because mass transport is insufficient for a larger distance (Folkman and Hochberg, 1973). Therefore, the fabrication of viable tissue-engineered constructs of a size larger than the latter distance range appears to be inconceivable in the absence of a natural vascular network, including vasculogenesis and angiogenesis. Vasculogenesis generates new vascularization in the absence of preexisting blood vessels, whereas angiogenesis is defined as the formation of new vessels from an existing vascular network (Auger et al., 2013). The vascular networks play a pivotal role in the survival of cells; however, their quality is more critical than their quantity. When aiming for vascular networks in engineered tissues, the blood perfusion and distribution over a tissue volume is more important than the number of vascular structures. An optimal vascular network must be highly organized and include capillaries, venules, and arterioles to sufficiently supply the cells with oxygen and nutrients. Besides vascular organization, other key parameters, such as perfusability and barrier function, must also be taken into account. In addition, there is a need for an optimum balance between vascular organization in engineered tissues before implantation and vascular remodeling after implantation. An initial degree of vascular organization is necessary for supplying the cells with nutrients, whereas vascular remodeling after implantation is critical to adapting to the post-implantation environment. Likewise, while it is clear that endothelial cells are needed to form the lining of the structures, it is essential to investigate which combination of cell types (i.e., macro/microvascular and progenitor based) can lead to the formation of an optimal vascular network for a specific tissue (Rouwkema and Khademhosseini, 2016). Therefore, a scaffold intended for completely tissue-engineered organs requires spatial control over different tissue layers and types and the incorporation of perfused vascularization to promote tissue health and recapitulate tissue function.

Despite several decades of intense research, the widespread use of TE remains encumbered not only due to the engineering design constraints highlighted in this article but also because of several regulatory hurdles. Concerns regarding cell seeding, poorly defined degradation products, and the need for extensive pre-clinical data increase both the time and the cost to achieve regulatory approval for clinical translation of scaffold-based TE technologies. Furthermore, most of the conducted studies have relied on scaffold implantation in animal models like rodents and rabbits. This raises many concerns about the performance of engineered scaffolds in the human body due to interspecies variability between animal models and human immunology (Mestas and Hughes, 2004; Seok et al., 2013). Therefore, more efforts must be devoted to the implementation of animal models that closely resemble human physiology, and pre-clinical data of the scaffold efficacy should be acquired from multiple animal models across various species. Finally, it is critical to understand that the majority of TE approaches combine cells seeded into scaffolds with signaling cues and chemical functionalities or drugs, thereby rendering the regulatory pathways more complex and necessitating the use of costly methods to demonstrate implant safety.

As the medical challenges become more abundant, the need to improve the quality of life for patients worldwide through TE innovation is becoming more evident. The limited clinical success of TE thus far signifies the enormous scientific, medical, 
and financial challenges faced in this field and underlines the importance of collaboration among scientists, engineers, and physicians more than ever. It is critically important that the requirements of medical groups are aligned with the responses of biomaterial groups and that a strong commitment exists among financial partners, government agencies, and corporations to enable innovative advances in scaffold engineering for a wide range of TE applications.

\section{REFERENCES}

Ababzadeh, S., Farzin, A., Goodarzi, A., Karimi, R., Farahani, M. S., Farsani, M. E., et al. (2020). High porous electrospun poly( $\varepsilon$-caprolactone)/gelatin/MgO scaffolds preseeded with endometrial stem cells promote tissue regeneration in full-thickness skin wounds: an in vivo study. J. Biomed. Mater. Res. B Appl. Biomater. 108, 2961-2970. doi: 10.1002/jbm.b.34626

Abaci, H. E., Coffman, A., Doucet, Y., Chen, J., Jacków, J., Wang, E., et al. (2018). Tissue engineering of human hair follicles using a biomimetic developmental approach. Nat. Commun. 9:5301. doi: 10.1038/s41467-018-07579-y

Abagnale, G., Steger, M., Nguyen, V. H., Hersch, N., Sechi, A., Joussen, S., et al. (2015). Surface topography enhances differentiation of mesenchymal stem cells towards osteogenic and adipogenic lineages. Biomaterials 61, 316-326. doi: 10.1016/j.biomaterials.2015.05.030

Abarzúa-Illanes, P. N., Padilla, C., Ramos, A., Isaacs, M., Ramos-Grez, J., Olguín, H. C., et al. (2017). Improving myoblast differentiation on electrospun poly( $\varepsilon$-caprolactone) scaffolds. J. Biomed. Mater. Res. A 105, 2241-2251. doi: 10.1002/jbm.a.36091

Abbott, N. J., Patabendige, A. A. K., Dolman, D. E. M., Yusof, S. R., and Begley, D. J. (2010). Structure and function of the blood-brain barrier. Neurobiol. Dis. 37, 13-25. doi: 10.1016/j.nbd.2009.07.030

Abbott, N. J., Rönnbäck, L., and Hansson, E. (2006). Astrocyte-endothelial interactions at the blood-brain barrier. Nat. Rev. Neurosci. 7, 41-53. doi: $10.1038 / \mathrm{nrn} 1824$

Aday, S., Zoldan, J., Besnier, M., Carreto, L., Saif, J., Fernandes, R., et al. (2017). Synthetic microparticles conjugated with VEGF 165 improve the survival of endothelial progenitor cells via microRNA-17 inhibition. Nat. Commun. 8:747. doi: 10.1038/s41467-017-00746-7

Adil, M. M., Vazin, T., Ananthanarayanan, B., Rodrigues, G. M. C., Rao, A. T., Kulkarni, R. U., et al. (2017). Engineered hydrogels increase the posttransplantation survival of encapsulated hESC-derived midbrain dopaminergic neurons. Biomaterials 136, 1-11. doi: 10.1016/j.biomaterials.2017.05.008

Afghah, F., Ullah, M., Seyyed Monfared Zanjani, J., Akkus Sut, P., Sen, O., Emanet, M., et al. (2020). 3D printing of silver-doped polycaprolactone-poly(propylene succinate) composite scaffolds for skin tissue engineering. Biomed. Mater. 15:035015. doi: 10.1088/1748-605X/ab7417

Aghmiuni, A. I., Baei, M. S., Keshel, S. H., and Khiyavi, A. A. (2020). Design of novel $3 \mathrm{D}$-scaffold as a potential material to induct epidermaldermal keratinocytes of human-adipose-derived stem cells and promote fibroblast cells proliferation for skin regeneration. Fibers Polym. 21, 33-44. doi: $10.1007 / \mathrm{s} 12221-020-9402-1$

Allen, L. T., Tosetto, M., Miller, I. S., O'Connor, D. P., Penney, S. C., Lynch, I., et al. (2006). Surface-induced changes in protein adsorption and implications for cellular phenotypic responses to surface interaction. Biomaterials 27, 3096-3108. doi: 10.1016/j.biomaterials.2006.01.019

Anderson, J. M., and Jiang, S. (2017). "Implications of the acute and chronic inflammatory response and the foreign body reaction to the immune response of implanted biomaterials," in The Immune Response to Implanted Materials and Devices. The Impact of the Immune System on the Success of an Implant, ed B. Corradetti (Cham, Germany: Springer International Publishing AG), 15-36. doi: 10.1007/978-3-319-45433-7_2

Anderson, J. M., Rodriguez, A., and Chang, D. T. (2008). Foreign body reaction to biomaterials. Semin. Immunol. 20, 86-100. doi: 10.1016/j.smim.2007. 11.004

Andorko, J. I., and Jewell, C. M. (2017). Designing biomaterials with immunomodulatory properties for tissue engineering and regenerative medicine. Bioeng. Transl. Med. 2, 139-155. doi: 10.1002/btm2.10063

\section{AUTHOR CONTRIBUTIONS}

MEM and KM collected most of the pertinent literature, created the figures, and wrote the first draft of the paper. KK defined the scope of the entire work, supervised the work of MEM and KM, examined the accumulated results, and edited the final manuscript. All authors contributed to the article and approved the submitted version.

Annor, A. H., Tang, M. E., Pui, C. L., Ebersole, G. C., Frisella, M. M., Matthews, B. D., et al. (2012). Effect of enzymatic degradation on the mechanical properties of biological scaffold materials. Surg. Endosc. 26, 2767-2778. doi: 10.1007/s00464-012-2277-5

AshaRani, P. V., Mun, G. L. K., Hande, M. P., and Valiyaveettil, S. (2009). Cytotoxicity and genotoxicity of silver nanoparticles in human cells. ACS Nano 3, 279-290. doi: 10.1021/nn800596w

Auger, F. A., Gibot, L., and Lacroix, D. (2013). The pivotal role of vascularization in tissue engineering. Annu. Rev. Biomed. Eng. 15, 177-200. doi: 10.1146/annurev-bioeng-071812-152428

Austin, J. W., Kang, C. E., Baumann, M. D., DiDiodato, L., Satkunendrarajah, K., Wilson, J. R., et al. (2012). The effects of intrathecal injection of a hyaluronan-based hydrogel on inflammation, scarring and neurobehavioural outcomes in a rat model of severe spinal cord injury associated with arachnoiditis. Biomaterials 33, 4555-4564. doi: 10.1016/j.biomaterials. 2012.03.022

Azagarsamy, M. A., and Anseth, K. S. (2013). Bioorthogonal click chemistry: an indispensable tool to create multifaceted cell culture scaffolds. ACS Macro Lett. 2, 5-9. doi: 10.1021/mz300585q

Babitha, S., and Korrapati, P. S. (2017). Biodegradable zein-polydopamine polymeric scaffold impregnated with $\mathrm{TiO}_{2}$ nanoparticles for skin tissue engineering. Biomed. Mater. 12:055008. doi: 10.1088/1748-605X/aa7d5a

Badami, A. S., Kreke, M. R., Thompson, M. S., Riffle, J. S., and Goldstein, A. S. (2006). Effect of fiber diameter on spreading, proliferation, and differentiation of osteoblastic cells on electrospun poly(lactic acid) substrates. Biomaterials 27, 596-606. doi: 10.1016/j.biomaterials.2005.05.084

Baji, A., Mai, Y.-W., Wong, S.-C., Abtahi, M., and Chen, P. (2010). Electrospinning of polymer nanofibers: effects on oriented morphology, structures and tensile properties. Compos. Sci. Technol. 70, 703-718. doi: 10.1016/j.compscitech.2010.01.010

Baker, B. M., Nerurkar, N. L., Burdick, J. A., Elliott, D. M., and Mauck, R. L. (2009). Fabrication and modeling of dynamic multipolymer nanofibrous scaffolds. $J$. Biomech. Eng. 131:101012. doi: 10.1115/1.3192140

Baker, B. M., Trappmann, B., Wang, W. Y., Sakar, M. S., Kim, I. L., Shenoy, V. B., et al. (2015). Cell-mediated fibre recruitment drives extracellular matrix mechanosensing in engineered fibrillar microenvironments. Nat. Mater. 14, 1262-1268. doi: 10.1038/nmat4444

Balguid, A., Mol, A., van Marion, M. H., Bank, R. A., Bouten, C. V. C., and Baaijens, F. P. T. (2009). Tailoring fiber diameter in electrospun poly( $\varepsilon$-caprolactone) scaffolds for optimal cellular infiltration in cardiovascular tissue engineering. Tissue Eng. A 15, 437-444. doi: 10.1089/ten.tea.2007.0294

Bashur, C. A., Shaffer, R. D., Dahlgren, L. A., Guelcher, S. A., and Goldstein, A. S. (2009). Effect of fiber diameter and alignment of electrospun polyurethane meshes on mesenchymal progenitor cells. Tissue Eng. A 15, 2435-2445. doi: 10.1089/ten.tea.2008.0295

Bean, A. C., and Tuan, R. S. (2015). Fiber diameter and seeding density influence chondrogenic differentiation of mesenchymal stem cells seeded on electrospun poly( $\varepsilon$-caprolactone) scaffolds. Biomed. Mater. 10:015018. doi: 10.1088/1748-6041/10/1/015018

Bi, L., Cao, Z., Hu, Y., Song, Y., Yu, L., Yang, B., et al. (2011). Effects of different cross-linking conditions on the properties of genipin-cross-linked chitosan/collagen scaffolds for cartilage tissue engineering. J. Mater. Sci. Mater. Med. 22, 51-62. doi: 10.1007/s10856-010-4177-3

Binder, C., Milleret, V., Hall, H., Eberli, D., and Lühmann, T. (2013). Influence of micro and submicro poly(lactic-glycolic acid) fibers on sensory neural cell locomotion and neurite growth. J. Biomed. Mater. Res. B Appl. Biomater. 101, 1200-1208. doi: 10.1002/jbm.b.32931 
Bittner, S. M., Guo, J. L., Melchiorri, A., and Mikos, A. G. (2018). Threedimensional printing of multilayered tissue engineering scaffolds. Mater Today 21, 861-874. doi: 10.1016/j.mattod.2018.02.006

Bolbasov, E. N., Maryin, P. V., Stankevich, K. S., Kozelskaya, A. I., Shesterikov, E. V., Khodyrevskaya, Y. I., et al. (2018). Surface modification of electrospun poly-(L-lactic) acid scaffolds by reactive magnetron sputtering. Coll. Surf. B Biointerfaces 162, 43-51. doi: 10.1016/j.colsurfb.2017.11.028

Bosworth, L. A., Turner, L.-A., and Cartmell, S. H. (2013). State of the art composites comprising electrospun fibres coupled with hydrogels: a review. Nanomedicine 9, 322-335. doi: 10.1016/j.nano.2012.10.008

Brannigan, R. P., and Dove, A. P. (2017). Synthesis, properties and biomedical applications of hydrolytically degradable materials based on aliphatic polyesters and polycarbonates. Biomater. Sci. 5, 9-21. doi: 10.1039/C6BM00584E

Brown, B. N., Londono, R., Tottey, S., Zhang, L., Kukla, K. A., Wolf, M. T., et al. (2012). Macrophage phenotype as a predictor of constructive remodeling following the implantation of biologically derived surgical mesh materials. Acta Biomater. 8, 978-987. doi: 10.1016/j.actbio.2011.11.031

Cai, N., Li, C., Han, C., Luo, X., Shen, L., Xue, Y., et al. (2016). Tailoring mechanical and antibacterial properties of chitosan/gelatin nanofiber membranes with $\mathrm{Fe}_{3} \mathrm{O}_{4}$ nanoparticles for potential wound dressing application. Appl. Surf. Sci. 369, 492-500. doi: 10.1016/j.apsusc.2016.02.053

Cai, Y., Li, J., Poh, C. K., Tan, H. C., San Thian, E., Fuh, J. Y. H., et al. (2013). Collagen grafted 3D polycaprolactone scaffolds for enhanced cartilage regeneration. J. Mater. Chem. B 1, 5971-5976. doi: 10.1039/c3tb20680g

Cajori, F. A., Crouter, C. Y., and Pemberton, R. (1924). The alleged role of lactic acid in arthritis and rheumatoid conditions. Arch. Intern. Med. 34, 566-572. doi: 10.1001/archinte.1924.00120040152014

Carlson, A. L., Bennett, N. K., Francis, N. L., Halikere, A., Clarke, S., Moore, J. C., et al. (2016). Generation and transplantation of reprogrammed human neurons in the brain using 3D microtopographic scaffolds. Nat. Commun. 7:10862. doi: $10.1038 /$ ncomms10862

Chaudhari, A. A., Vig, K., Baganizi, D. R., Sahu, R., Dixit, S., Dennis, V., et al. (2016). Future prospects for scaffolding methods and biomaterials in skin tissue engineering: a review. Int. J. Mol. Sci. 17:1974. doi: 10.3390/ijms17121974

Chen, H., Cheng, R., Zhao, X., Zhang, Y., Tam, A., Yan, Y., et al. (2019). An injectable self-healing coordinative hydrogel with antibacterial and angiogenic properties for diabetic skin wound repair. NPG Asia Mater. 11:3. doi: 10.1038/s41427-018-0103-9

Chen, H., Huang, X., Zhang, M., Damanik, F., Baker, M., Leferink, A. M., et al. (2017). Tailoring surface nanoroughness of electrospun scaffolds for skeletal tissue engineering. Acta Biomater. 59, 82-93. doi: 10.1016/j.actbio.2017.07.003

Chen, S., Sun, L., Zhou, X., Guo, Y., Song, J., Qian, S., et al. (2020). Mechanically and biologically skin-like elastomers for bio-integrated electronics. Nat. Commun. 11:1107. doi: 10.1038/s41467-020-14446-2

Cheng, L., Cai, Z., Ye, T., Yu, X., Chen, Z., Yan, Y., et al. (2020). Injectable polypeptide-protein hydrogels for promoting infected wound healing. Adv. Funct. Mater. 30:2001196. doi: 10.1002/adfm.202001196

Cheng, Q., Lee, B. L.-P., Komvopoulos, K., and Li, S. (2013). Engineering the microstructure of electrospun fibrous scaffolds by microtopography. Biomacromolecules 14, 1349-1360. doi: 10.1021/bm302000n

Cheng, W., Zeng, X., Chen, H., Li, Z., Zeng, W., Mei, L., et al. (2019). Versatile polydopamine platforms: synthesis and promising applications for surface modification and advanced nanomedicine. ACS Nano 13, 8537-8565. doi: $10.1021 /$ acsnano.9b04436

Chew, S. Y., Mi, R., Hoke, A., and Leong, K. W. (2007). Aligned protein-polymer composite fibers enhance nerve regeneration: a potential tissue-engineering platform. Adv. Funct. Mater. 17, 1288-1296. doi: 10.1002/adfm.200600441

Christman, K. L. (2019). Biomaterials for tissue repair. Science 363, 340-341. doi: 10.1126/science.aar2955

Christopherson, G. T., Song, H., and Mao, H.-Q. (2009). The influence of fiber diameter of electrospun substrates on neural stem cell differentiation and proliferation. Biomaterials 30, 556-564. doi: 10.1016/j.biomaterials.2008.10.004

Cleetus, C. M., Primo, F. A., Fregoso, G., Raveendran, N. L., Noveron, J. C., Spencer, C. T., et al. (2020). Alginate hydrogels with embedded ZnO nanoparticles for wound healing therapy. Int. J. Nanomedicine 15, 5097-5111. doi: 10.2147/IJN.S255937

Cooke, M. J., Wang, Y., Morshead, C. M., and Shoichet, M. S. (2011). Controlled epi-cortical delivery of epidermal growth factor for the stimulation of endogenous neural stem cell proliferation in stroke-injured brain. Biomaterials 32, 5688-5697. doi: 10.1016/j.biomaterials.2011.04.032
Cooke, S. L., and Whittington, A. R. (2016). Influence of therapeutic radiation on polycaprolactone and polyurethane biomaterials. Mater. Sci. Eng. C 60, 78-83. doi: 10.1016/j.msec.2015.10.089

Costantini, M., and Barbetta, A. (2018). "Gas foaming technologies for 3D scaffold engineering," in Functional 3D Tissue Engineering Scaffolds, eds Y. Deng and J. Kuiper (Duxford: Woodhead Publishing), 127-149. doi: 10.1016/B978-0-08-100979-6.00006-9

Crapo, P. M., Medberry, C. J., Reing, J. E., Tottey, S., van der Merwe, Y., Jones, K. E., et al. (2012). Biologic scaffolds composed of central nervous system extracellular matrix. Biomaterials 33, 3539-3547. doi: 10.1016/j.biomaterials.2012.01.044

Crescenzi, V., Cornelio, L., Di Meo, C., Nardecchia, S., and Lamanna, R. (2007). Novel hydrogels via click chemistry: synthesis and potential biomedical applications. Biomacromolecules 8, 1844-1850. doi: 10.1021/bm0700800

Cui, W., Li, X., Zhou, S., and Weng, J. (2008). Degradation patterns and surface wettability of electrospun fibrous mats. Polym. Degrad. Stab. 93, 731-738. doi: 10.1016/j.polymdegradstab.2007.12.002

Cui, W., Li, X., Zhu, X., Yu, G., Zhou, S., and Weng, J. (2006). Investigation of drug release and matrix degradation of electrospun poly(DL-lactide) fibers with paracetanol inoculation. Biomacromolecules 7, 1623-1629. doi: $10.1021 / \mathrm{bm} 060057 \mathrm{z}$

Dai, C., Shih, S., and Khachemoune, A. (2020). Skin substitutes for acute and chronic wound healing: an updated review. J. Dermatolog. Treat. 31, 639-648. doi: 10.1080/09546634.2018.1530443

Daly, A. C., Riley, L., Segura, T., and Burdick, J. A. (2019). Hydrogel microparticles for biomedical applications. Nat. Rev. Mater. 5, 20-43. doi: 10.1038/s41578-019-0148-6

Daniele, M. A., Adams, A. A., Naciri, J., North, S. H., and Ligler, F. S. (2014). Interpenetrating networks based on gelatin methacrylamide and PEG formed using concurrent thiol click chemistries for hydrogel tissue engineering scaffolds. Biomaterials 35, 1845-1856. doi: 10.1016/j.biomaterials.2013. 11.009

Daud, M. F. B., Pawar, K. C., Claeyssens, F., Ryan, A. J., and Haycock, J. W. (2012). An aligned 3D neuronal-glial co-culture model for peripheral nerve studies. Biomaterials 33, 5901-5913. doi: 10.1016/j.biomaterials.2012.05.008

DeForest, C. A., and Anseth, K. S. (2011). Cytocompatible click-based hydrogels with dynamically tunable properties through orthogonal photoconjugation and photocleavage reactions. Nat. Chem. 3, 925-931. doi: 10.1038/nchem.1174

DeForest, C. A., and Anseth, K. S. (2012). Photoreversible patterning of biomolecules within click-based hydrogels. Angew. Chem. Int. Ed. 51, 1816-1819. doi: 10.1002/anie.201106463

DeForest, C. A., Polizzotti, B. D., and Anseth, K. S. (2009). Sequential click reactions for synthesizing and patterning three-dimensional cell microenvironments. Nat. Mater. 8, 659-664. doi: 10.1038/nmat2473

DeForest, C. A., and Tirrell, D. A. (2015). A photoreversible protein-patterning approach for guiding stem cell fate in three-dimensional gels. Nat. Mater. 14, 523-531. doi: 10.1038/nmat4219

Dellacherie, M. O., Seo, B. R., and Mooney, D. J. (2019). Macroscale biomaterials strategies for local immunomodulation. Nat. Rev. Mater. 4, 379-397. doi: 10.1038/s41578-019-0106-3

Di Luca, A., Longoni, A., Criscenti, G., Mota, C., van Blitterswijk, C., and Moroni, L. (2016a). Toward mimicking the bone structure: design of novel hierarchical scaffolds with a tailored radial porosity gradient. Biofabrication 8:045007. doi: 10.1088/1758-5090/8/4/045007

Di Luca, A., Lorenzo-Moldero, I., Mota, C., Lepedda, A., Auhl, D., van Blitterswijk, C., et al. (2016b). Tuning cell differentiation into a 3D scaffold presenting a pore shape gradient for osteochondral regeneration. Adv. Healthc. Mater. 5, 1753-1763. doi: 10.1002/adhm.201600083

Di Luca, A., Ostrowska, B., Lorenzo-Moldero, I., Lepedda, A., Swieszkowski, W., Van Blitterswijk, C., et al. (2016c). Gradients in pore size enhance the osteogenic differentiation of human mesenchymal stromal cells in three-dimensional scaffolds. Sci. Rep. 6:22898. doi: 10.1038/srep22898

Di Luca, A., Szlazak, K., Lorenzo-Moldero, I., Ghebes, C. A., Lepedda, A., Swieszkowski, W., et al. (2016d). Influencing chondrogenic differentiation of human mesenchymal stromal cells in scaffolds displaying a structural gradient in pore size. Acta Biomater. 36, 210-219. doi: 10.1016/j.actbio.2016. 03.014

Do, A.-V., Khorsand, B., Geary, S. M., and Salem, A. K. (2015). 3D printing of scaffolds for tissue regeneration applications. Adv. Healthc. Mater. 4, 1742-1762. doi: 10.1002/adhm.201500168 
Doyle, A. D., Carvajal, N., Jin, A., Matsumoto, K., and Yamada, K. M. (2015). Local 3D matrix microenvironment regulates cell migration through spatiotemporal dynamics of contractility-dependent adhesions. Nat. Commun. 6:8720. doi: $10.1038 /$ ncomms 9720

Drury, J. L., and Mooney, D. J. (2003). Hydrogels for tissue engineering: scaffold design variables and applications. Biomaterials 24, 4337-4351. doi: 10.1016/S0142-9612(03)00340-5

Dutta, R. C., Dey, M., Dutta, A. K., and Basu, B. (2017). Competent processing techniques for scaffolds in tissue engineering. Biotechnol. Adv. 35, 240-250. doi: 10.1016/j.biotechadv.2017.01.001

Dvir, T., Timko, B. P., Kohane, D. S., and Langer, R. (2011). Nanotechnological strategies for engineering complex tissues. Nat. Nanotechnol. 6, 13-22. doi: 10.1038/nnano.2010.246

Dziki, J. L., and Badylak, S. F. (2018). Immunomodulatory biomaterials. Curr. Opin. Biomed. Eng. 6, 51-57. doi: 10.1016/j.cobme.2018.02.005

Dziki, J. L., Wang, D. S., Pineda, C., Sicari, B. M., Rausch, T., and Badylak, S. F. (2017). Solubilized extracellular matrix bioscaffolds derived from diverse source tissues differentially influence macrophage phenotype. J. Biomed. Mater. Res. A 105A, 138-147. doi: 10.1002/jbm.a.35894

Edwards, C., and Marks, R. (1995). Evaluation of biomechanical properties of human skin. Clin. Dermatol. 13, 375-380. doi: 10.1016/0738-081X(95)00078-T

Elkasaby, M., Hegab, H. A., Mohany, A., and Rizvi, G. M. (2018). Modeling and optimization of electrospinning of polyvinyl alcohol (PVA). Adv. Polym. Technol. 37, 2114-2122. doi: 10.1002/adv.21869

Entekhabi, E., Nazarpak, M. H., Moztarzadeh, F., and Sadeghi, A. (2016). Design and manufacture of neural tissue engineering scaffolds using hyaluronic acid and polycaprolactone nanofibers with controlled porosity. Mater. Sci. Eng. C 69, 380-387. doi: 10.1016/j.msec.2016.06.078

Erisken, C., Zhang, X., Moffat, K. L., Levine, W. N., and Lu, H. H. (2013). Scaffold fiber diameter regulates human tendon fibroblast growth and differentiation. Tissue Eng. A 19, 519-528. doi: 10.1089/ten.tea.2012.0072

Erning, K., and Segura, T. (2020). Materials to promote recovery after stroke. Curr. Opin. Biomed. Eng. 14, 9-17. doi: 10.1016/j.cobme.2020.04.002

Estabridis, H. M., Jana, A., Nain, A., and Odde, D. J. (2018). Cell migration in 1D and 2D nanofiber microenvironments. Ann. Biomed. Eng. 46, 392-403. doi: 10.1007/s10439-017-1958-6

Ezhilarasu, H., Ramalingam, R., Dhand, C., Lakshminarayanan, R., Sadiq, A., Gandhimathi, C., et al. (2019). Biocompatible aloe vera and tetracycline hydrochloride loaded hybrid nanofibrous scaffolds for skin tissue engineering. Int. J. Mol. Sci. 20:5174. doi: 10.3390/ijms20205174

Faia-Torres, A. B., Charnley, M., Goren, T., Guimond-Lischer, S., Rottmar, M., Maniura-Weber, K., et al. (2015). Osteogenic differentiation of human mesenchymal stem cells in the absence of osteogenic supplements: a surface-roughness gradient study. Acta Biomater. 28, 64-75. doi: 10.1016/j.actbio.2015.09.028

Fernández-Cervantes, I., Rodríguez-Fuentes, N., León-Deniz, L. V., Alcántara Quintana, L. E., Cervantes-Uc, J. M., Herrera Kao, W. A., et al. (2020). Cell-free scaffold from jellyfish Cassiopea andromeda (Cnidaria; Scyphozoa) for skin tissue engineering. Mater. Sci. Eng. C 111:110748. doi: 10.1016/j.msec.2020.110748

Ferrari, P. F., Aliakbarian, B., Lagazzo, A., Tamayol, A., Palombo, D., and Perego, P. (2017). Tailored electrospun small-diameter graft for vascular prosthesis. Int. J. Polym. Mater. Polym. Biomater. 66, 635-643. doi: 10.1080/00914037.2016.1252361

Ferreira, C. L., Valente, C. A., Zanini, M. L., Sgarioni, B., Ferreira Tondo, P. H., Chagastelles, P. C., et al. (2019). Biocompatible PCL/PLGA/polypyrrole composites for regenerating nerves. Macromol. Symp. 383:1800028. doi: 10.1002/masy.201800028

Folkman, J., and Hochberg, M. (1973). Self-regulation of growth in three dimensions. J. Exp. Med. 138, 745-753. doi: 10.1084/jem.138.4.745

Freytes, D. O., Martin, J., Velankar, S. S., Lee, A. S., and Badylak, S. F. (2008). Preparation and rheological characterization of a gel form of the porcine urinary bladder matrix. Biomaterials 29, 1630-1637. doi: 10.1016/j.biomaterials.2007.12.014

Fu, W., Liu, Z., Feng, B., Hu, R., He, X., Wang, H., et al. (2014). Electrospun gelatin/PCL and collagen/PLCL scaffolds for vascular tissue engineering. Int. J. Nanomed. 9, 2335-2344. doi: 10.2147/IJN.S61375
Gammon, J. M., and Jewell, C. M. (2019). Engineering immune tolerance with biomaterials. Adv. Healthcare Mater. 8:1801419. doi: 10.1002/adhm.201801419

Gao, X., Han, S., Zhang, R., Liu, G., and Wu, J. (2019). Progress in electrospun composite nanofibers: composition, performance and applications for tissue engineering. J. Mater. Chem. B 7, 7075-7089. doi: 10.1039/C9TB01730E

Garg, K., Pullen, N. A., Oskeritzian, C. A., Ryan, J. J., and Bowlin, G. L. (2013). Macrophage functional polarization $(\mathrm{M} 1 / \mathrm{M} 2)$ in response to varying fiber and pore dimensions of electrospun scaffolds. Biomaterials 34, 4439-4451. doi: 10.1016/j.biomaterials.2013.02.065

Ge, Z., Tian, X., Heng, B. C., Fan, V., Yeo, J. F., and Cao, T. (2009). Histological evaluation of osteogenesis of 3D-printed poly-lactic-co-glycolic acid (PLGA) scaffolds in a rabbit model. Biomed. Mater. 4:021001. doi: 10.1088/1748-6041/4/2/021001

Ghanian, M. H., Farzaneh, Z., Barzin, J., Zandi, M., Kazemi-Ashtiani, M., Alikhani, M., et al. (2015). Nanotopographical control of human embryonic stem cell differentiation into definitive endoderm. J. Biomed. Mater. Res. A 103, 3539-3553. doi: 10.1002/jbm.a.35483

Ghaseminezhad, K., Zare, M., Lashkarara, S., Yousefzadeh, M., and Mohandesi, J. A. (2020). Fabrication of althea officinalis loaded electrospun nanofibrous scaffold for potential application of skin tissue engineering. J. Appl. Polym. Sci. 137:48587. doi: 10.1002/app.48587

Ghuman, H., Massensini, A. R., Donnelly, J., Kim, S.-M., Medberry, C. J., Badylak, S. F., et al. (2016). ECM hydrogel for the treatment of stroke: characterization of the host cell infiltrate. Biomaterials 91, 166-181. doi: 10.1016/j.biomaterials.2016.03.014

Ghuman, H., Mauney, C., Donnelly, J., Massensini, A. R., Badylak, S. F., and Modo, M. (2018). Biodegradation of ECM hydrogel promotes endogenous brain tissue restoration in a rat model of stroke. Acta Biomater. 80, 66-84. doi: 10.1016/j.actbio.2018.09.020

Gonçalves de Pinho, A. R., Odila, I., Leferink, A., van Blitterswijk, C., CamareroEspinosa, S., and Moroni, L. (2019). Hybrid polyester-hydrogel electrospun scaffolds for tissue engineering applications. Front. Bioeng. Biotechnol. 7:231. doi: $10.3389 /$ fbioe.2019.00231

Gopinathan, J., and Noh, I. (2018). Click chemistry-based injectable hydrogels and bioprinting inks for tissue engineering applications. Tissue Eng. Regen. Med. 15, 531-546. doi: 10.1007/s13770-018-0152-8

Graeber, M. B., and Streit, W. J. (2010). Microglia: biology and pathology. Acta Neuropathol. 119, 89-105. doi: 10.1007/s00401-009-0622-0

Grand View Research (2020). Tissue Engineering Market Size, Share \& Trends Analysis Report by Application (Cord Blood \& Cell Banking, Cancer, GI \& Gynecology, Dental, Orthopedics, Musculoskeletal, \& Spine), by Region, and Segment Forecasts, 2020-2027. Research and Markets, Report 4538854.

Greener, B., Hughes, A. A., Bannister, N. P., and Douglass, J. (2005). Proteases and $\mathrm{pH}$ in chronic wounds. J. Wound Care 14, 59-61. doi: 10.12968/jowc.2005.14.2.26739

Greenwood, J. E., and Wagstaff, M. J. D. (2016). “The use of biodegradable polyurethane in the development of dermal scaffolds," in Advances in Polyurethane Biomaterials, eds S. L. Cooper and J. Guan (Duxford: Woodhead Publishing Series in Biomaterials; Elsevier Inc.), 631-662. doi: 10.1016/B978-0-08-100614-6.00022-6

Griffin, D. R., Weaver, W. M., Scumpia, P. O., Di Carlo, D., and Segura, T. (2015). Accelerated wound healing by injectable microporous gel scaffolds assembled from annealed building blocks. Nat. Mater. 14, 737-744. doi: 10.1038/ nmat4294

Guan, J., Zhu, Z., Zhao, R. C., Xiao, Z., Wu, C., Han, Q., et al. (2013). Transplantation of human mesenchymal stem cells loaded on collagen scaffolds for the treatment of traumatic brain injury in rats. Biomaterials 34, 5937-5946. doi: 10.1016/j.biomaterials.2013.04.047

Guo, S., and DiPietro, L. A. (2010). Factors affecting wound healing. J. Dent. Res. 89, 219-229. doi: 10.1177/0022034509359125

Guvendiren, M., and Burdick, J. A. (2012). Stiffening hydrogels to probe shortand long-term cellular responses to dynamic mechanics. Nat. Commun. 3:792. doi: $10.1038 /$ ncomms1792

Guvendiren, M., Perepelyuk, M., Wells, R. G., and Burdick, J. A. (2014). Hydrogels with differential and patterned mechanics to study stiffnessmediated myofibroblastic differentiation of hepatic stellate cells. J. Mech. Behav. Biomed. Mater. 38, 198-208. doi: 10.1016/j.jmbbm.2013.11.008 
Hafeman, A. E., Zienkiewicz, K. J., Zachman, A. L., Sung, H.-J., Nanney, L. B., Davidson, J. M., et al. (2011). Characterization of the degradation mechanisms of lysine-derived aliphatic poly(ester urethane) scaffolds. Biomaterials 32, 419-429. doi: 10.1016/j.biomaterials.2010.08.108

Han, F., Dong, Y., Su, Z., Yin, R., Song, A., and Li, S. (2014). Preparation, characteristics and assessment of a novel gelatin-chitosan sponge scaffold as skin tissue engineering material. Int. J. Pharm. 476, 124-133. doi: 10.1016/j.ijpharm.2014.09.036

Han, Y., Jia, B., Lian, M., Sun, B., Wu, Q., Sun, B., et al. (2021). High-precision, gelatin-based, hybrid, bilayer scaffolds using melt electro-writing to repair cartilage injury. Bioact. Mater. 6, 2173-2186. doi: 10.1016/j.bioactmat.2020.12.018

Hansen, J. T. (2009). Netter's Clinical Anatomy. 2nd Edn. (Philadelphia, PA: Saunders).

He, L., Liao, S., Quan, D., Ma, K., Chan, C., Ramakrishna, S., et al. (2010). Synergistic effects of electrospun PLLA fiber dimension and pattern on neonatal mouse cerebellum C17.2 stem cells. Acta Biomater. 6, 2960-2969. doi: 10.1016/j.actbio.2010.02.039

Holloway, J. L., Ma, H., Rai, R., and Burdick, J. A. (2014). Modulating hydrogel crosslink density and degradation to control bone morphogenetic protein delivery and in vivo bone formation. J. Control. Release 191, 63-70. doi: 10.1016/j.jconrel.2014.05.053

Hong, J., Yeo, M., Yang, G. H., and Kim, G. (2019). Cell-electrospinning and its application for tissue engineering. Int. J. Mol. Sci. 20:6208. doi: 10.3390/ijms20246208

Hong, S., Yang, K., Kang, B., Lee, C., Song, I. T., Byun, E., et al. (2013). Hyaluronic acid catechol: a biopolymer exhibiting a pH-dependent adhesive or cohesive property for human neural stem cell engineering. Adv. Funct. Mater. 23, 1774-1780. doi: 10.1002/adfm.201202365

Hopkins, A. M., DeSimone, E., Chwalek, K., and Kaplan, D. L. (2015). 3D in vitro modeling of the central nervous system. Prog. Neurobiol. 125, 1-25. doi: 10.1016/j.pneurobio.2014.11.003

Hoyle, C. E., and Bowman, C. N. (2010). Thiol-ene click chemistry. Angew. Chem. Int. Ed. 49, 1540-1573. doi: 10.1002/anie.200903924

Hoyle, C. E., Lowe, A. B., and Bowman, C. N. (2010). Thiol-click chemistry: a multifaceted toolbox for small molecule and polymer synthesis. Chem. Soc. Rev. 39, 1355-1387. doi: 10.1039/b901979k

Hsia, H. C., Nair, M. R., Mintz, R. C., and Corbett, S. A. (2011). The fiber diameter of synthetic bioresorbable extracellular matrix influences human fibroblast morphology and fibronectin matrix assembly. Plast. Reconstr. Surg. 127, 2312-2320. doi: 10.1097/PRS.0b013e3182139fa4

Hsieh, F.-Y., Tao, L., Wei, Y., and Hsu, S. (2017). A novel biodegradable selfhealing hydrogel to induce blood capillary formation. NPG Asia Mater. 9:e363. doi: 10.1038/am.2017.23

Huaga, H. S., Choub, S. H., Don, T. M., Lai, W. C., and Cheng, L. P. (2009). Formation of microporous poly(hydroxybutyric acid) membranes for culture of osteoblast and fibroblast. Polym. Adv. Technol. 20, 1082-1090. doi: 10.1002/pat.1366

Idaszek, J., Zinn, M., Obarzanek-Fojt, M., Zell, V., Swieszkowski, W., and Bruinink, A. (2013). Tailored degradation of biocompatible poly(3-hydroxybutyrateco-3-hydroxyvalerate)/calcium silicate/poly(lactide-co-glycolide) ternary composites: an in vitro study. Mater. Sci. Eng. C 33, 4352-4360. doi: 10.1016/j.msec.2013.06.025

Iga, C., Agata, T., Marcin, Ł., Natalia, F., and Justyna, K.-L. (2020). Ciprofloxacin-modified degradable hybrid polyurethane-polylactide porous scaffolds developed for potential use as an antibacterial scaffold for regeneration of skin. Polymers 12:171. doi: 10.3390/polym12010171

Israni, A. K., Zaun, D., Hadley, N., Rosendale, J. D., Schaffhausen, C., McKinney, W., et al. (2020). OPTN/SRTR 2018 annual data report: deceased organ donation. Am. J. Transplant. 20, 509-541. doi: 10.1111/ajt.15678

Iwasaki, A., and Medzhitov, R. (2010). Regulation of adaptive immunity by the innate immune system. Science 327, 291-295. doi: 10.1126/science.1183021

Jafarkhani, M., Salehi, Z., Bagheri, Z., Aayanifard, Z., Rezvan, A., Doosthosseini, H., et al. (2020). Graphene functionalized decellularized scaffold promotes skin cell proliferation. Can. J. Chem. Eng. 98, 62-68. doi: 10.1002/cjce. 23588

Jain, A., McKeon, R. J., Brady-Kalnay, S. M., and Bellamkonda, R. V. (2011). Sustained delivery of activated Rho GTPases and BDNF promotes axon growth in CSPG-rich regions following spinal cord injury. PLoS ONE 6:e16135 doi: 10.1371/journal.pone.0016135

Janeway, C. A., Travers, P., Walport, M., and Shlomchik, M. J. (2001). "Part V - The immune system in health and disease," in Immunobiology: The Immune System in Health and Disease, 5th Edn. (New York, NY: Garland Science).

Jatoi, A. W., Kim, I. S., Ogasawara, H., and Ni, Q.-Q. (2019). Characterizations and application of $\mathrm{CA} / \mathrm{ZnO} / \mathrm{AgNP}$ composite nanofibers for sustained antibacterial properties. Mater. Sci. Eng. C 105:110077. doi: 10.1016/j.msec.2019.110077

Jenkins, T. L., and Little, D. (2019). Synthetic scaffolds for musculoskeletal tissue engineering: cellular responses to fiber parameters. NPJ Regen. Med. 4:15 doi: 10.1038/s41536-019-0076-5

Jiang, Y., Chen, J., Deng, C., Suuronen, E. J., and Zhong, Z. (2014). Click hydrogels, microgels and nanogels: emerging platforms for drug delivery and tissue engineering. Biomaterials 35, 4969-4985. doi: 10.1016/j.biomaterials.2014.03.001

Jin, Y., Kim, I.-Y., Kim, I.-D., Lee, H.-K., Park, J.-Y., Han, P.-L., et al. (2014) Biodegradable gelatin microspheres enhance the neuroprotective potency of osteopontin via quick and sustained release in the post-ischemic brain. Acta Biomater. 10, 3126-3135. doi: 10.1016/j.actbio.2014.02.045

Jones, E. M., Cochrane, C. A., and Percival, S. L. (2015). The effect of $\mathrm{pH}$ on the extracellular matrix and biofilms. Adv. Wound Care 4, 431-439. doi: 10.1089/wound.2014.0538

Jorgensen, A. M., Chou, Z., Gillispie, G., Lee, S. J., Yoo, J. J., Soker, S., et al. (2020). Decellularized skin extracellular matrix (dsECM) improves the physical and biological properties of fibrinogen hydrogel for skin bioprinting applications. Nanomaterials 10:1484. doi: 10.3390/nano10081484

Kalia, J., and Raines, R. T. (2008). Hydrolytic stability of hydrazones and oximes. Angew. Chem. Int. Ed. 47, 7523-7526. doi: 10.1002/anie.200802651

Kannaiyan, J., Khare, S., Narayanan, S., and Mahuvawalla, F. (2019). Fabrication of electrospun polycaprolactone/gelatin composite nanofibrous scaffolds with cellular responses. Am. J. Nano Res. Appl. 7, 11-20. doi: 10.11648/j.nano.20190702.11

Karpov, T. E., Peltek, O. O., Muslimov, A. R., Tarakanchikova, Y. V., Grunina, T. M., Poponova, M. S., et al. (2020). Development of optimized strategies for growth factor incorporation onto electrospun fibrous scaffolds to promote prolonged release. ACS Appl. Mater. Interfaces 12, 5578-5592. doi: 10.1021/acsami.9b20697

Keirouz, A., Zakharova, M., Kwon, J., Robert, C., Koutsos, V., Callanan, A., et al. (2020). High-throughput production of silk fibroin-based electrospun fibers as biomaterial for skin tissue engineering applications. Mater. Sci. Eng. C 112:110939. doi: 10.1016/j.msec.2020.110939

Kennedy, K. M., Bhaw-Luximon, A., and Jhurry, D. (2017). Cell-matrix mechanical interaction in electrospun polymeric scaffolds for tissue engineering: implications for scaffold design and performance. Acta Biomater. 50, 41-55. doi: 10.1016/j.actbio.2016.12.034

Khaing, Z. Z., and Schmidt, C. E. (2012). Advances in natural biomaterials for nerve tissue repair. Neurosci. Lett. 519, 103-114. doi: 10.1016/j.neulet.2012.02.027

Khaing, Z. Z., Thomas, R. C., Geissler, S. A., and Schmidt, C. E. (2014). Advanced biomaterials for repairing the nervous system: what can hydrogels do for the brain? Mater. Today 17, 332-340. doi: 10.1016/j.mattod.2014. 05.011

Khetan, S., Guvendiren, M., Legant, W. R., Cohen, D. M., Chen, C. S., and Burdick, J. A. (2013). Degradation-mediated cellular traction directs stem cell fate in covalently crosslinked three-dimensional hydrogels. Nat. Mater. 12, 458-465. doi: $10.1038 /$ nmat3586

Kianpour, G., Bagheri, R., Pourjavadi, A., and Ghanbari, H. (2020). In situ synthesized $\mathrm{TiO}_{2}$-polyurethane nanocomposite for bypass graft application: in vitro endothelialization and degradation. Mater. Sci. Eng. C 114:111043. doi: 10.1016/j.msec.2020.111043

Kievit, F. M., Cooper, A., Jana, S., Leung, M. C., Wang, K., Edmondson, D., et al. (2013). Aligned chitosan-polycaprolactone polyblend nanofibers promote the migration of glioblastoma cells. Adv. Healthcare Mater. 2, 1651-1659. doi: 10.1002/adhm.201300092

Kim, B. S., Gao, G., Kim, J. Y., and Cho, D.-W. (2019). 3D cell printing of perfusable vascularized human skin equivalent composed of epidermis, dermis, and hypodermis for better structural recapitulation of native skin. Adv. Healthcare Mater. 8:1801019. doi: 10.1002/adhm.201801019 
Kishan, A. P., Nezarati, R. M., Radzicki, C. M., Renfro, A. L., Robinson, J. L., Whitely, M. E., et al. (2015). In situ crosslinking of electrospun gelatin for improved fiber morphology retention and tunable degradation. J. Mater. Chem. B 3, 7930-7938. doi: 10.1039/C5TB00937E

Koffler, J., Zhu, W., Qu, X., Platoshyn, O., Dulin, J. N., Brock, J., et al. (2019). Biomimetic 3D-printed scaffolds for spinal cord injury repair. Nat. Med. 25, 263-269. doi: 10.1038/s41591-018-0296-Z

Kolb, H. C., Finn, M. G., and Sharpless, K. B. (2001). Click chemistry: diverse chemical function from a few good reactions. Angew. Chem. Int. Ed. 40, 2004-2021. doi: 10.1002/1521-3773(20010601)40:11<2004::AID-ANIE2004>3. $0 . \mathrm{CO} ; 2-5$

Kornev, V. A., Grebenik, E. A., Solovieva, A. B., Dmitriev, R. I., and Timashev, P. S. (2018). Hydrogel-assisted neuroregeneration approaches towards brain injury therapy: a state-of-the-art review. Comput. Struct. Biotechnol. J. 16, 488-502. doi: 10.1016/j.csbj.2018.10.011

$\mathrm{Ku}$, S. H., and Park, C. B. (2010). Human endothelial cell growth on musselinspired nanofiber scaffold for vascular tissue engineering. Biomaterials 31, 9431-9437. doi: 10.1016/j.biomaterials.2010.08.071

Kuppan, P., Sethuraman, S., and Krishnan, U. M. (2015). Interaction of human smooth muscle cells with nanofibrous scaffolds: effect of fiber orientation on cell adhesion, proliferation, and functional gene expression. J. Biomed. Mater. Res. A 103, 2236-2250. doi: 10.1002/jbm.a. 35360

Kurosaki, T., Kometani, K., and Ise, W. (2015). Memory B cells. Nat. Rev. Immunol. 15, 149-159. doi: 10.1038/nri3802

Kweon, H., Yoo, M. K., Park, I. K., Kim, T. H., Lee, H. C., Lee, H.-S., et al. (2003). A novel degradable polycaprolactone networks for tissue engineering. Biomaterials 24, 801-808. doi: 10.1016/S0142-9612(02)00370-8

Lam, C. X. F., Hutmacher, D. W., Schantz, J.-T., Woodruff, M. A., and Teoh, S. H. (2009). Evaluation of polycaprolactone scaffold degradation for 6 months in vitro and in vivo. J. Biomed. Mater. Res. A 90A, 906-919. doi: $10.1002 /$ jbm.a.32052

Lam, J., Lowry, W. E., Carmichael, S. T., and Segura, T. (2014). Delivery of iPS-NPCs to the stroke cavity within a hyaluronic acid matrix promotes the differentiation of transplanted cells. Adv. Funct. Mater. 24, 7053-7062. doi: 10.1002/adfm.201401483

Lancuški, A., Bossard, F., and Fort, S. (2013). Carbohydrate-decorated PCL fibers for specific protein adhesion. Biomacromolecules 14, 1877-1884. doi: 10.1021/bm400263d

Lancuški, A., Fort, S., and Bossard, F. (2012). Electrospun azido-PCL nanofibers for enhanced surface functionalization by click chemistry. ACS Appl. Mater. Interfaces 4, 6499-6504. doi: 10.1021/am301458y

Lanza, R., Langer, R., Vacanti, J. P., and Atala, A. (2020). Principles of Tissue Engineering. 5th Edn. (London, UK: Academic Press).

Laughlin, S. T., Baskin, J. M., Amacher, S. L., and Bertozzi, C. R. (2008). In vivo imaging of membrane-associated glycans in developing zebrafish. Science 320, 664-667. doi: 10.1126/science.1155106

Lee, H., Dellatore, S. M., Miller, W. M., and Messersmith, P. B. (2007). Musselinspired surface chemistry for multifunctional coatings. Science 318, 426-430. doi: $10.1126 /$ science. 1147241

Lee, K. Y., and Mooney, D. J. (2001). Hydrogels for tissue engineering. Chem. Rev. 101, 1869-1880. doi: 10.1021/cr000108x

Lee, N. M., Erisken, C., Iskratsch, T., Sheetz, M., Levine, W. N., and Lu, H. H. (2017). Polymer fiber-based models of connective tissue repair and healing. Biomaterials 112, 303-312. doi: 10.1016/j.biomaterials.2016.10.013

Lee, Y. B., Shin, Y. M., Lee, J., Jun, I., Kang, J. K., Park, J.-C., et al. (2012). Polydopamine-mediated immobilization of multiple bioactive molecules for the development of functional vascular graft materials. Biomaterials 33, 8343-8352. doi: 10.1016/j.biomaterials.2012.08.011

Leijten, J., Seo, J., Yue, K., Trujillo-de Santiago, G., Tamayol, A., Ruiz-Esparza, G. U., et al. (2017). Spatially and temporally controlled hydrogels for tissue engineering. Mater. Sci. Eng. R Rep. 119, 1-35. doi: 10.1016/j.mser.2017.07.001

Li, J., Wang, T., Kirtane, A. R., Shi, Y., Jones, A., Moussa, Z., et al. (2020). Gastrointestinal synthetic epithelial linings. Sci. Transl. Med. 12:eabc0441. doi: 10.1126/scitranslmed.abc0441

Liang, R., Gu, Y., Wu, Y., Bunpetch, V., and Zhang, S. (2021). Lithography-based $3 \mathrm{D}$ bioprinting and bioinks for bone repair and regeneration. ACS Biomater. Sci. Eng. 7, 806-816. doi: 10.1021/acsbiomaterials.9b01818
Liao, H., Munoz-Pinto, D., Qu, X., Hou, Y., Grunlan, M. A., and Hahn, M. S. (2008). Influence of hydrogel mechanical properties and mesh size on vocal fold fibroblast extracellular matrix production and phenotype. Acta Biomater. 4, 1161-1171. doi: 10.1016/j.actbio.2008.04.013

Lim, S. H., Liu, X. Y., Song, H., Yarema, K. J., and Mao, H.-Q. (2010). The effect of nanofiber-guided cell alignment on the preferential differentiation of neural stem cells. Biomaterials 31, 9031-9039. doi: 10.1016/j.biomaterials.2010. 08.021

Lins, L. C., Wianny, F., Livi, S., Dehay, C., Duchet-Rumeau, J., and Gérard, J.F. (2017). Effect of polyvinylidene fluoride electrospun fiber orientation on neural stem cell differentiation. J. Biomed. Mater. Res. B Appl. Biomater. 105, 2376-2393. doi: 10.1002/jbm.b.33778

Liu, H., Wang, S., and Qi, N. (2012). Controllable structure, properties, and degradation of the electrospun PLGA/PLA-blended nanofibrous scaffolds. J. Appl. Polym. Sci. 125, E468-E476. doi: 10.1002/app.36757

Lokhande, G., Carrow, J. K., Thakur, T., Xavier, J. R., Parani, M., Bayless, K. J., et al. (2018). Nanoengineered injectable hydrogels for wound healing application. Acta Biomater. 70, 35-47. doi: 10.1016/j.actbio.2018.01.045

Lokmic, Z., and Mitchell, G. M. (2008). Engineering the microcirculation. Tissue Eng. B Rev. 14, 87-103. doi: 10.1089/teb.2007.0299

Lowe, A. B. (2010). Thiol-ene "click" reactions and recent applications in polymer and materials synthesis. Polym. Chem. 1, 17-36. doi: 10.1039/B9PY00216B

Lowery, J. L., Datta, N., and Rutledge, G. C. (2010). Effect of fiber diameter, pore size and seeding method on growth of human dermal fibroblasts in electrospun poly $(\varepsilon$-caprolactone) fibrous mats. Biomaterials 31, 491-504. doi: 10.1016/j.biomaterials.2009.09.072

Lozano, R., Stevens, L., Thompson, B. C., Gilmore, K. J., Gorkin III, R. Stewart, E. M., et al. (2015). 3D printing of layered brain-like structures using peptide modified gellan gum substrates. Biomaterials 67, 264-273. doi: 10.1016/j.biomaterials.2015.07.022

Ma, C. H., Zhang, H. B., Yang, S. M., Yin, R. X., Yao, X. J., and Zhang, W. J. (2018). Comparison of the degradation behavior of PLGA scaffolds in micro-channel, shaking, and static conditions. Biomicrofluidics 12:034106. doi: 10.1063/1.5021394

Ma, Z., He, W., Yong, T., and Ramakrishna, S. (2005). Grafting of gelatin on electrospun poly(caprolactone) nanofibers to improve endothelial cell spreading and proliferation and to control cell orientation. Tissue Eng. 11, 1149-1158. doi: 10.1089/ten.2005.11.1149

Mabry, K. M., Lawrence, R. L., and Anseth, K. S. (2015). Dynamic stiffening of poly(ethylene glycol)-based hydrogels to direct valvular interstitial cell phenotype in a three-dimensional environment. Biomaterials 49, 47-56. doi: 10.1016/j.biomaterials.2015.01.047

Madden, L. R., Mortisen, D. J., Sussman, E. M., Dupras, S. K., Fugate, J. A., Cuy, J. L., et al. (2010). Proangiogenic scaffolds as functional templates for cardiac tissue engineering. Proc. Natl. Acad. Sci. U.S.A 107, 15211-15216. doi: $10.1073 /$ pnas. 1006442107

Madhurakkat Perikamana, S. K., Lee, J., Lee, Y. B., Shin, Y. M., Lee, E. J., Mikos, A. G., et al. (2015). Materials from mussel-inspired chemistry for cell and tissue engineering applications. Biomacromolecules 16, 2541-2555. doi: 10.1021/acs.biomac.5b00852

Mahumane, G. D., Kumar, P., du Toit, L. C., Choonara, Y. E., and Pillay, V. (2018). $3 \mathrm{D}$ scaffolds for brain tissue regeneration: architectural challenges. Biomater. Sci. 6, 2812-2837. doi: 10.1039/C8BM00422F

Malollari, K. G., Delparastan, P., Sobek, C., Vachhani, S. J., Fink, T. D., Zha, R. H., et al. (2019). Mechanical enhancement of bioinspired polydopamine nanocoatings. ACS Appl. Mater. Interfaces 11, 43599-43607. doi: 10.1021/acsami.9b15740

Mandal, B. B., and Kundu, S. C. (2009). Cell proliferation and migration in silk fibroin 3D scaffolds. Biomaterials 30, 2956-2965. doi: 10.1016/j.biomaterials. 2009.02.006

Martin, R. L., Lloyd, H. G. E., and Cowan, A. I. (1994). The early events of oxygen and glucose deprivation: setting the scene for neuronal death? Trends Neurosci. 17, 251-257. doi: 10.1016/0166-2236(94)90008-6

McWhorter, F. Y., Wang, T., Nguyen, P., Chung, T., and Liu, W. F. (2013). Modulation of macrophage phenotype by cell shape. Proc. Natl. Acad. Sci.U.S.A 110, 17253-17258. doi: 10.1073/pnas.1308887110

Medzhitov, R. (2008). Origin and physiological roles of inflammation. Nature 454, 428-435. doi: 10.1038/nature07201 
Meehan, S., and Nain, A. S. (2014). Role of suspended fiber structural stiffness and curvature on single-cell migration, nucleus shape, and focal-adhesion-cluster length. Biophys. J. 107, 2604-2611. doi: 10.1016/j.bpj.2014.09.045

Mehrasa, M., Asadollahi, M. A., Nasri-Nasrabadi, B., Ghaedi, K., Salehi, H., Dolatshahi-Pirouz, A., et al. (2016). Incorporation of mesoporous silica nanoparticles into random electrospun PLGA and PLGA/gelatin nanofibrous scaffolds enhances mechanical and cell proliferation properties. Mater. Sci. Eng. C 66, 25-32. doi: 10.1016/j.msec.2016.04.031

Meldal, M., and Tornøe, C. W. (2008). Cu-catalyzed azide - alkyne cycloaddition. Chem. Rev. 108, 2952-3015. doi: 10.1021/cr0783479

Mestas, J., and Hughes, C. C. W. (2004). Of mice and not men: differences between mouse and human immunology. J. Immunol. 172, 2731-2738. doi: 10.4049/jimmunol.172.5.2731

Milleret, V., Hefti, T., Hall, H., Vogel, V., and Eberli, D. (2012). Influence of the fiber diameter and surface roughness of electrospun vascular grafts on blood activation. Acta Biomater. 8, 4349-4356. doi: 10.1016/j.actbio.2012.07.032

Milošev, I., Levašič, V., Vidmar, J., Kovač, S., and Trebše, R. (2017). pH and metal concentration of synovial fluid of osteoarthritic joints and joints with metal replacements. J. Biomed. Mater. Res. B Appl. Biomater. 105, 2507-2515. doi: 10.1002/jbm.b.33793

Mittapalli, R. K., Liu, X., Adkins, C. E., Nounou, M. I., Bohn, K. A., Terrell, T. B., et al. (2013). Paclitaxel-hyaluronic nanoconjugates prolong overall survival in a preclinical brain metastases of breast cancer model. Mol. Cancer Ther. 12, 2389-2399. doi: 10.1158/1535-7163.MCT-13-0132

Mohiti-Asli, M., Saha, S., Murphy, S. V., Gracz, H., Pourdeyhimi, B., Atala, A., et al. (2017). Ibuprofen loaded PLA nanofibrous scaffolds increase proliferation of human skin cells in vitro and promote healing of full thickness incision wounds in vivo. J. Biomed. Mater. Res. B Appl. Biomater. 105, 327-339. doi: 10.1002/jbm.b.33520

Moore, K. L., Dalley, A. F., and Agur, A. M. R. (2013). Clinically Oriented Anatomy, 7th Edn. (Baltimore, MD: Wolters Kluwer/Lippincott Williams \& Wilkins).

Narayanan, N., Jiang, C., Wang, C., Uzunalli, G., Whittern, N., Chen, D., et al. (2020). Harnessing fiber diameter-dependent effects of myoblasts toward biomimetic scaffold-based skeletal muscle regeneration. Front. Bioeng. Biotechnol. 8:203. doi: 10.3389/fbioe.2020.00203

Nathan, C. (2006). Neutrophils and immunity: challenges and opportunities. Nat. Rev. Immunol. 6, 173-182. doi: 10.1038/nri1785

Ng, W. L., Goh, M. H., Yeong, W. Y., and Naing, M. W. (2018). Applying macromolecular crowding to $3 \mathrm{D}$ bioprinting: fabrication of $3 \mathrm{D}$ hierarchical porous collagen-based hydrogel constructs. Biomater. Sci. 6, 562-574. doi: 10.1039/C7BM01015J

Nguyen, A. T., Sathe, S. R., and Yim, E. K. F. (2016). From nano to micro: topographical scale and its impact on cell adhesion, morphology and contact guidance. J. Phys. Condens. Matter 28:183001. doi: 10.1088/0953-8984/28/18/ 183001

Nih, L. R., Carmichael, S. T., and Segura, T. (2016). Hydrogels for brain repair after stroke: an emerging treatment option. Curr. Opin. Biotechnol. 40, 155-163. doi: 10.1016/j.copbio.2016.04.021

Nih, L. R., Gojgini, S., Carmichael, S. T., and Segura, T. (2018). Dual-function injectable angiogenic biomaterial for the repair of brain tissue following stroke. Nat. Mater. 17, 642-651. doi: 10.1038/s41563-018-0083-8

Nih, L. R., Sideris, E., Carmichael, S. T., and Segura, T. (2017). Injection of microporous annealing particle (MAP) hydrogels in the stroke cavity reduces gliosis and inflammation and promotes NPC migration to the lesion. Adv. Mater. 29:1606471. doi: 10.1002/adma.201606471

Nimmo, C. M., Owen, S. C., and Shoichet, M. S. (2011). Diels-Alder click crosslinked hyaluronic acid hydrogels for tissue engineering. Biomacromolecules 12, 824-830. doi: 10.1021/bm101446k

Noriega, S. E., Hasanova, G. I., Schneider, M. J., Larsen, G. F., and Subramanian, A. (2012). Effect of fiber diameter on the spreading, proliferation and differentiation of chondrocytes on electrospun chitosan matrices. Cells Tissues Organs 195, 207-221. doi: 10.1159/000325144

Nunes-Pereira, J., Ribeiro, S., Ribeiro, C., Gombek, C. J., Gama, F. M., Gomes, A. C., et al. (2015). Poly(vinylidene fluoride) and copolymers as porous membranes for tissue engineering applications. Polym. Test. 44, 234-241. doi: 10.1016/j.polymertesting.2015.05.001

Obermeyer, J. M., Tuladhar, A., Payne, S. L., Ho, E., Morshead, C. M., and Shoichet, M. S. (2019). Local delivery of brain-derived neurotrophic factor enables behavioral recovery and tissue repair in stroke-injured rats. Tissue Eng. A 25, 1175-1187. doi: 10.1089/ten.tea.2018.0215

Oh, S. H., Park, I. K., Kim, J. M., and Lee, J. H. (2007). In vitro and in vivo characteristics of PCL scaffolds with pore size gradient fabricated by a centrifugation method. Biomaterials 28, 1664-1671. doi: 10.1016/j.biomaterials.2006.11.024

Orive, G., Anitua, E., Pedraz, J. L., and Emerich, D. F. (2009). Biomaterials for promoting brain protection, repair and regeneration. Nat. Rev. Neurosci. 10, 682-692. doi: 10.1038/nrn2685

Ottosson, M., Jakobsson, A., and Johansson, F. (2017). Accelerated wound closure - Differently organized nanofibers affect cell migration and hence the closure of artificial wounds in a cell based in vitro model. PLOS ONE 12:e0169419. doi: 10.1371/journal.pone.0169419

Owen, S. C., and Shoichet, M. S. (2010). Design of three-dimensional biomimetic scaffolds. J. Biomed. Mater. Res. A 94, 1321-1331. doi: 10.1002/jbm.a.32834

Park, K.-S., Kim, B.-J., Lih, E., Park, W., Lee, S.-H., Joung, Y. K., et al. (2018). Versatile effects of magnesium hydroxide nanoparticles in PLGA scaffoldmediated chondrogenesis. Acta Biomater. 73, 204-216. doi: 10.1016/j.actbio. 2018.04.022

Park, S.-H., Gil, E. S., Shi, H., Kim, H. J., Lee, K., and Kaplan, D. L. (2010). Relationships between degradability of silk scaffolds and osteogenesis. Biomaterials 31, 6162-6172. doi: 10.1016/j.biomaterials.2010.04.028

Parmaksiz, M., Elçin, A. E., and Elçin, Y. M. (2019). "Decellularized bSIS-ECM as a regenerative biomaterial for skin wound repair," in Skin Stem Cells. Methods in Molecular Biology, ed K. Turksen (New York, NY: Humana Press), 1879, 175-185. doi: 10.1007/7651_2018_147

Peppas, N. A., and Hoffman, A. S. (2020). "Hydrogels," in Biomaterials Science: An Introduction to Materials in Medicine, 4th Edn, eds W. R. Wagner, S. E. Sakiyama-Elbert, G. Zhang, and M. J. Yaszemski (London: Academic Press), 153-166. doi: 10.1016/B978-0-12-816137-1.00014-3

Pettikiriarachchi, J. T. S., Parish, C. L., Shoichet, M. S., Forsythe, J. S., and Nisbet, D. R. (2010). Biomaterials for brain tissue engineering. Aust. J. Chem. 63, 1143-1154. doi: 10.1071/CH10159

Pourchet, L. J., Thepot, A., Albouy, M., Courtial, E. J., Boher, A., Blum, L. J., et al. (2017). Human skin 3D bioprinting using scaffold-free approach. Adv. Healthcare Mater. 6:1601101. doi: 10.1002/adhm.201601101

Prado-Prone, G., Bazzar, M., Focarete, M. L., García-Macedo, J. A., PerezOrive, J., Ibarra, C., et al. (2020). Single-step, acid-based fabrication of homogeneous gelatin-polycaprolactone fibrillar scaffolds intended for skin tissue engineering. Biomed. Mater. 15:035001. doi: 10.1088/1748-605X/ ab673b

Prescher, J. A., Dube, D. H., and Bertozzi, C. R. (2004). Chemical remodelling of cell surfaces in living animals. Nature 430, 873-877. doi: 10.1038/nature02791

Prest, T. A., Yeager, E., LoPresti, S. T., Zygelyte, E., Martin, M. J., Dong, L., et al. (2018). Nerve-specific, xenogeneic extracellular matrix hydrogel promotes recovery following peripheral nerve injury. J. Biomed. Mater. Res. A 106, 450-459. doi: 10.1002/jbm.a.36235

Pruitt, L. A., and Chakravartula, A. M. (2011). Mechanics of Biomaterials: Fundamental Principles for Implant Design (Cambridge, UK: Cambridge University Press). doi: 10.1017/CBO9780511977923

$\mathrm{Pu}$, J., and Komvopoulos, K. (2014). Mechanical properties of electrospun bilayer fibrous membranes as potential scaffolds for tissue engineering. Acta Biomater. 10, 2718-2726. doi: 10.1016/j.actbio.2013.12.060

Pu, J., Yuan, F., Li, S., and Komvopoulos, K. (2015). Electrospun bilayer fibrous scaffolds for enhanced cell infiltration and vascularization in vivo. Acta Biomater. 13, 131-141. doi: 10.1016/j.actbio.2014.11.014

Pucino, V., Certo, M., Bulusu, V., Cucchi, D., Goldmann, K., Pontarini, E., et al. (2019). Lactate buildup at the site of chronic inflammation promotes disease by inducing $\mathrm{CD}^{+} \mathrm{T}$ cell metabolic rewiring. Cell Metabolism 30, 1055-1074. doi: 10.1016/j.cmet.2019.10.004

Radwan-Pragłowska, J., Janus, Ł., Piatkowski, M., Bogdał, D., and Matýsek, D. (2020). Hybrid bilayer PLA/chitosan nanofibrous scaffolds doped with $\mathrm{ZnO}, \mathrm{Fe}_{3} \mathrm{O}_{4}$, and $\mathrm{Au}$ nanoparticles with bioactive properties for skin tissue engineering. Polymers 12:159. doi: 10.3390/polym12010159

Rediguieri, C. F., Sassonia, R. C., Dua, K., Kikuchi, I. S., and de Jesus Andreoli Pinto, T. (2016). Impact of sterilization methods on electrospun scaffolds for tissue engineering. Eur. Polym. J. 82, 181-195. doi: 10.1016/j.eurpolymj.2016.07.016 
Ren, Y.-J., Zhang, S., Mi, R., Liu, Q., Zeng, X., Rao, M., et al. (2013). Enhanced differentiation of human neural crest stem cells towards the Schwann cell lineage by aligned electrospun fiber matrix. Acta Biomater. 9, 7727-7736. doi: 10.1016/j.actbio.2013.04.034

Ribeiro, C., Sencadas, V., Areias, A. C., Gama, F. M., and Lanceros-Méndez, S. (2015). Surface roughness dependent osteoblast and fibroblast response on poly(L-lactide) films and electrospun membranes. J. Biomed. Mater. Res. A 103, 2260-2268. doi: 10.1002/jbm.a.35367

Rivet, C. J., Zhou, K., Gilbert, R. J., Finkelstein, D. I., and Forsythe, J. S. (2015). Cell infiltration into a 3D electrospun fiber and hydrogel hybrid scaffold implanted in the brain. Biomatter 5:e1005527. doi: 10.1080/21592535.2015.1005527

Roman, M. D., Fleaca, R. S., Boicean, A., Bratu, D., Birlutiu, V., Rus, L. L., et al. (2017). Assesment of synovial fluid $\mathrm{pH}$ in osteoarthritis of the HIP and knee. Rev. Chim. 68, 1242-1244. doi: 10.37358/RC.17.6.5649

Rosique, R. G., Rosique, M. J., and Farina Junior, A. (2015). Curbing inflammation in skin wound healing: a review. Int. J. Inflammation 2015:316235. doi: $10.1155 / 2015 / 316235$

Rouwkema, J., and Khademhosseini, A. (2016). Vascularization and angiogenesis in tissue engineering: beyond creating static networks. Trends Biotechnol. 34, 733-745. doi: 10.1016/j.tibtech.2016.03.002

Rühs, P. A., Malollari, K. G., Binelli, M. R., Crockett, R., Balkenende, D. W. R., Studart, A. R., et al. (2020). Conformal bacterial cellulose coatings as lubricious surfaces. ACS Nano 14, 3885-3895. doi: 10.1021/acsnano.9b09956

Ruskowitz, E. R., and DeForest, C. A. (2018). Photoresponsive biomaterials for targeted drug delivery and 4D cell culture. Nat. Rev. Mater. 3:17087. doi: $10.1038 /$ natrevmats.2017.87

Ryu, J., Ku, S. H., Lee, H., and Park, C. B. (2010). Mussel-inspired polydopamine coating as a universal route to hydroxyapatite crystallization. Adv. Funct. Mater. 20, 2132-2139. doi: 10.1002/adfm.200902347

Ryu, J. H., Lee, Y., Kong, W. H., Kim, T. G., Park, T. G., and Lee, H. (2011). Catechol-functionalized chitosan/pluronic hydrogels for tissue adhesives and hemostatic materials. Biomacromolecules 12, 2653-2659. doi: 10.1021/bm2 00464x

Ryu, J. H., Messersmith, P. B., and Lee, H. (2018). Polydopamine surface chemistry: a decade of discovery. ACS Appl. Mater. Interfaces 10, 7523-7540. doi: 10.1021/acsami.7b19865

Sadeghi-avalshahr, A. R., Nokhasteh, S., Molavi, A. M., Mohammad-pour, N., and Sadeghi, M. (2020). Tailored PCL scaffolds as skin substitutes using sacrificial PVP fibers and collagen/chitosan blends. Int. J. Mol. Sci. 21:2311. doi: 10.3390/ijms21072311

Sadtler, K., Estrellas, K., Allen, B. W., Wolf, M. T., Fan, H., Tam, A. J., et al. (2016). Developing a pro-regenerative biomaterial scaffold microenvironment requires T helper 2 cells. Science 352, 366-370. doi: 10.1126/science.aad9272

Sadtler, K., Sommerfeld, S. D., Wolf, M. T., Wang, X., Majumdar, S., Chung, L., et al. (2017). Proteomic composition and immunomodulatory properties of urinary bladder matrix scaffolds in homeostasis and injury. Semin. Immunol. 29, 14-23. doi: 10.1016/j.smim.2017.05.002

Sadtler, K., Wolf, M. T., Ganguly, S., Moad, C. A., Chung, L., Majumdar, S., et al. (2019). Divergent immune responses to synthetic and biological scaffolds. Biomaterials 192, 405-415. doi: 10.1016/j.biomaterials.2018.11.002

Sanz-Herrera, J. A., García-Aznar, J. M., and Doblaré, M. (2009). On scaffold designing for bone regeneration: a computational multiscale approach. Acta Biomater. 5, 219-229. doi: 10.1016/j.actbio.2008.06.021

Selders, G. S., Fetz, A. E., Radic, M. Z., and Bowlin, G. L. (2017). An overview of the role of neutrophils in innate immunity, inflammation and host-biomaterial integration. Regen. Biomater. 4, 55-68. doi: 10.1093/rb/rbw041

Seok, J., Warren, H. S., Cuenca, A. G., Mindrinos, M. N., Baker, H. V., $\mathrm{Xu}, \mathrm{W}$., et al. (2013). Genomic responses in mouse models poorly mimic human inflammatory diseases. Proc. Natl. Acad. Sci. U.S.A 110, 3507-3512. doi: $10.1073 /$ pnas. 1222878110

Sharpe, J. R., Harris, K. L., Jubin, K., Bainbridge, N. J., and Jordan, N. R. (2009). The effect of $\mathrm{pH}$ in modulating skin cell behaviour. Br. J. Dermatol. 161, 671-673. doi: 10.1111/j.1365-2133.2009.09168.x

Sheikh, Z., Brooks, P. J., Barzilay, O., Fine, N., and Glogauer, M. (2015). Macrophages, foreign body giant cells and their response to implantable biomaterials. Materials 8, 5671-5701. doi: 10.3390/ma8095269
Shields, K. J., Beckman, M. J., Bowlin, G. L., and Wayne, J. S. (2004). Mechanical properties and cellular proliferation of electrospun collagen type II. Tissue Eng. 10, 1510-1517. doi: 10.1089/ten.2004.10.1510

Shin, H., Jo, S., and Mikos, A. G. (2003). Biomimetic materials for tissue engineering. Biomaterials 24, 4353-4364. doi: 10.1016/S0142-9612(03)00339-9

Shuai, C., Zan, J., Qi, F., Wang, G., Liu, Z., Yang, Y., et al. (2019). nMgOincorporated PLLA bone scaffolds: enhanced crystallinity and neutralized acidic products. Mater. Des. 174:107801. doi: 10.1016/j.matdes.2019.107801

Sideris, E., Yu, A., Chen, J., Carmichael, S. T., and Segura, T. (2019). Hyaluronic acid particle hydrogels decrease cerebral atrophy and promote pro-reparative astrocyte/axonal infiltration in the core after ischemic stroke. bioRxiv 768291. doi: 10.1101/768291

Sofroniew, M. V., and Vinters, H. V. (2010). Astrocytes: biology and pathology. Acta Neuropathol. 119, 7-35. doi: 10.1007/s00401-009-0619-8

Sorg, H., Tilkorn, D. J., Hager, S., Hauser, J., and Mirastschijski, U. (2017). Skin wound healing: an update on the current knowledge and concepts. Eur. Surg. Res. 58, 81-94. doi: 10.1159/000454919

Spagnuolo, M., and Liu, L. (2012). Fabrication and degradation of electrospun scaffolds from L-tyrosine-based polyurethane blends for tissue engineering applications. ISRN Nanotechnol. 2012:627420. doi: 10.5402/2012/627420

Sperling, L. E., Reis, K. P., Pozzobon, L. G., Girardi, C. S., and Pranke, P. (2017). Influence of random and oriented electrospun fibrous poly(lacticco-glycolic acid) scaffolds on neural differentiation of mouse embryonic stem cells. J. Biomed. Mater. Res. A 105, 1333-1345. doi: 10.1002/jbm.a. 36012

Stabler, C. L., Li, Y., Stewart, J. M., and Keselowsky, B. G. (2019). Engineering immunomodulatory biomaterials for type 1 diabetes. Nat. Rev. Mater. 4, 429-450. doi: 10.1038/s41578-019-0112-5

Stachewicz, U., Bailey, R. J., Wang, W., and Barber, A. H. (2012). Size dependent mechanical properties of electrospun polymer fibers from a composite structure. Polymer 53, 5132-5137. doi: 10.1016/j.polymer.2012. 08.064

Stojic, M., López, V., Montero, A., Quílez, C., de Aranda Izuzquiza, G., Vojtova, L., et al. (2019). "Skin tissue engineering," in Biomaterials for Skin Repair and Regeneration, 1st Edn, ed E. García-Gareta (Duxford: Woodhead Publishing), 59-99. doi: 10.1016/B978-0-08-102546-8.00003-0

Sundaramurthi, D., Krishnan, U. M., and Sethuraman, S. (2014). Electrospun nanofibers as scaffolds for skin tissue engineering. Polym. Rev. 54, 348-376. doi: 10.1080/15583724.2014.881374

Sundararaghavan, H. G., Saunders, R. L., Hammer, D. A., and Burdick, J. A. (2013). Fiber alignment directs cell motility over chemotactic gradients. Biotechnol. Bioeng. 110, 1249-1254. doi: 10.1002/bit.24788

Sussman, E. M., Halpin, M. C., Muster, J., Moon, R. T., and Ratner, B. D. (2014). Porous implants modulate healing and induce shifts in local macrophage polarization in the foreign body reaction. Ann. Biomed. Eng. 42, 1508-1516. doi: 10.1007/s10439-013-0933-0

Suuronen, R., Pohjonen, T., Hietanen, J., and Lindqvist, C. (1998). A 5-year in vitro and in vivo study of the biodegradation of polylactide plates. J. Oral Maxillofacial Surg. 56, 604-614. doi: 10.1016/S0278-2391(98)90461-X

Tasdelen, M. A. (2011). Diels-Alder "click" reactions: recent applications in polymer and material science. Polym. Chem. 2, 2133-2145. doi: 10.1039/c1py00041a

Thakar, R. G., Cheng, Q., Patel, S., Chu, J., Nasir, M., Liepmann, D., et al. (2009). Cell-shape regulation of smooth muscle cell proliferation. Biophys. J. 96, 3423-3432. doi: 10.1016/j.bpj.2008.11.074

Tian, W. M., Zhang, C. L., Hou, S. P., Yu, X., Cui, F. Z., Xu, Q. Y., et al. (2005). Hyaluronic acid hydrogel as Nogo-66 receptor antibody delivery system for the repairing of injured rat brain: in vitro. J. Control. Release 102, 13-22. doi: 10.1016/j.jconrel.2004.09.025

Tijore, A., Cai, P., Nai, M. H., Zhuyun, L., Yu, W., Tay, C. Y., et al. (2015). Role of cytoskeletal tension in the induction of cardiomyogenic differentiation in micropatterned human mesenchymal stem cell. Adv. Healthcare Mater. 4, 1399-1407. doi: 10.1002/adhm.201500196

Tokatlian, T., Cam, C., and Segura, T. (2014). Non-viral DNA delivery from porous hyaluronic acid hydrogels in mice. Biomaterials 35, 825-835. doi: 10.1016/j.biomaterials.2013.10.014 
Truong, V. X., Ablett, M. P., Richardson, S. M., Hoyland, J. A., and Dove, A. P. (2015). Simultaneous orthogonal dual-click approach to tough, in-situforming hydrogels for cell encapsulation. J. Am. Chem. Soc. 137, 1618-1622. doi: $10.1021 /$ ja511681s

Tsai, W.-B., Chen, W.-T., Chien, H.-W., Kuo, W.-H., and Wang, M.-J. (2014). Poly(dopamine) coating to biodegradable polymers for bone tissue engineering. J. Biomater. Appl. 28, 837-848. doi: 10.1177/0885328213483842

Tuladhar, A., Payne, S. L., and Shoichet, M. S. (2018). Harnessing the potential of biomaterials for brain repair after stroke. Front. Mater. 5:14. doi: 10.3389/fmats.2018.00014

Ulrich, T. A., Jain, A., Tanner, K., MacKay, J. L., and Kumar, S. (2010). Probing cellular mechanobiology in three-dimensional culture with collagen-agarose matrices. Biomaterials 31, 1875-1884. doi: 10.1016/j.biomaterials.2009.10.047

Valentin, J. E., Stewart-Akers, A. M., Gilbert, T. W., and Badylak, S. F. (2009). Macrophage participation in the degradation and remodeling of extracellular matrix scaffolds. Tissue Eng. A 15, 1687-1694. doi: 10.1089/ten.tea.2008.0419

Vatankhah, E., Prabhakaran, M. P., Semnani, D., Razavi, S., Zamani, M., and Ramakrishna, S. (2014). Phenotypic modulation of smooth muscle cells by chemical and mechanical cues of electrospun tecophilic/gelatin nanofibers. ACS Appl. Mater. Interfaces 6, 4089-4101. doi: 10.1021/am405673h

Veiseh, O., Doloff, J. C., Ma, M., Vegas, A. J., Tam, H. H., Bader, A. R., et al. (2015). Size- and shape-dependent foreign body immune response to materials implanted in rodents and non-human primates. Nat. Mater. 14, 643-651. doi: $10.1038 /$ nmat4290

Vimal, S. K., Ahamad, N., and Katti, D. S. (2016). A simple method for fabrication of electrospun fibers with controlled degree of alignment having potential for nerve regeneration applications. Mater. Sci. Eng. C 63, 616-627. doi: 10.1016/j.msec.2016.03.008

Vogel, V., and Sheetz, M. (2006). Local force and geometry sensing regulate cell functions. Nat. Rev. Mol. Cell Biol. 7, 265-275. doi: 10.1038/nrm1890

Walker, J. L., and Santoro, M. (2017). "Processing and production of bioresorbable polymer scaffolds for tissue engineering," in Bioresorbable Polymers for Biomedical Applications: From Fundamentals to Translational Medicine, eds G. Perale and J. Hilborn (Duxford: Woodhead Publishing), 181-203. doi: 10.1016/B978-0-08-100262-9.00009-4

Wan, Y., Wu, H., Cao, X., and Dalai, S. (2008). Compressive mechanical properties and biodegradability of porous poly(caprolactone)/chitosan scaffolds. Polym. Degrad. Stab. 93, 1736-1741. doi: 10.1016/j.polymdegradstab.2008.08.001

Wang, H. B., Mullins, M. E., Cregg, J. M., McCarthy, C. W., and Gilbert, R. J. (2010). Varying the diameter of aligned electrospun fibers alters neurite outgrowth and Schwann cell migration. Acta Biomater. 6, 2970-2978. doi: 10.1016/j.actbio.2010.02.020

Wang, J., Ye, R., Wei, Y., Wang, H., Xu, X., Zhang, F., et al. (2012). The effects of electrospun TSF nanofiber diameter and alignment on neuronal differentiation of human embryonic stem cells. J. Biomed. Mater. Res. A 100A, 632-645. doi: 10.1002/jbm.a.33291

Wang, N., Tytell, J. D., and Ingber, D. E. (2009). Mechanotransduction at a distance: mechanically coupling the extracellular matrix with the nucleus. Nat. Rev. Mol. Cell Biol. 10, 75-82. doi: 10.1038/nrm2594

Wang, Y., Wei, Y. T., Zu, Z. H., Ju, R. K., Guo, M. Y., Wang, X. M., et al. (2011). Combination of hyaluronic acid hydrogel scaffold and PLGA microspheres for supporting survival of neural stem cells. Pharm. Res. 28:1406. doi: 10.1007/ s11095-011-0452-3

Watari, S., Hayashi, K., Wood, J. A., Russell, P., Nealey, P. F., Murphy, C. J., et al. (2012). Modulation of osteogenic differentiation in hMSCs cells by submicron topographically-patterned ridges and grooves. Biomaterials 33, 128-136. doi: 10.1016/j.biomaterials.2011.09.058

Weir, N. A., Buchanan, F. J., Orr, J. F., Farrar, D. F., and Dickson, G. R. (2004). Degradation of poly-L-lactide. Part 2: increased temperature accelerated degradation. Proc. Inst. Mech. Eng. H J. Eng. Med. 218, 321-330. doi: 10.1243/0954411041932809

Wen, J. H., Vincent, L. G., Fuhrmann, A., Choi, Y. S., Hribar, K. C., Taylor-Weiner, H., et al. (2014). Interplay of matrix stiffness and protein tethering in stem cell differentiation. Nat. Mater. 13, 979-987. doi: 10.1038/nmat4051

Wingate, K., Bonani, W., Tan, Y., Bryant, S. J., and Tan, W. (2012). Compressive elasticity of three-dimensional nanofiber matrix directs mesenchymal stem cell differentiation to vascular cells with endothelial or smooth muscle cell markers. Acta Biomater. 8, 1440-1449. doi: 10.1016/j.actbio.2011.12.032
Wong, S.-C., Baji, A., and Leng, S. (2008). Effect of fiber diameter on tensile properties of electrospun poly( $\varepsilon$-caprolactone). Polymer 49, 4713-4722. doi: $10.1016 /$ j.polymer.2008.08.022

World Health Organization (2018). The Top 10 Causes of Death. Available online at: https://www.who.int/news-room/fact-sheets/detail/the-top-10-causes-ofdeath

Wu, M.-H., Urban, J. P. G., Cui, Z. F., Cui, Z., and Xu, X. (2007). Effect of extracellular $\mathrm{pH}$ on matrix synthesis by chondrocytes in $3 \mathrm{D}$ agarose gel. Biotechnol. Prog. 23, 430-434. doi: 10.1021/bp060024v

Wu, Q., Liu, J., Wang, X., Feng, L., Wu, J., Zhu, X., et al. (2020). Organ-on-achip: recent breakthroughs and future prospects. Biomed. Eng. Online 19:9. doi: 10.1186/s12938-020-0752-0

Wu, Y., Wang, J., Shi, Y., Pu, H., Leak, R. K., Liou, A. K. F., et al. (2017) Implantation of brain-derived extracellular matrix enhances neurological recovery after traumatic brain injury. Cell Transplant. 26, 1224-1234. doi: $10.1177 / 0963689717714090$

Wylie, R. G., Ahsan, S., Aizawa, Y., Maxwell, K. L., Morshead, C. M., and Shoichet, M. S. (2011). Spatially controlled simultaneous patterning of multiple growth factors in three-dimensional hydrogels. Nat. Mater. 10, 799-806. doi: $10.1038 /$ nmat3101

Xi, W., Scott, T. F., Kloxin, C. J., and Bowman, C. N. (2014). Click chemistry: click chemistry in materials science. Adv. Funct. Mater. 24, 2572-2590. doi: 10.1002/adfm.201302847

Xiong, S., Zhang, X., Lu, P., Wu, Y., Wang, Q., Sun, H., et al. (2017). A gelatin-sulfonated silk composite scaffold based on 3D printing technology enhances skin regeneration by stimulating epidermal growth and dermal neovascularization. Sci. Rep. 7:4288. doi: 10.1038/s41598-017-04149-y

$\mathrm{Xu}, \mathrm{Y}$. , and Guan, J. (2016). "Interaction of cells with polyurethane scaffolds," in Advances in Polyurethane Biomaterials, eds S. L. Cooper and J. Guan (Duxford: Woodhead Publishing), 523-542. doi: 10.1016/B978-0-08-100614-6.00018-4

Yan, J., Qiang, L., Gao, Y., Cui, X., Zhou, H., Zhong, S., et al. (2012). Effect of fiber alignment in electrospun scaffolds on keratocytes and corneal epithelial cells behavior. J. Biomed. Mater. Res. A 100A, 527-535. doi: 10.1002/jbm.a.33301

Yang, H., Zhang, Q., Lin, B., Fu, G., Zhang, X., and Guo, L. (2012). Thermosensitive electrospun fibers prepared by a sequential thiol-ene click chemistry approach. J. Polym. Sci. A Polym. Chem. 50, 4182-4190. doi: 10.1002/pola. 26244

Yang, J., Stuart, M. A. C., and Kamperman, M. (2014). Jack of all trades: versatile catechol crosslinking mechanisms. Chem. Soc. Rev. 43, 8271-8298. doi: 10.1039/C4CS00185K

Yang, Y., Tang, G., Zhao, Y., Yuan, X., and Fan, Y. (2010). Effect of cyclic loading on in vitro degradation of poly(L-lactide-co-glycolide) scaffolds. J. Biomater. Sci. Polym. Ed. 21, 53-66. doi: 10.1163/156856209X4 10229

Yang, Z., Duan, H., Mo, L., Qiao, H., and Li, X. (2010). The effect of the dosage of NT-3/chitosan carriers on the proliferation and differentiation of neural stem cells. Biomaterials 31, 4846-4854. doi: 10.1016/j.biomaterials.2010.02.015

Ye, K., Wang, X., Cao, L., Li, S., Li, Z., Yu, L., et al. (2015). Matrix stiffness and nanoscale spatial organization of cell-adhesive ligands direct stem cell fate. Nano Lett. 15, 4720-4729. doi: 10.1021/acs.nanolett.5b01619

Ye, Q., Harmsen, M. C., van Luyn, M. J. A., and Bank, R. A. (2010). The relationship between collagen scaffold cross-linking agents and neutrophils in the foreign body reaction. Biomaterials 31, 9192-9201. doi: 10.1016/j.biomaterials.2010.08.049

Yevick, H. G., Duclos, G., Bonnet, I., and Silberzan, P. (2015). Architecture and migration of an epithelium on a cylindrical wire. Proc. Natl. Acad. Sci. U.S.A 112, 5944-5949. doi: 10.1073/pnas. 1418857112

Yixiang, D., Yong, T., Liao, S., Chan, C. K., and Ramakrishna, S. (2008). Degradation of electrospun nanofiber scaffold by short wave length ultraviolet radiation treatment and its potential applications in tissue engineering. Tissue Eng. A 14, 1321-1329. doi: 10.1089/ten.tea.2007.0395

You, Y., Min, B.-M., Lee, S. J., Lee, T. S., and Park, W. H. (2005). In vitro degradation behavior of electrospun polyglycolide, polylactide, and poly(lactide-co-glycolide). J. Appl. Polym. Sci. 95, 193-200. doi: 10.1002/app. 21116

Zhang, B., Korolj, A., Lai, B. F. L., and Radisic, M. (2018). Advances in organon-a-chip engineering. Nat. Rev. Mater. 3, 257-278. doi: 10.1038/s41578-018 0034-7 
Zhang, H., Zhou, L., and Zhang, W. (2014). Control of scaffold degradation in tissue engineering: a review. Tissue Eng. B Rev. 20, 492-502. doi: $10.1089 /$ ten.teb.2013.0452

Zhang, Q., Lu, H., Kawazoe, N., and Chen, G. (2014). Pore size effect of collagen scaffolds on cartilage regeneration. Acta Biomater. 10, 2005-2013. doi: 10.1016/j.actbio.2013.12.042

Zhang, Y., Fan, W., Ma, Z., Wu, C., Fang, W., Liu, G., et al. (2010). The effects of pore architecture in silk fibroin scaffolds on the growth and differentiation of mesenchymal stem cells expressing BMP7. Acta Biomater. 6, 3021-3028. doi: 10.1016/j.actbio.2010.02.030

Zhao, P., Gu, H., Mi, H., Rao, C., Fu, J., and Turng, L. (2018). Fabrication of scaffolds in tissue engineering: a review. Front. Mech. Eng. 13, 107-119. doi: $10.1007 /$ s11465-018-0496-8

Zheng, J., Liu, K., Reneker, D. H., and Becker, M. L. (2012). Post-assembly derivatization of electrospun nanofibers via strain-promoted azide alkyne cycloaddition. J. Am. Chem. Soc. 134, 17274-17277. doi: 10.1021/ja307647x

Zheng, Q., Chu, Z., Li, X., Kang, H., Yang, X., and Fan, Y. (2017). The effect of fluid shear stress on the in vitro release kinetics of sirolimus from PLGA films. Polymers 9:618. doi: 10.3390/polym9110618

Zheng, X., Ding, Z., Cheng, W., Lu, Q., Kong, X., Zhou, X., et al. (2020). Injectable hydrogels: microskin-inspired injectable MSC-laden hydrogels for scarless wound healing with hair follicles. Adv. Healthcare Mater. 9:2070029. doi: 10.1002/adhm.202070029

Zhong, Y., and Bellamkonda, R. V. (2008). Biomaterials for the central nervous system. J. R. Soc. Interface 5, 957-975. doi: 10.1098/rsif.2008.0071

Zhou, G., Jiang, H., Yin, Z., Liu, Y., Zhang, Q., Zhang, C., et al. (2018). In vitro regeneration of patient-specific ear-shaped cartilage and its first clinical application for auricular reconstruction. EBioMedicine 28, 287-302. doi: 10.1016/j.ebiom.2018.01.011

Zhu, S., Nih, L., Carmichael, S. T., Lu, Y., and Segura, T. (2015). Enzymeresponsive delivery of multiple proteins with spatiotemporal control. Adv. Mater. 27, 3620-3625. doi: 10.1002/adma.201500417

Zou, Y., Zhang, L., Yang, L., Zhu, F., Ding, M., Lin, F., et al. (2018). "Click" chemistry in polymeric scaffolds: bioactive materials for tissue engineering. J. Control. Release 273, 160-179. doi: 10.1016/j.jconrel.2018.01.023

Zouani, O. F., Chanseau, C., Brouillaud, B., Bareille, R., Deliane, F., Foulc, M.-P., et al. (2012). Altered nanofeature size dictates stem cell differentiation. J. Cell Sci. 125, 1217-1224. doi: 10.1242/jcs.093229

Zulkifli, F. H., Hussain, F. S. J., Zeyohannes, S. S., Rasad, M. S. B. A., and Yusuff, M. M. (2017). A facile synthesis method of hydroxyethyl cellulose-silver nanoparticle scaffolds for skin tissue engineering applications. Mater. Sci. Eng. C 79, 151-160. doi: 10.1016/j.msec.2017.05.028

Conflict of Interest: The authors declare that the research was conducted in the absence of any commercial or financial relationships that could be construed as a potential conflict of interest.

Copyright (c) 2021 Echeverria Molina, Malollari and Komvopoulos. This is an openaccess article distributed under the terms of the Creative Commons Attribution License (CC BY). The use, distribution or reproduction in other forums is permitted, provided the original author(s) and the copyright owner(s) are credited and that the original publication in this journal is cited, in accordance with accepted academic practice. No use, distribution or reproduction is permitted which does not comply with these terms. 